\title{
Evaluation of DSRC For V2V communications
}

\author{
by
}

\section{Rami Sabouni, MEng.}

A thesis submitted to the Faculty of Graduate and Postdoctoral Affairs in partial fulfillment of the requirements for the degree of

Master of Applied Science in Electrical and Computer Engineering

Ottawa-Carleton Institute for Electrical and Computer Engineering (OCIECE)

Department of Systems and Computer Engineering

Carleton University

Ottawa, Ontario, Canada

April 2011

(C)Copyright 2011, Rami Sabouni 


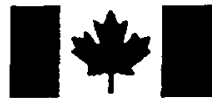

Library and Archives
Canada

Published Heritage

Branch

395 Wellington Street

Ottawa ON K1A ON4

Canada
Bibliothèque et

Archives Canada

Direction du

Patrimoine de l'édition

395 , rue Wellington

Ottawa ON K1A ON4

Canada
Your file Votre référence

ISBN: 978-0-494-81716-2

Our file Notre référence

ISBN: 978-0-494-81716-2
NOTICE:

The author has granted a nonexclusive license allowing Library and Archives Canada to reproduce, publish, archive, preserve, conserve, communicate to the public by telecommunication or on the Internet, loan, distribute and sell theses worldwide, for commercial or noncommercial purposes, in microform, paper, electronic and/or any other formats.

The author retains copyright ownership and moral rights in this thesis. Neither the thesis nor substantial extracts from it may be printed or otherwise reproduced without the author's permission.
AVIS:

L'auteur a accordé une licence non exclusive permettant à la Bibliothèque et Archives Canada de reproduire, publier, archiver, sauvegarder, conserver, transmettre au public par télécommunication ou par l'Internet, prêter, distribuer et vendre des thèses partout dans le monde, à des fins commerciales ou autres, sur support microforme, papier, électronique et/ou autres formats.

L'auteur conserve la propriété du droit d'auteur et des droits moraux qui protège cette thèse. $\mathrm{Ni}$ la thèse ni des extraits substantiels de celle-ci ne doivent être imprimés ou autrement reproduits sans son autorisation.
In compliance with the Canadian Privacy Act some supporting forms may have been removed from this thesis.

While these forms may be included in the document page count, their removal does not represent any loss of content from the thesis.
Conformément à la loi canadienne sur la protection de la vie privée, quelques formulaires secondaires ont été enlevés de cette thèse.

Bien que ces formulaires aient inclus dans la pagination, il n'y aura aucun contenu manquant. 
The undersigned recommend to

the Faculty of Graduate Studies and Research

acceptance of the thesis

\title{
Evaluation of DSRC For V2V communications
}

\author{
Submitted by \\ Rami Sabouni, MEng. \\ in partial fulfillment of the requirements for \\ the degree of Master of Applied Science in Electrical and Computer Engineering
}

Chair, Prof. Howard Schwartz, Department of Systems and Computer Engineering

Thesis Supervisor, Prof. Roshdy Hafez

Carleton University

April, 2011 


\section{Abstract}

A variety of ITS systems are oriented toward reducing travel risk. Some of these systems are oriented toward reducing crashes while others lessen the probability of fatalities should a crash occur. Among the ITS systems oriented toward reducing crashes, traffic management systems limit the conflict of traffic streams thus reducing the likelihood of accidents.

This thesis presents a study of the Dedicated Short Range Communication (DSRC) Physical Layer in order to determine its reliability for Vehicle-2-Vehicle (V2V) communication under varying Signal-to-Noise Ratio (SNR), vehicle speed, delay spread, and packet lengths. IEEE 802.11a MatLab model was used to simulate the DSRC Physical Layer.

After determining performance of the DSRC physical layer using simulations and analyzing the results, we were able to come up with several solutions that improve the performance. Some scenarios of these solutions were simulated. Also this thesis identifies some ideas that can be used towards the implementation of DSRC in V2V communication. 


\section{Acknowledgments}

Many people supported me during the completion of this thesis with criticism, helpful assistance and references. This thesis would have never been possible without them.

I am greatly thankful to my supervisor Prof. Roshdy Hafez, for his guidance, insights, thoughtful suggestions and continuous support during the course of this research. In addition, I would like to express my appreciation to my friends, colleagues, secretaries and personnel in the Department of System and Computer Engineering and Carleton University without whom this work would not have been possible.

Furthermore, I would like to express my gratitude to my mother Mrs. Maissaa Baroudi and my father Prof. Abdul-Rahim Sabouni for their love, support, encouragement, prayers and all their sacrifices.

Rami Sabouni 


\section{Contents}

Abstract $\quad$ ii

Acknowledgments $\quad$ iii

Table of Contents $\quad$ iv

List of Acronyms $\quad$ vii

$\begin{array}{ll}\text { List of Symbols } & \text { x }\end{array}$

1 Introduction $\quad 1$

1.1 General Introduction . . . . . . . . . . . . . . . . . . . 1

1.2 Problem Statement . . . . . . . . . . . . . . . 2

1.3 Thesis Contributions .................... . . 4

1.4 Thesis Organization . . . . . . . . . . . . . . . 5

2 Literature Review $\quad 6$

2.1 Importance of Intelligent Transportation Systems (ITS) . . . . . . . . 6

2.1.1 Wireless Communication . . . . . . . . . . . . 6

2.1.2 Computational Technologies .............. 8

2.2 Examples of Intelligent Transportation Systems (ITS) Applications . 8

2.2 .1 Intelligent Infrastructure . . . . . . . . . . . . . . . 9

2.2 .2 Intelligent Vehicles . . . . . . . . . . . . . . 11 
2.3 Introduction to Dedicated Short Range Communications (DSRC) . . 13

2.4 IEEE $802.11 \mathrm{a}$ Vs. IEEE $802.11 \mathrm{p} \ldots \ldots \ldots \ldots \ldots \ldots$

$2.4 .1 \quad$ IEEE $802.11 \mathrm{a} \ldots \ldots \ldots \ldots \ldots \ldots \ldots$

2.4 .2 IEEE $802.11 \mathrm{p}(\mathrm{WAVE}) \ldots \ldots \ldots \ldots \ldots$

2.5 Existing DSRC Applications . . . . . . . . . . . . . . . 17

2.5.1 Electronic Toll Collection (ETC) $\ldots \ldots \ldots \ldots$

2.5.2 Travelers, alert, and warning information . . . . . . . 18

2.5.3 Travel time and delay measurement . . . . . . . . . 18

2.6 DSRC Technical Requirements $\ldots \ldots \ldots \ldots$

3 Methodology 20

3.1 Background . . . . . . . . . . . . . . . . . 20

3.2 Scenairos and Services . . . . . . . . . . . . . . . . . 21

3.3 Delay Calculation . . . . . . . . . . . . . . . . . . 26

3.4 System Model . . . . . . . . . . . . . . . . . . . . . . . . . 29

3.5 Explanation of the IEEE 802.11a MatLab Simulation . . . . . . . 31

3.5.1 DSRC Transmitter . . . . . . . . . . . . . . . . . 31

3.5 .2 Channel Model . . . . . . . . . . . . . . . . . . . . . 34

3.5.3 DSRC Receiver . . . . . . . . . . . . . . . . . . 34

3.6 Explanation of the developed SNR/Doppler Shift Generator model . . 37

3.7 Explanation of experiments and system setup . . . . . . . . . . 42

3.8 Evaluating the DSRC for various parameters . . . . . . . . . . 46

3.8.1 Suburban Environments . . . . . . . . . . . . . . . 46

3.8.2 Highways Environments . . . . . . . . . . . . . . 47

3.8.3 Urban Environments . . . . . . . . . . . . . . . . 48

3.8.4 Rural Environments . . . . . . . . . . . . . . . 48

3.8 .5 Delay spread $\ldots \ldots \ldots \ldots$. . . . . . . . . . . . 49 
3.8 .6 Delay time . . . . . . . . . . . . . . . . . . . . . . 49

4 Performance of V2V DSRC Network $\quad 52$

4.1 Background . . . . . . . . . . . . . . . . . . . . . . 52

4.2 Packet Size and delay spread Effect . . . . . . . . . . . . 53

4.3 Suburban Environment . . . . . . . . . . . . . . . . . 57

4.4 Highway Environment . . . . . . . . . . . . . . . . . 61

4.5 Urban Environment . . . . . . . . . . . . . . . . . . . . . . 61

4.6 Rural Environment . . . . . . . . . . . . . . . . . . . . 63

5 Conclusions and Recommendations for Future Research 66

5.1 Conclusions . . . . . . . . . . . . . . . . . . 66

5.2 Recommendations for Future Research . . . . . . . . . . . . 67

A Extra Test Results $\quad 69$

A.1 Suburban Environments . . . . . . . . . . . . . . . . . 69

A.2 Highway Environments . . . . . . . . . . . . . . . 73

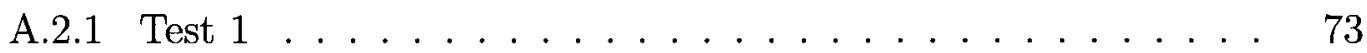

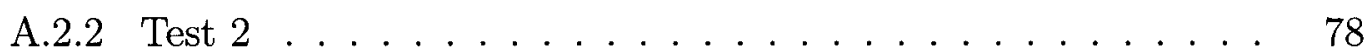

A.3 Urban Environments . . . . . . . . . . . . . . . . . . . 82

A.3.1 Test $1(\operatorname{LOS}) \ldots \ldots \ldots \ldots \ldots$

A.3.2 Test $2(\mathrm{NLOS}) \ldots \ldots \ldots \ldots \ldots$

A.4 Rural Environments . . . . . . . . . . . . . . . . . . . . . . 90

A.4.1 Test 1 (LOS) $\ldots \ldots \ldots \ldots \ldots$

A.4.2 Test 2 (NLOS) $\ldots \ldots \ldots \ldots \ldots$

$\begin{array}{lr}\text { List of References } & 97\end{array}$ 


\section{List of Acronyms}

\begin{tabular}{ll} 
Acronyms & Definition \\
\hline \hline AMC & Adaptive Modulation and Coding \\
ASTM & American Society of Testing and Materials \\
AVI & Automated vehicle identification \\
BER & Bit Error Rate \\
BSS & Basic Service Set \\
CAN & Collision Avoidance Notification systems \\
DOT & Department of Transportation \\
DS & Distribution Service \\
DSRC & Dedicated Short Range Communication \\
ESS & Extended Service Set \\
ETC & Electronic Toll Collection \\
ETR & Electronic Toll Route \\
FCC & US Federal Communications Commission
\end{tabular}




$\begin{array}{ll}\text { FCD } & \text { Floating Car Data } \\ \text { FFT } & \text { Fast Fourier Transform } \\ \text { FSPL } & \text { Free Space Path Loss } \\ \text { GSM } & \text { Global System for Mobile Communications } \\ \text { I2V } & \text { Infrastructure-2-V ehicle } \\ \text { IBSS } & \text { Independent Basic Service Set } \\ \text { IEEE } & \text { Institute of Electrical and Electronics Engineers } \\ \text { ITS } & \text { Intelligent Transportation Systems } \\ \text { LOS } & \text { Line Of Sight } \\ \text { MDOT } & \text { Michigan Department of Transportation } \\ \text { NHTSA } & \text { National Highway Traffic Safety Administration } \\ \text { OFDM } & \text { Orthogonal Frequency Division Multiplexing } \\ \text { PER } & \text { Packet Error Rate } \\ \text { PLCP } & \text { Physical Layer Convergence Procedure } \\ \text { PRN } & \text { Private Radio Networks } \\ \text { RFID } & \text { Radio Frequency Identification } \\ \text { Road Weather Information Systems } & \text { Signal to Noise Ratio } \\ \text { REvice Set Identification }\end{array}$


TIM Traffic Incident Management

V2I Vehicle-2-Infrastructure

V2V Vehicle-2-Vehicle

WAVE Wireless Access in Vehicular Environments

WBSS WAVE BSS

WiMAX Worldwide Interoperability for Microwave Access

WLAN Wireless Local Area Network 


\section{List of Symbols}

\section{Symbols Definition}

\begin{tabular}{ll}
\hline \hline$\gamma$ & Path-Loss exponent \\
$\sigma$ & Standard Deviation \\
$f$ & Observed Frequency \\
$f_{0}$ & Emitted Frequency \\
$d_{r}$ & Distance between transmitter and receiver \\
$d_{0}$ & Reference Distance \\
$d_{F}$ & Critical Distance \\
$v_{r}$ & Receiver Velocity \\
$v_{s}$ & Source Velocity \\
$v$ & Speed of light \\
$N_{0}$ & Thermanitted Power \\
&
\end{tabular}




$\begin{array}{ll}n_{a v} & \text { Average Number of Transmitions } \\ X_{\sigma} & \text { Gaussian Noise } \\ T_{S L O T} & \text { slot time } \\ T_{D I F S} & \text { DIFS time } \\ C_{\text {min }} & \text { Minimum back off window size } \\ T_{P} & \text { Transmission time of the physical preamble } \\ T_{P H Y} & \text { Transmission time of the PHY header } \\ T_{H D A T A} & \text { Transmission time of MAC overhead. MAC overhead in } \\ & \text { bytes, i.e., } 28 \text { bytes } \\ T_{S i g a n l} & \text { Duration of the Signal BPSK-OFDM symbol } \\ T_{S Y M} & \text { Symbol interval } \\ T_{D A T A} & \text { Transmission time for the payload in } \mu s e c \text { and depends on } \\ & \text { the packet size and data rate } \\ & \text { Propagation delay }\end{array}$




\section{Chapter 1}

\section{Introduction}

\subsection{General Introduction}

One of the objectives common to almost all transportation systems is the minimization of accidents by all means. Since the invention of automobiles, researchers are trying to increase the safety of roads. That is usually done by improving the geometry and the physical layout of the roadway. For example smoothing curves in roads and increasing stopping sight distance can make roads safer to use. On the other hand, several advanced safety features were added to automobiles, such as airbags, and antilock brakes. Recent advances in information technology and telecommunications; has introduced Intelligent Transportation Systems (ITS) as another important solution to road safety problems. [1] Vehicle-2-Vehicle (V2V) wireless communications systems have attracted more interest due to their improved efficiency and reliability. The increase in demand for safer transportation made traffic telematics applications undergo intense research and development. To reduce injuries and fatalities because of car accidents, vehicle safety needs to be more than the traditional passive safety technologies such as airbags and seatbelts. The vision for automotive safety applications is that all vehicles are equipped with sensors that are used to gather road and traffic 
conditions and share this data with other vehicles around them. Each vehicle can receive and process information from the data collected from other vehicles to improve its braking system timing, enhance airbag functionality and reduce fuel consumption and travel time. In order for these vehicles to share this kind of data they need to create an ad-hoc network, which requires a reliable low-latency V2V communication links capable of meeting strict delay and error rates. This kind of applications and services require fast and efficient $\mathrm{V} 2 \mathrm{~V}$ wireless communication, at data rates between 1 and $10 \mathrm{Mb} / \mathrm{s}$. Such V2V communication systems require accurate models for the V2V propagation channel.

The main challenge in the development of the $\mathrm{V} 2 \mathrm{~V}$ is the temporal variability and inherent non-stationarity of the wireless channels involved, which affect data packet transmission reliability and latency.

Dedicated Short Range Communication (DSRC), is an international standard dedicated in part to the Wireless Access in Vehicular Environments (WAVE) initiative. The new standard is based on the IEEE 802.11a standard, it is intended for both $\mathrm{V} 2 \mathrm{~V}$ and vehicle-to-infrastructure traffic telematics applications. [2] In general it is referred to as $\mathrm{V} 2 \mathrm{X}$ where $\mathrm{X}$ could means $\mathrm{V}$ for another vehicle or I for infrastructure. The frequency allocated for V2V communication, in North America, is $70 \mathrm{MHz}$ at 5.9 GHz. [3]

\subsection{Problem Statement}

The current research aims at evaluating the reliability of DSRC in V2V communication. Many aspects affect the reliability of any wireless link, such as the multipath propagation and delay involved in processing critical messages. In V2V communications, other factors include; scattering, antenna height, and mobility. The distance 
between the receiver and the transmitter affect the reliability of the wireless connection, because when the distance increases the path-loss increases causing high error rate.

This thesis evaluates the suitability of the DSRC communication systems in term of meeting the requirements of the safety applications mentioned in the previous section. In order to test the reliability of DSRC, multiple factors have been included in the model and were tested. They are:

- The maximum distance between the transmitter and the receiver within which reliable communications can be maintained.

- Different test environments, such as, highway, rural, suburban, and urban, which are characterized by different propagation environments .

- Different vehicle speeds were used for each test, which affects the Doppler Shift according to the speed and direction of the transmitter and the receiver.

Throughout this thesis, we assume that the communications protocol is provided by the DSRC and WAVE physical and MAC layers standards. Also this thesis provides some solutions and suggestions to increase the reliability of DSRC for V2V communications.

In order to facilitate the evaluation process a model was developed to simulate the $\mathrm{V} 2 \mathrm{~V}$ communication between two vehicles based on the following characteristics:

- Two vehicles are moving with different speeds and we use the relative speed between the two vehicles.

- The two vehicles are assumed to be able to communicate with each other via DSRC.

- The modeling is based using IEEE 802.11a WLAN PHY layer in MatLab and a special model has been developed using the Simulink, for the study of the 
effect of changing of distance on the quality of communication between the two vehicles.

- To validate the developed code, computer runs have been first benchmarked against problems with known solutions reported in the literature and found to compare favorably with these available solutions.

- Then a total of over 100 simulations each involves different environment and speed has been executed using the developed model and the Simulink model measuring each time the following factors; bit rate, PER, and BER.

- Graphical representations are automatically generated using a special program developed to compare the results.

\subsection{Thesis Contributions}

To the best knowledge of the author the V2V Communication based on DSRC using specially developed MathLab code that includes the factors to test the effect of distance and speed on the reliability of the DSRC communication has not been reported in the literature. Accordingly, it is believed that the current research has added the following contributions to the study of the evaluation of the V2V DRSC communication:

- A special model has been developed using Simulink to automatically evaluate the SNR values for different distances and environments.

- The combination of the results with all the factors that are included in the year 2005 report of the National Highway Traffic Safety Administration (NHTSA) and U. S. Department of Transportation (USDOT) regarding the requirements 
for a reliable DSRC V2V communication provided an understanding of the suggested architectures for $\mathrm{V} 2 \mathrm{~V}$ communication.

\subsection{Thesis Organization}

The rest of the thesis is organized as follows. Chapter 2 gives a brief introduction to ITS and DSRC as well as discusses the importance of ITS. Also it presents some implemented and potential applications of DSRC.

Chapter 3 presents the IEEE 802.11a PHY model and the developed model that was used to simulate and generate this research test results. This chapter also explains the tests parameters used to evaluate the performance of DSRC for V2V communication.

Chapter 4 contains the performance evaluation results.

Chapter 5 presents the conclusions, along with some directions for future work. 


\section{Chapter 2}

\section{Literature Review}

\subsection{Importance of Intelligent Transportation Sys- tems (ITS)}

Intelligent transportation systems (ITS) have many applications. They vary from basic management systems such as traffic signal control systems, car navigation, container management systems, variable message signs and automatic number plate recognition or speed cameras to monitor applications. Other advanced applications integrate live data and feedback from a number of other sources, such as parking guidance and information systems, and weather information systems. Some of the constituent technologies typically implemented in ITS are described in [4] and [5].

\subsubsection{Wireless Communication}

Several types of wireless communications have been proposed for intelligent transportation systems such as: 
Private Radio networks (PRN) Private Radio Networks are used in several realtime data communication applications PRN eliminates the need for using telecommunications or satellite network operators. Usually they use licensed UHF or VHF frequencies. Each user in a certain area reserves a frequency to insure that there is no interference with other RF transmitters. Unlike license-free systems (such as $\mathrm{WiFi}$ ), PRNs are relatively interference free over longer distances. Some of ITS applications that use PRN are: fleet management applications and telemetry applications. Since many ITS applications require high reliability of data transfer and very high uptime, the performance of radio communications plays a key role. Radio links are affected by many factors such as: Antenna type, elevation of antenna above ground, radio sensitivity, transmitted power and system design.

Short-range communication Wireless Access in Vehicular Environment (WAVE), and Dedicated Short Range Communications standard (DSRC) use the IEEE 802.11 MAC protocol, which is explained more later in this thesis.

Long-range communication Worldwide Interoperability for Microwave Access (WiMAX) which are based on the IEEE 802.16 standard, Global System for Mobile Communications (GSM), or 3G are examples of some long-range communications that was proposed for ITS applications. Of course the main disadvantage of using these commercial systems is the high cost, the DSDC deployments will be dedicated and free.

Floating Car Data/Floating Cellular Data (FCD): [6] Nowadays every car usually has at least one mobile phone. Any mobile phone periodically sends its location information to the base station that is serving it, even when it is idle. This allows mobile phones to be used as traffic probes. After measuring and analyzing the network data using triangulation, and pattern matching or cell-sector statistics, the 
data is converted into accurate traffic flow information. An increase of the number of cars (more congestion) increases the number of probes. Distances between antennas in urban environments are usually short and that increases accuracy. The advantage of this scheme is that there is no need for new infrastructure, because it uses the excising mobile phone networks.

\subsubsection{Computational Technologies}

Vehicles manufactured in the early 2000s have between $20-100$ individual microprocessors with non-real-time operating systems. Advances in computer processors and vehicle electronics made vehicular companies able to move toward fewer more costly microprocessors with real-time operating systems, which allowed for the implementation of more sophisticated software applications such as, model-based process control, artificial intelligence, and ubiquitous computing. The most important of all these applications for ITS, is the artificial intelligence.

\subsection{Examples of Intelligent Transportation Sys- tems (ITS) Applications}

There are many examples of ITS systems that can be used to increase the safety of roads and the environment. These applications can be divided into two different categories; depending on whether the vehicle is part of the system that helps in increasing the safety (Intelligent Vehicle) or it is the roadside units that do the job (Intelligent Infrastructure). Some applications of these two classifications are discussed in the next section. 


\subsubsection{Intelligent Infrastructure}

Technological advances in sensors have enhanced the technical capabilities of ITS systems. Infrastructure sensors are durable devices that are installed or embedded on the road, or surrounding the road. These sensors can be manually installed during road construction or by adding them later. Vehicle-sensing systems should implement Infrastructure-2-Vehicle (I2V) and Vehicle-2-Infrastructure (V2I) communication. Multiple Intelligent Infrastructure applications are discussed next.

\section{Crash Prevention and Safety Systems [7]}

Crash prevention and safety systems main objective is to detect unsafe road conditions and provide warning messages to travellers in order to take action to avoid accidents. These systems provide critical information to travellers approaching dangerous curves, high-volume intersections, off ramps. They can also inform travellers about the presence of pedestrians, bicyclists, even animals on the roadway. These systems usually use sensors to monitor the speed approaching vehicles. It can also include environmental sensors monitoring road and weather conditions.

These systems can be either permanent (monitoring the road conditions at all times and broadcast this information to all vehicles within hearing range) or temporary(pedestrians or bicyclists manually activating the system to provide warning of their presence to vehicles passing by [1].

Although ITS systems are oriented toward reducing crashes, traffic management systems can manage the flow of traffic streams and that will reduce accidents. This can be accomplished using traffic control devices such as ramp meters or speed cameras, which their job is to enforce traffic laws. Using traveler information systems improve safety by informing drivers about any risk situations so they will have enough time for avoiding accidents. 


\section{Road Weather Management [7]}

Road weather management systems include several subsystems that help in reducing number of accidents due to changes in weather. Winter maintenance technologies and Road weather information systems (RWIS) are some examples of road weather management systems. In the United States, these systems coordinate operations within and between state departments of transportation (DOTs). ITS applications can help in monitoring roads and atmospheric conditions and broadcasting this weather related information weather-related traffic control measures and winter maintenance activities to travellers.

\section{Traffic Incident Management (TIM)}

Incident management systems are used to reduce congestion due to accidents by decreasing the time between detecting an accident, arrival of responding vehicles, and the time required for traffic flow to return to its normal condition. Incident management systems use variety of surveillance technologies and enhanced communications in order to coordinate response to accidents. [8]

The main advantage for using TIM systems is that for every minute saved in clearing the incident, an estimated four to five minutes are saved from motorist delay. Traffic police officers spend a substantial amount of time documenting an incident and measuring important scene characteristics. So the use of TIM will help recording incident information in a database that can be accessed by police officers while on the way to the incident location to analyze accident and reduce processing time. [9]

\section{Electronic Payment and Pricing}

Electronic payment systems implement various electronic and communication technologies to facilitate commerce between transportation agencies and travellers. These 
systems are typical for the purpose of paying transit fares,tolls and parking fee payment.On the other hand, pricing systems are used to charge motorists toll fee that varies with the time of the day or the level of demand [10].

\subsubsection{Intelligent Vehicles}

Intelligent vehicles contain electronic, electromagnetic, and electromechanical devices that are controlled by computers their function is to increase vehicle safety on the road. Electromechanical sensors generate warnings that can be shared with surrounding vehicles or infrastructure. Intelligent vehicles also provide commercial communications between vehicles or between vehicle and infrastructure. The in-vehicle system updates the vehicle information periodically (depending on the speed of the vehicle) and transmits it to surrounding vehicles. This information is broadcasted using DSRC protocol. Some intelligent vehicle applications are discussed next.

\section{Collision Avoidance}

Collision avoidance applications are the most important type of applications in ITS to increase safety. The best way to improve road safety is by providing drivers with early warning messages to avoid collisions. Collision avoidance systems are connected with a variety of in-vehicle or infrastructure sensors to monitor the vehicles surroundings and provide the driver with alerts of road conditions that could lead to a collision [11].

Here are some collision avoidance applications that are available in industry:

1. Crash avoidance system:

This system will show drivers warning of any potential accidents (with other vehicles, pedestrians, or objects) while changing lanes, backing up, approaching a slowingor stopping vehicle also can provide a warning if the car is running off the road. 
2. Drowsy driver detection system:

In the 1996 National Highway Traffic Safety Administration NHTSA indicated that in the recent years there have been annually about 56,000 crashes caused by drowsiness/fatigue. [12]. This number is most likely an underestimate, because it is difficult to determine drivers conditions unless someone witnesses or survives the crash. So drowsy driver detection systems come in place to detect early signs of drowsiness and provide the driver with a sound alarm when he/she is about to fall asleep at the wheel.

3. Adaptive cruise control:

This is an enhanced version of the conventional cruise control system that will adjust the vehicle speed automatically to maintain a constant safe distance from the vehicle immediately ahead.

4. Vision enhancement package:

This system is used to increase visibility in darkness, glare conditions and poor weather, by using advanced headlamps and windshield glass. Also these systems can add the possibility of a projection on the windscreen using an infrared image in a head-up display.

5. Intersection assistance option:

Intersection assistance system job is to detect unsafe conditions of intersections and warn the driver of potential accidents with other vehicles at the intersection. This system work by collecting position and speed of all vehicles approaching the intersection and share it with other vehicles at the intersection. 


\section{Collision Notification}

Faster response to crashes improves medical service and though decreasing the chances of fatalities. Also that reduces the time of removing the crash from the travel way decreasing the delay caused by the accident and the probability of a secondary accident. Collision notification systems come handy to detect and report the location and severity of accidents to emergency agencies in order to improve response times and save lives [13]. These systems can be activated automatically using automatic Collision Avoidance Notification systems (CAN) or manually using Mayday systems. Advanced versions of collision notification systems can provide information on crash type, number of passengers and possibility of injuries.

\section{Driver Assistance}

Various intelligent vehicle technologies exist to help the driver operate the vehicle safely. Driver assistance systems are available to help with safety and non-safety applications. Navigation is one of the non-safety applications that driver assistance systems provide. Driver assistance safety applications can work together with collision avoidance to provide users with warnings to avoid accidents. Other systems can help with difficult driving tasks for transit and commercial vehicles such as, roll stability control, precision docking, coupling/decoupling, on-board monitoring. [13]

\subsection{Introduction to Dedicated Short Range Com- munications (DSRC)}

ITS needed a way of wireless communication to exchange data between vehicles and vehicles and infrastructure; accordingly, US Federal Communications Commission 
(FCC), in 1999, allocated the frequency range 5.85 to $5.925 \mathrm{GHz}$ of the wireless spectrum to be used by the Dedicated Short Range Communications (DSRC) systems to support ITS applications. In the year 2003, a report was issued regarding the use of the $5.9 \mathrm{GHz}$ spectrum for ITS applications (FCC 2003). This report specified the use of American Society of Testing and Materials (ASTM) E2213-03, which is a standard for telecommunications and information exchange between vehicle and roadside unites. This ASTM standard was based on the IEEE 802.11a standard, but used $8 \mu$ sec symbol period [14], which uses Orthogonal Frequency Division Multiplexing (OFDM). ASTM made several changes in the IEEE 802.11a standard to meet the requirement of vehicle movement at high speeds [15]. The main goal of establishing the DSRC standard was to improve the vehicle safety applications. In the year 2006, FCC refined the rules for DSRC to be the only standard used for Vehicle-to-Vehicle collision avoidance systems.

In 2008 , FCC changed the required standard for use in the $5.9 \mathrm{GHz}$ spectrum from ASTM E2213-03 to IEEE 802.11p.The IEEE 802.11p uses the same OFDM approach of IEEE 802.11a, but it uses $10 \mathrm{MHz}$ channel width instead of the 20 $\mathrm{MHz}$ channel width used by IEEE 802.11a.Also, the IEEE 802.11p uses the same modulation as IEEE 802.11a, but because IEEE 802.11p uses half the duration of each symbol with $10 \mathrm{MHz}$ channel width so each IEEE 802.11p modulation level result in half the data throughput. The advantages of these modifications in IEEE 802.11a are to allow IEEE 802.11 p to operate more reliable where very short-duration communication is required and where multipath changes rapidly such asin case of vehicular environments. Also, due to high speeds, the normal Wireless Local Area Networks (WLAN) approach may not be possible in many road scenarios, so IEEE 802.11p allows the exchange of messages between vehicles without the need to join a network, by using broadcast message protocols. Also, IEEE $802.11 \mathrm{p}$ allows for the WLAN two-way communications mode. [16] 


\subsection{IEEE 802.11a Vs. IEEE 802.11p}

This section discusses similarities and differences between both standards IEEE 802.11a and IEEE 802.11p. Also it discusses enhancements of IEEE 802.11p over IEEE 802.11a to make DSRC more applicable for V2V communications. [17] [18] The main difference between IEEE 802.11a and IEEE 802.11p is in the MAC layer.

\subsubsection{IEEE 802.11a}

In IEEE 802.11a wireless LAN, the basic network building block is called Basic Service Set (BSS) based on the IEEE 802.11a standard. BSS consists of multiple Access Points (AP) which are controlled by a master AP. The advantage of using BSS is to control access to resources and services of APs, also to filter any unrelated transmissions from nearby access points. Each BSS is identified by a BSSID. In order for an AP to join a BSS, it first listens for beacons from any nearby AP and when found, it joins the BSS and goes through authentication and association. Figure 2.1 shows a simple concept of a BSS network, and also it shows that IEEE 802.11a standard allows the combining of multiple BSSs into one Extended Service Set (ESS) using Distribution Service (DS).

IEEE 802.11a standard allows the implementation of ad-hoc networks between APs without the need for a controlling access point and that is called Independent Basic Service Set(IBSS) and in that case each BSS is known to users using Service Set Identification (SSID). The problem with IBSS is that it has too much complexity and overhead to be suitable for $\mathrm{V} 2 \mathrm{~V}$ communications. 

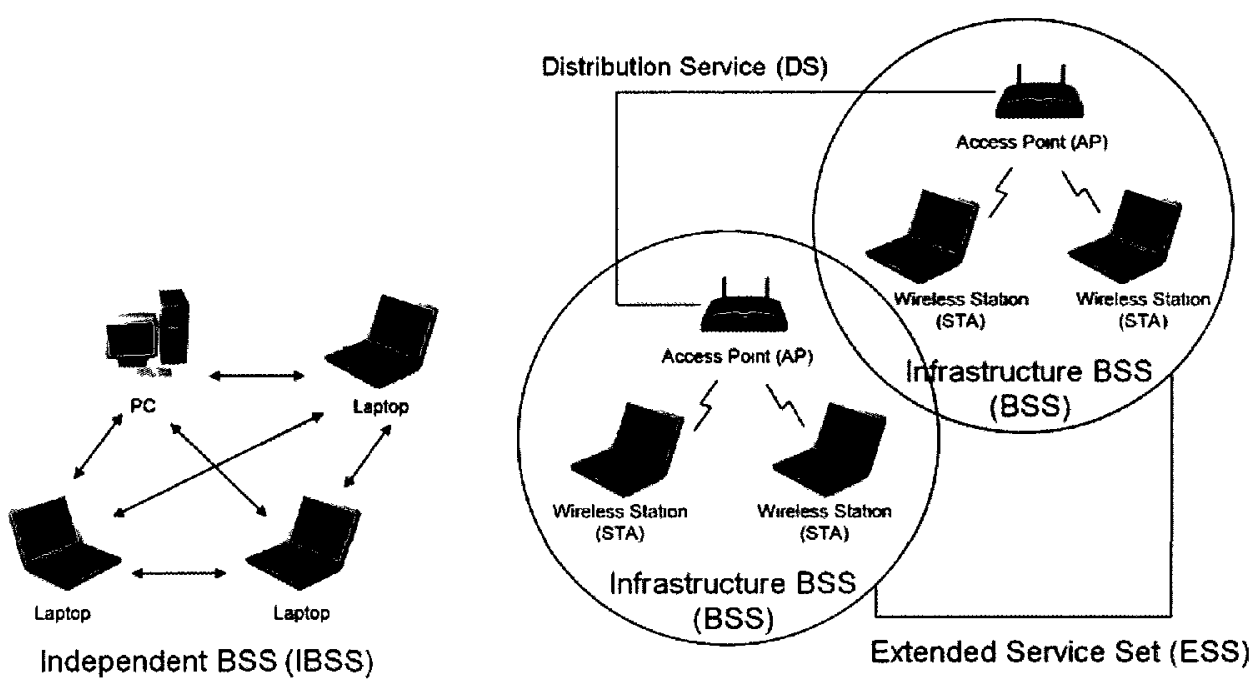

Figure 2.1: Independent and extended service set [17]

\subsubsection{IEEE 802.11p (WAVE)}

\section{WAVE mode}

In Vehicular safety applications instantaneous data exchange is needed and these applications cant afford consuming time to scan channels for BSS beacons to establish communications, as mentioned before, IEEE 802.11a IBSS is too time consuming to be used in IEEE 802.11p. In IEEE 802.11p WAVE a new feature was introduced as "WAVE mode", In case of emergency a vehicle start transmitting an urgent message (high priority message) without the need to belong to a BSS to do that, and that allows two V2V communication without the need for any additional overhead.

\section{WAVE BSS}

The overhead of traditional BSS setup may be too big even for non-safety communications and services. To avoid this problem a new BSS type was introduced by WAVE standard which is WAVE BSS (WBSS). This type of BSS setup can be used 
for V2I communication. A WAVE station advertises a WBSS using a well known beacon frame and needs not to be periodically repeated. The advertised WBSS message contain all the needed information for the receiver to decide whether to join or not, including the information needed to be a member of the WBSS. This will reduce the overhead for WBSS by eliminating all association and authentication needed to join. As known that the focus of WAVE is on Safety, so the high priority message BSSID is supported for even a station that already belongs to another WBSS.

\subsection{Existing DSRC Applications}

Many ITS applications have been implemented over the past few years. Most of these applications have been used in Europe and Japan. In this section, some of these applications are discussed.

\subsubsection{Electronic Toll Collection (ETC)}

Electronic Toll Collection (ETC) is the most widely used DSRC application. It is used to eliminate the delay on toll roads by electronically collecting tolls. Basically it is a technological implementation of road pricing concept, by detecting if cars passing are enrolled in the program or not and automatically charge passing cars without the need to stop.

ETC uses Automated vehicle identification (AVI) feature in order to identify the car passing by. Radio Frequency Identification (RFID) technology was the first technology that was used by AVI (in Bergen, Norway in 1986) [19].Most Current AVI systems rely on radio frequency identification, which communicates with the tollgate through a DSRC device. The disadvantage of using DSRC is the cost, so some roads (407 ETR (Electronic Toll Route) near Toronto) use automatic plate number recognition. Other applications of radio frequency identification technology are payment 
of parking facilities and fuel in gas stations, which eliminate the need for stopping for payments.

\subsubsection{Travelers, alert, and warning information}

Travelers information systems are used to inform drivers about the existence of any upcoming emergency vehicles or construction zones. Michigan Department of Transportation (MDOT) is conducting a test bed of this type of systems to provide drivers with this kind of information ahead of time so they can avoid accidents and increase safety on roads. [5]

\subsubsection{Travel time and delay measurement}

This application is used in Norway in order to calculate vehicles travel time and traffic delay. Old versions of ETC used RFIDs to identify a vehicle, so when a car passes under a toll gate it will record time, station number, and tag identification. The new system, using DSRC, records time and place information at one travel time measurement point and compare it with the information at the next point. The system calculates travel time based on the time-and-place stored between different points.

\subsection{DSRC Technical Requirements}

DSRC applications fall roughly into two groups: (1) Information Messages and (2) Safety Messages. All messages to and from each car and roadside units share certain number of physical radio channels and must compete for access and quality of service. From a wireless point of view, we must account for the channel capacity, transmission errors, delay and packet discards. The tolerance of different applications to these 
parameters are different. In the next few chapters we will discuss these issues in the context of some time-sensitive message exchanges. 


\section{Chapter 3}

\section{Methodology}

\subsection{Background}

This chapter describes the parts of DSRC standards that apply to our work. Specifically, we introduce and explain the IEEE-1609 set of standards for Wireless Access for Vehicular Environment (WAVE) and the IEEE-802.11p. The IEEE-802.11p pro-

tocol is similar to the well known Distributed Coordination Function (DCF) MAC protocol for IEEE802.11a/b/g. Some of the issues that need to be addressed include prioritized access, unpredictable response and reliability.

The physical layer of IEEE-802.11p is identical to that of IEEE-802.11a. Therefore, it uses OFDM with adaptive coding and modulation as indicated in Table 3.3.

The MAC layer of $802.11 \mathrm{p}$ is based on DCF, which is common in all 802.11. The EDCA (Enhanced Distributed Channel Access) provides MAC extensions, which allow for priorities and lower access delay. The concepts of Access Category (AC) and Arbitrary Inter-Frame Space (AIFS) provide the mechanisms for service differentiation.

The basic communication parameters of DSRC standards vary in different parts of the world. In our work we adopt the standards in North America. The main parameters include, the frequency bands, the total available BW, the number of 
Table 3.3: Rate-dependent parameters [20]

\begin{tabular}{|l|l|l|l|l|l|l|}
\hline $\begin{array}{l}\text { Data rate } \\
(\text { Mbits/s) }\end{array}$ & Modulation & $\begin{array}{r}\text { Coding } \\
\text { rate (R) }\end{array}$ & $\begin{array}{l}\text { Coded bits } \\
\text { per subcar- } \\
\text { rier }\end{array}$ & $\begin{array}{r}\text { Coded } \\
\text { bits per } \\
\text { OFDM } \\
\text { symbol }\end{array}$ & $\begin{array}{l}\text { Data } \\
\text { bits per } \\
\text { OFDM } \\
\text { symbol }\end{array}$ & $\begin{array}{l}\text { Max pit per } \\
\text { OFDM } \\
\text { Frame }\end{array}$ \\
\hline 6 & BPSK & $1 / 2$ & 1 & 48 & 24 & 480 \\
\hline 9 & BPSK & $3 / 4$ & 1 & 48 & 36 & 720 \\
\hline 12 & QPSK & $1 / 2$ & 2 & 96 & 48 & 960 \\
\hline 18 & QPSK & $3 / 4$ & 2 & 96 & 72 & 1440 \\
\hline 24 & 16 -QAM & $1 / 2$ & 4 & 192 & 96 & 1920 \\
\hline 36 & 16 -QAM & $3 / 4$ & 4 & 192 & 144 & 2880 \\
\hline 48 & 64 -QAM & $2 / 3$ & 6 & 288 & 192 & 3840 \\
\hline 54 & 64 -QAM & $3 / 4$ & 6 & 288 & 216 & 4320 \\
\hline
\end{tabular}

channels, the bandwidth per channel, the coverage range, the data rate and the modulation methods. These parameters are listed in Table 3.4.

\subsection{Scenairos and Services}

In the technical report that was issued in 2005 by the National Highway Traffic Safety Administration (NHTSA) and U.S. Department of Transportation (USDOT), some requirements for intelligent vehicle safety applications using DSRC were stated. The definitions of requirements for several safety applications are:

- Transmission Mode: describes whether the transmission event-driven or it is periodic.

- Minimum Frequency: which is the information update rate in $(\mathrm{Hz})$.

- Allowable Latency: the maximum allowed time between information generated, transmitted and received by the other side in (sec). 
Table 3.4: Main Parameters of DSRC [20]

\begin{tabular}{|c|c|c|c|c|c|c|}
\hline & Japan & Europe & Americas & $\begin{array}{l}\text { Coded bits } \\
\text { per OFDM } \\
\text { symbol }\end{array}$ & $\begin{array}{l}\text { Data bits } \\
\text { per OFDM } \\
\text { symbol }\end{array}$ & $\begin{array}{l}\text { Max bit } \\
\text { per OFDM } \\
\text { Frame }\end{array}$ \\
\hline \multirow[t]{2}{*}{ Duplex } & $\begin{array}{l}\text { OBU: Half } \\
\text { Duplex }\end{array}$ & \multirow[t]{2}{*}{ Half Duplex } & \multirow[t]{2}{*}{ Half Duplex } & 48 & 24 & 480 \\
\hline & $\begin{array}{l}\text { RSU: Full } \\
\text { Duplex }\end{array}$ & & & 48 & 36 & 720 \\
\hline \multirow{2}{*}{$\begin{array}{l}\text { Radio Fre- } \\
\text { quency } \\
\text { Bands }\end{array}$} & $5.8 \mathrm{GHz}$ & $5.8 \mathrm{MHz}$ & $5.9 \mathrm{GHz}$ & 96 & 48 & 960 \\
\hline & $\begin{array}{l}80 \mathrm{MHz} \\
\text { Bandwidth }\end{array}$ & $\begin{array}{|lr|}20 \mathrm{MHz} \\
\text { Bandwidth }\end{array}$ & $\begin{array}{lr}75 \mathrm{MHz} \\
\text { Bandwidth }\end{array}$ & 96 & 72 & 1440 \\
\hline \multirow{2}{*}{ Channels } & $\mathrm{D} / \mathrm{L}: 7$ & \multirow{2}{*}{4} & \multirow{2}{*}{7} & 192 & 96 & 1920 \\
\hline & $\mathrm{U} / \mathrm{L}: 7$ & & & 192 & 144 & 2880 \\
\hline $\begin{array}{l}\text { Channel } \\
\text { Separation }\end{array}$ & $5 \mathrm{MHz}$ & $5 \mathrm{MHz}$ & $10 \mathrm{MHz}$ & 288 & 192 & 3840 \\
\hline $\begin{array}{l}\text { Data } \\
\text { Trans- } \\
\text { mission } \\
\text { Rate }\end{array}$ & 1-4 Mbps & $\begin{array}{ll}\mathrm{D} / \mathrm{L}: & 500 \\
\mathrm{kbps} & \end{array}$ & 3-27 Mbps & 288 & 216 & 4320 \\
\hline
\end{tabular}


- Type of Data to be Transmitted and/or Received

- Maximum Required Range of Communication: different applications require different distances between the two units in $(\mathrm{m})$.

Table 3.5: Requirements for different types of safety applications

\begin{tabular}{|c|c|c|c|}
\hline No. & Application & \multicolumn{2}{|c|}{ Required No. of Bits } \\
\hline 1 & Curve Speed Warning & \multicolumn{2}{|c|}{238} \\
\hline 2 & Emergency Electronic Break Light & \multicolumn{2}{|c|}{288} \\
\hline \multirow{2}{*}{3} & Cooperative Pre-Crash sensing & Static Vehicle & Dynamic Vehicle \\
\cline { 3 - 4 } & & 172 & 263 \\
\hline 4 & Cooperative Forward Collision Warning & & \multicolumn{2}{|c|}{419} \\
\hline 5 & Lane Change Message & \multicolumn{2}{|c|}{288} \\
\hline
\end{tabular}


Table 3.6: Requirements for different types of safety applications [21]

\begin{tabular}{|c|c|c|c|c|c|}
\hline No. & Application & Application Definition & \begin{tabular}{c|} 
Max. \\
Required \\
Range (m) \\
\end{tabular} & $\begin{array}{c}\text { Allowable } \\
\text { Latency } \\
\text { (sec) }\end{array}$ & $\begin{array}{c}\text { Min. } \\
\text { Update } \\
\text { Rate (Hz) }\end{array}$ \\
\hline 1 & Curve Speed Warning & Helps the driver in negotiating curves at appropriate speeds & 200 & 1 & 1 \\
\hline 2 & $\begin{array}{l}\text { Emergency Electronic } \\
\text { Brake Lights }\end{array}$ & $\begin{array}{l}\text { Sends a message to other vehicles following behind when a vehicle brakes } \\
\text { hard }\end{array}$ & 300 & 0.1 & 10 \\
\hline 3 & $\begin{array}{l}\text { Traffic Signal Violation } \\
\text { Warning }\end{array}$ & $\begin{array}{l}\text { Uses I2V communication to warn the driver to stop at a traffic signal if it } \\
\text { indicates a stop and it is predicted that the driver will be in violation. }\end{array}$ & 250 & 0.1 & 10 \\
\hline 4 & $\begin{array}{c}\text { Intersection Collision } \\
\text { Warning }\end{array}$ & Warns drivers when a collision at an intersection is probable & 300 & 0.1 & 10 \\
\hline 5 & Blind Merge Warning & $\begin{array}{c}\text { Warns a vehicle if it is attempting to merge from a location with limited } \\
\text { visibility and another vehicle is approaching }\end{array}$ & 200 & 0.1 & 10 \\
\hline 6 & $\begin{array}{l}\text { Approaching Emergency } \\
\text { Vehicle Warning }\end{array}$ & $\begin{array}{c}\begin{array}{l}\text { Warns the driver to yield the right of way for an approaching emergency } \\
\text { vehicle }\end{array}\end{array}$ & 1000 & 1 & 1 \\
\hline 7 & Pre-Crash Sensing & Prepare for imminent, unavoidable collisions & 50 & 0.02 & 50 \\
\hline 8 & SOS Messages & In-vehicle application that will send SOS messages after an accident & 400 & 1 & 1 \\
\hline 9 & Post Crash Warning & In-vehicle application warns approaching traffic of a disabled vehicle & 300 & 0.5 & 1 \\
\hline 10 & $\begin{array}{l}\text { Wrong Way Driver } \\
\text { Warning }\end{array}$ & $\begin{array}{l}\text { Warns drivers that a vehicle is driving or about to drive against the flow of } \\
\text { traffic }\end{array}$ & 500 & 0.1 & 10 \\
\hline 11 & $\begin{array}{l}\text { Cooperative Forward } \\
\text { Collision Warning }\end{array}$ & $\begin{array}{l}\text { Designed to aid the driver in avoiding or mitigating collisions with the rear- } \\
\text { end of vehicles through driver notification or warning of the impending } \\
\text { collision }\end{array}$ & 150 & 0.1 & 10 \\
\hline 12 & $\begin{array}{l}\text { Vehicle-Based Road } \\
\text { Condition Warning }\end{array}$ & $\begin{array}{l}\text { In-vehicle application will detect road conditions using on-board systems } \\
\text { and sensors and transmit a road condition warning to other vehicles }\end{array}$ & 400 & 0.5 & 2 \\
\hline 13 & Visibility Enhancer & $\begin{array}{l}\text { Senses poor visibility situations (fog, glare, heavy rain, night), V2V } \\
\text { communication is used to obtain position, velocity and heading of nearby } \\
\text { vehicles }\end{array}$ & 300 & 0.1 & 2 \\
\hline 14 & $\begin{array}{l}\text { Cooperative Adaptive } \\
\text { Cruise Contrel }\end{array}$ & $\begin{array}{l}\text { Uses V2V communication to obtain ahead vehicle's dynamics and enhance } \\
\text { the performance of current adaptive cruise control }\end{array}$ & 150 & 0.1 & 10 \\
\hline 15 & Lane Change Warning & $\begin{array}{l}\text { Provide a waming to the driver if an intended lane change may cause a } \\
\text { crash with a nearby vehicle }\end{array}$ & 150 & 0.1 & 10 \\
\hline 16 & Road Condition Warning & $\begin{array}{l}\text { Provide warning messages to nearby vehicles when the road surface is icy, } \\
\text { or when traction reduced }\end{array}$ & 200 & 1 & 1 \\
\hline
\end{tabular}


Table (3.5 and 3.6) state some of these requirements for various types of safety applications.

We focus on a critical safety mode. The basic idea is that, when a car detects a critical situation such as; an accident, a dangerous slippery section, the sensors in the car would generate an urgent alert message and transmits it to the cars behind it. The most critical parameter is the delay. Each car approaching the detected "event" must receive the message within a Maximum Tolerable Delay (MTD). The MTD is calculated such that the driver would have enough time to react to the event and stop the car. An example of this application is the avoidance of pile-ups. When two cars collide and the vision is not clear, the incoming cars could be alerted in order to avoid multiple collisions (a pile-up). This can be accomplished by sending critical safety message.

We make the following assumptions:

- The cars are travelling in both directions.

- Urgent safety messages are transmitted on a dedicated channel which remains idle most of the time and is accessed only under certain conditions.

- Non-urgent safety messages including information messages compete for access on a separate channel or channels.

- Car sensors will determine if the message is urgent or not, and there is a list of specific conditions that trigger an urgent mode.

Obviously, the level of criticality of the message decreases when an incoming car is too far away from the location of the "event". This will reduce the need or urgent multi-hop message relay. We still need message relay to pass the information to cars further away from the accident location but we should not allow the relay mode to interfere with the urgent safety message. A mechanism must exist to prevent 
unnecessary message relay. For example, a car too close to the accident location should not relay the message because it can interfere with a repeat of the original message. Only cars further away from the accident location would be allowed to relay the message.

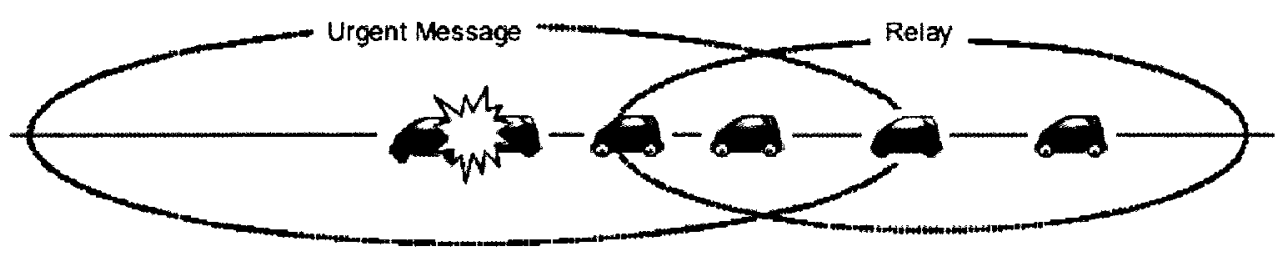

Figure 3.1: Basic Model

We assume that there are restrictions on the message relaying. The most important restriction is to give the original urgent message and its possible repeat priority over the relaying. This can be implemented by putting the two messages in different classes with two different AIFS or alternatively, we can classify the relayed message as "safety message" but not an "urgent safety message". In such case, relayed messages could be broadcast on a separate channel.

\subsection{Delay Calculation}

In DSRC there are 8 channels, one channel is used for control, one for safety messages, one for urgent messages and the remaining 5 channels are used for non-safety applications. The process is triggered when an urgent event (accident) is detected, the vehicle that is in the accident sends a high priority urgent message which will be repeated for a period of time or until it is turned off manually. When a vehicle behind it receives that message it will relay that message to other vehicles behind it, and the relayed message will be sent as a safety application on a safety channel. The total delay is divided into two major parts. The first part is called the access time and it 
consists of a mechanical part where the car sensors detect the event and an electrical part where the microprocessor assemble the message and the communication device triggers the MAC protocol to access the media.

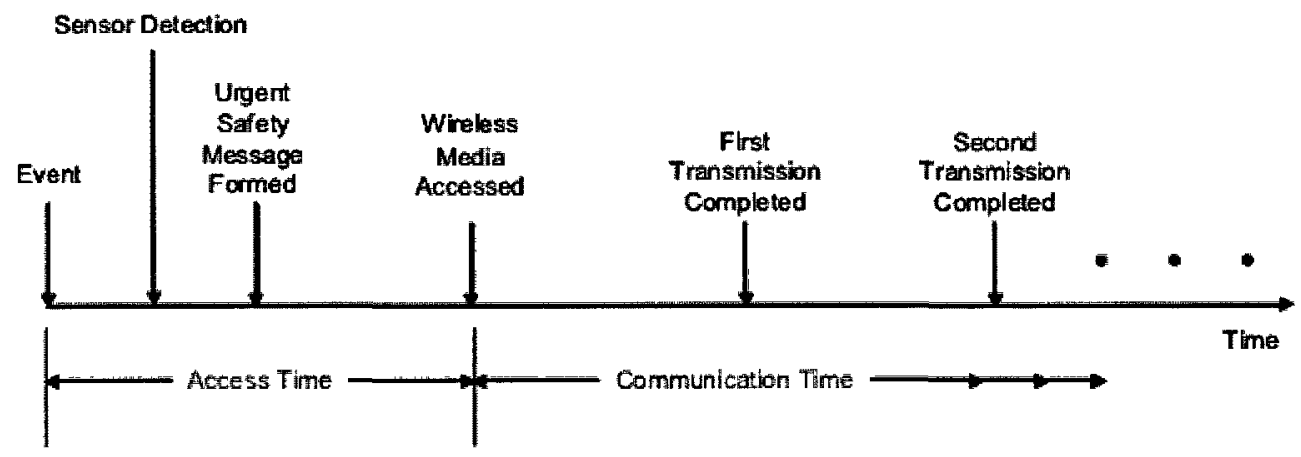

Figure 3.2: Delay Components

Once the media is accessed, the source car sends the urgent message several times. Each receiving car tries to decode the message and it might fail. Assuming that the decoding of each copy of the transmitted message succeeds with probability (1-P), where $\mathrm{P}$ is the packet error rate. Further assume that several transmission trials are statistically independent then the average number of trials needed to decode the packet correctly is approximately $n_{a v}$. The number of trials (transmissions) is N. The probability that all $\mathrm{N}$ trials fail is $P^{N}$ the probability that success occurs on the last trial is $(1-P) P^{N-1} \ldots$, the probability that success will occur on the second last trial is $(1-P) P^{N-2}$ and so on. The average number of trials till success is:

$$
n_{a v}=\sum_{k=1}^{N} k(1-P) P^{k-1}
$$

When $\mathrm{N}$ is infinite, $n_{a v}=1 /(1-P)^{N}$. $\mathrm{P}$ is a function of several parameters including distance. The main parameters are:

- Packet length

- RMS delay spread 
- Delay spread profile

- Relative speed between the source and destination

- Pathloss distance factor

- Variance of pathloss

- Distance

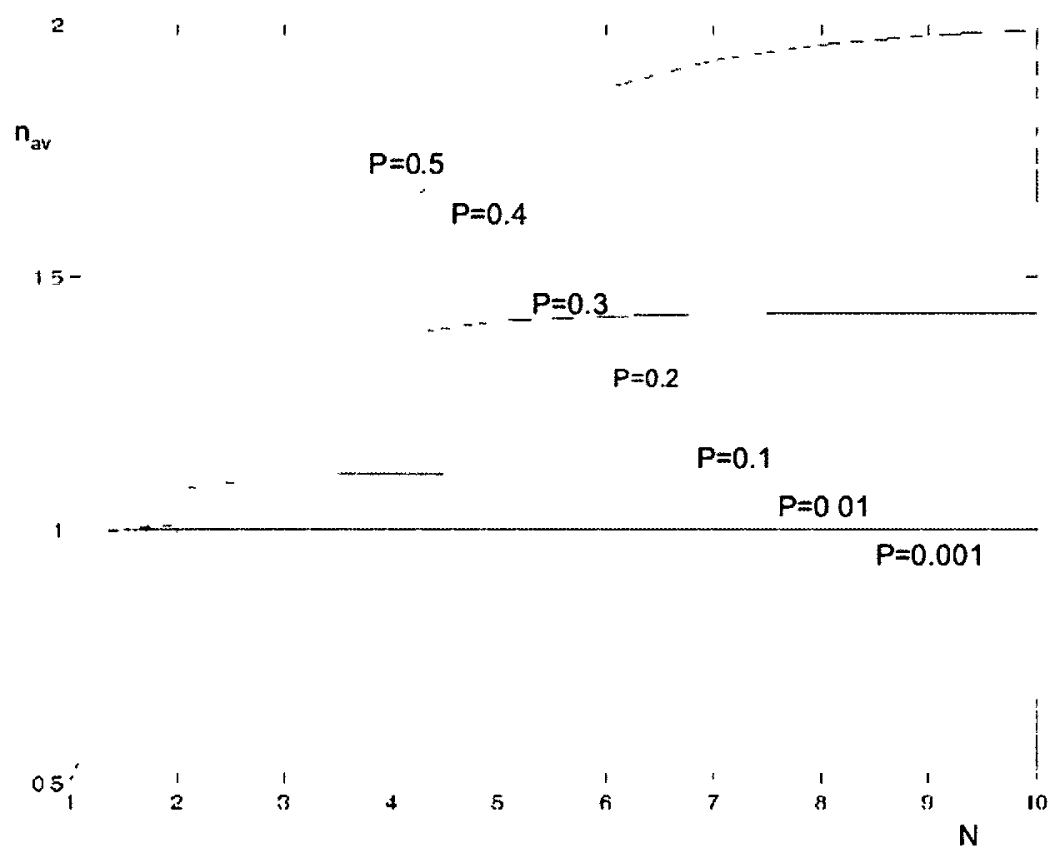

Figure 3.3: Average Number of Transmissions Till First Success

Figure 3.3 illustrates the average number of trials until we get the first success as a function of $\mathrm{N}$, and $\mathrm{P}$.

The cumulative probability of succeeding on trial number $m$ or less is shown in Figure 3.3 for different packet error rates.

For a fixed set of parameters, the probability of packet failure increases with distance. Therefore, cars further away from the accident will take longer to decode 
the message correctly. Essentially, each driver should be given enough reaction time, $T_{C}$. A car located at distance, $\mathrm{d}$, from the accident, traveling towards the accident's location at speed $\mathrm{v}$, has total time to react $d / v$. This time must be larger than or equal to the critical time $T_{C}$.

\subsection{System Model}

This section describes the test model structure for all environments. When an even occurs, the vehicle involved in the event access the "urgent safety channel". If two cars are involved one of them will grab the channel before the other. The message is broadcast on the channel repeatedly in separate OFDM frames. Cars within a certain critical distance decode the message but do not re-broadcast it. Cars further away from that same critical distance relay the message on a different but less urgent channel which is called the "safety channel". The relaying of the message could be repeated by cars further and further away from the location of the event. For each environment several parameters have been taken into consideration in order to achieve the required results. These parameters are explained in details throughout this chapter.

The system model used in this thesis concentrates on the effect speed and distance on the quality of communication between vehicles. The communication reliability is tested between two cars, one is stationary or has suddenly stopped, the other is moving towards the stationary car. The stopped car sends warning messages to cars behind it to avoid a potential accident or relay information to the incoming traffic. So the model tests the maximum distance reliable communication can be achieved between two vehicles. Figure 3.4 demonstrates the main concept of the various tests that have been done in this thesis and how communication between vehicles is established, to determine the maximum distance that the DSRC communication can cover for several 


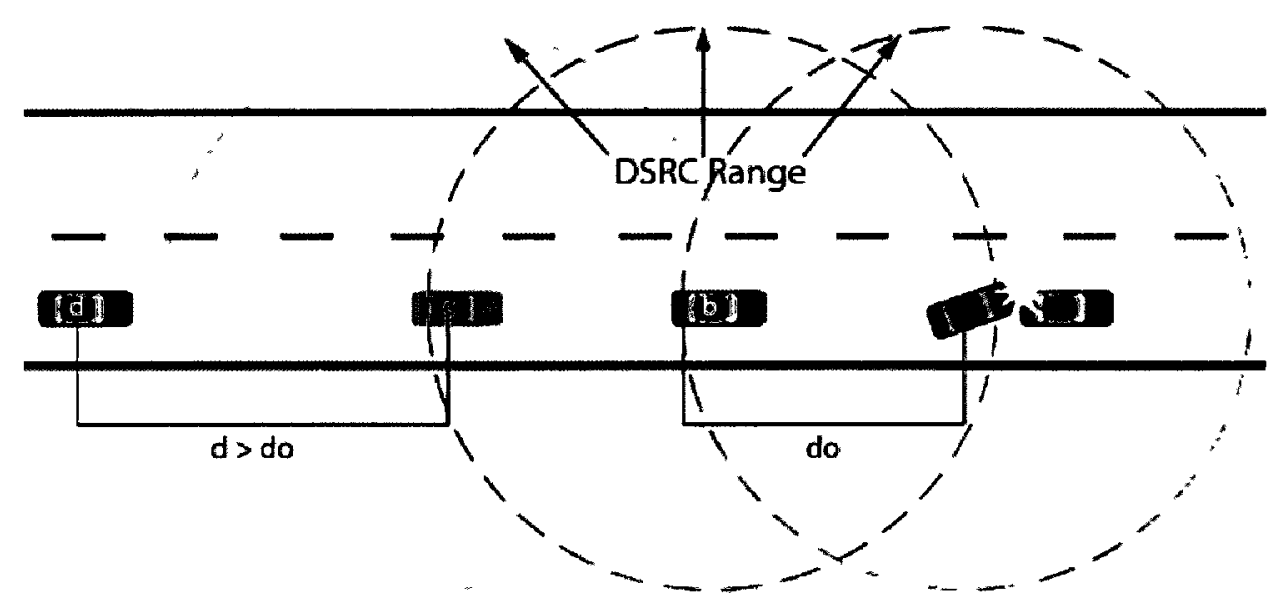

Figure 3.4: Test concept

environments.

Also these tests can provide an understanding on how to relay messages to other vehicles when designing the V2V system without the use of infrastructure. Two road classifications have been used in this thesis depending on the probability of having a higher number of vehicles and lower distance between these vehicles, which are in city (urban and suburban) and between cities (highway and rural) respectively.

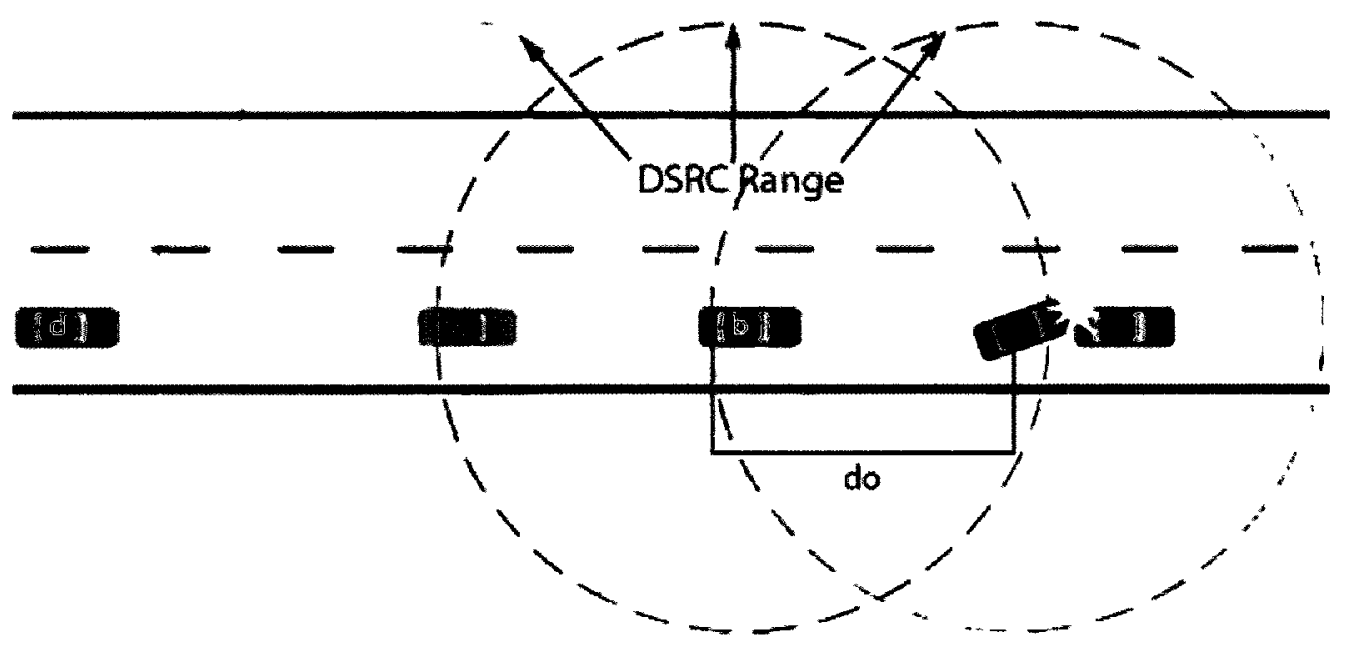

Figure 3.5: In-city car distribution vs. DSRC range 


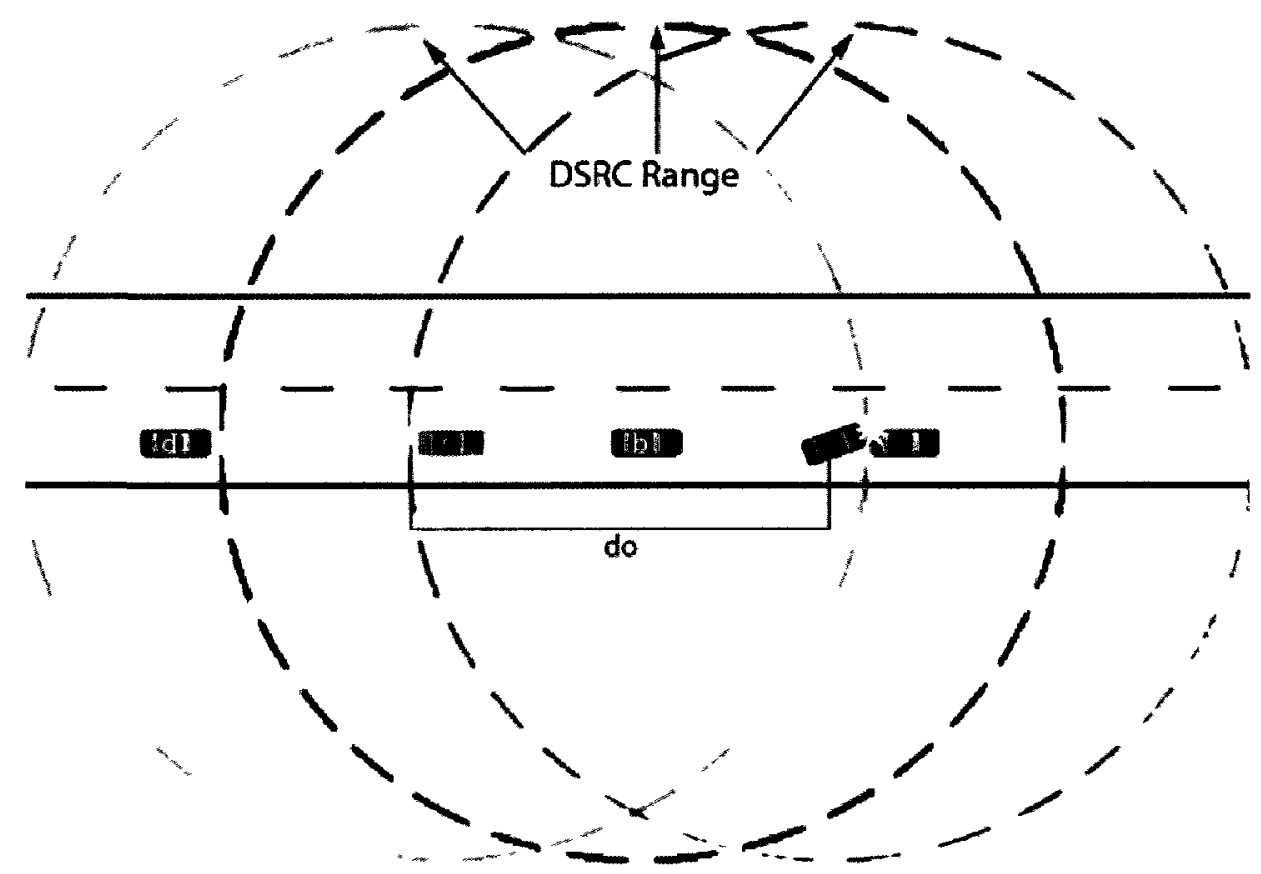

Figure 3.6: Open highways car distribution vs. DSRC range

Usually vehicles in cities move at slow speeds $(25-60 \mathrm{~km} / \mathrm{h})$ and the number of vehicles tends to be high, on the other hand vehicles on highways move with higher speeds $(100-120 \mathrm{~km} / \mathrm{h})$ but with lower car density. Also on highways the DSRC signal range increases compared with in cities. This difference in distance and speed can change the system architecture. Figures (3.5 and 3.6) demonstrate the difference between the in-city and open highways cases.

\subsection{Explanation of the IEEE 802.11a MatLab Sim- ulation}

\subsubsection{DSRC Transmitter}

Figure 3.7 illustrates the transmitter processing blocks. Variable data generator generates the data to be transmitted then the model uses the SNR value, because the 


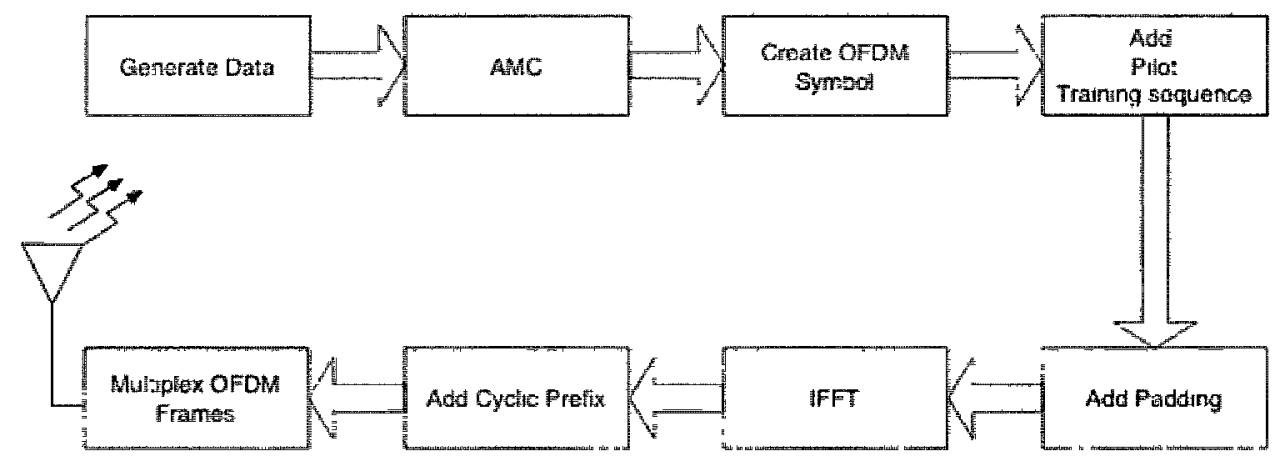

Figure 3.7: DSRC Transmitter model

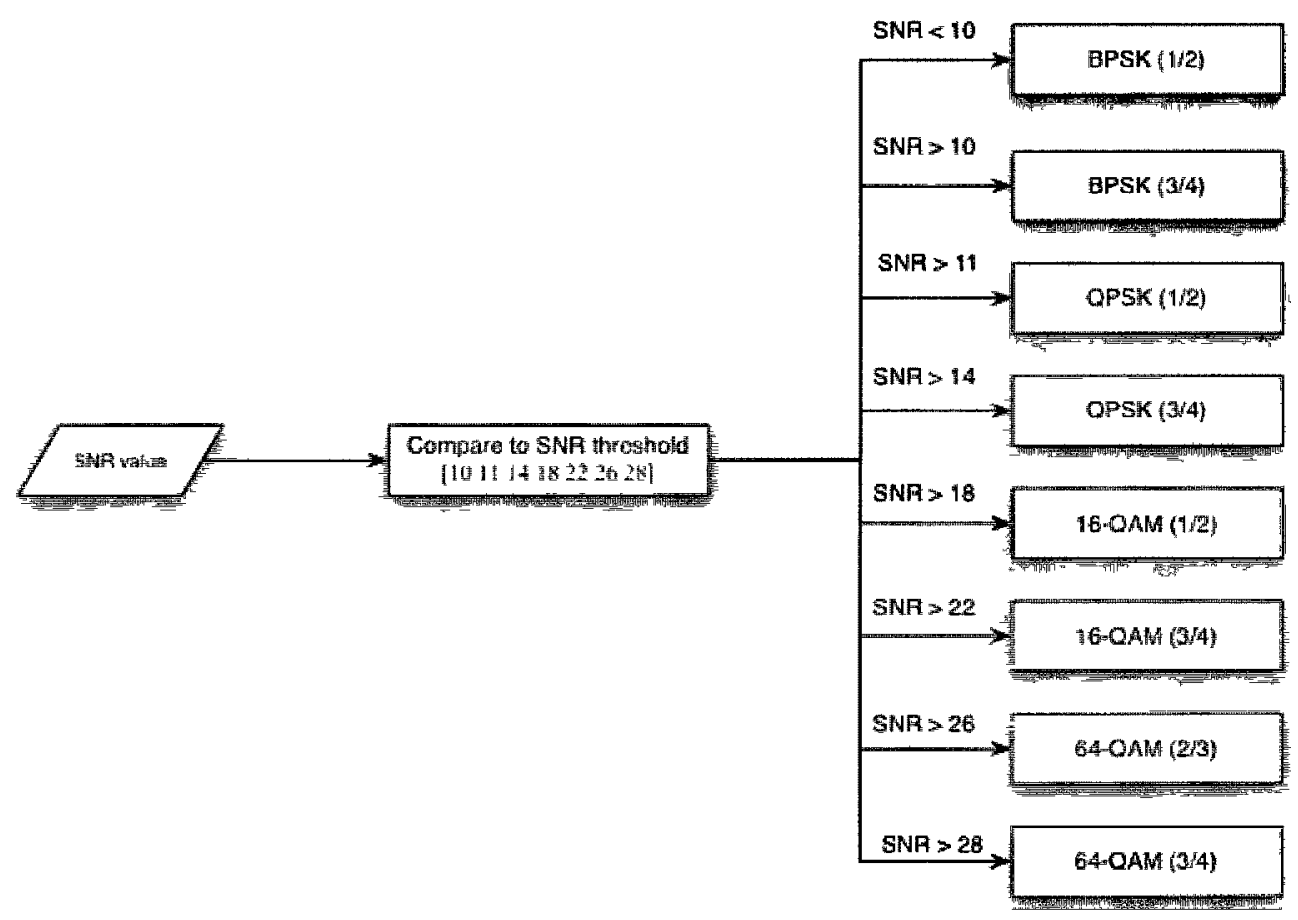

Figure 3.8: Modulation and coding selection using SNR thresholds 
model uses Adaptive Modulation and Coding AMC, provided by user to determine which modulation mode is used, by comparing the SNR value with the Low-SNR threshold values (in $\mathrm{dB})(10,11,14,18,22,26,28)$ and no threshold for lowest modulation [22]. Figure 3.8 shows how the DSRC model chooses the modulation mode.

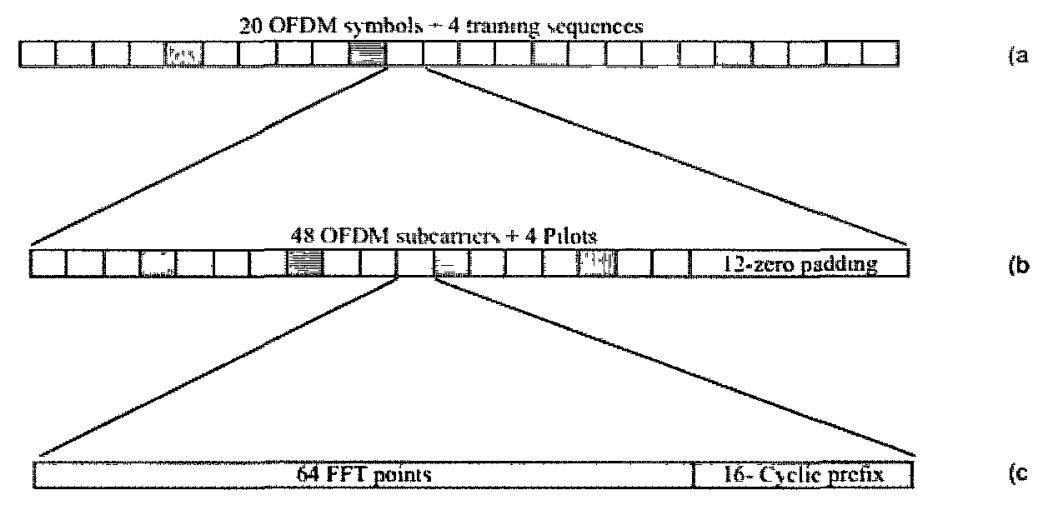

Figure 3.9: IEEE 802.11a PLCP frame structure

After data bits are modulated and coded, they proceed to the block that creates the OFDM Frame. The model used in the IEEE 802.11a standard Physical Layer Convergence Procedure (PLCP) frame structure, which is clarified in Figure (3.9a). It contains 20 OFDM symbols and 4 training sequences. The structure of each OFDM symbol combines 48 OFDM subcarriers and 4 pilots, shown in Figure (3.9-b). Each OFDM symbol consists of 64 Fast Fourier Transform (FFT) points and 16 cyclic prefix, shown in Figure (3.9-c) [20].

After the OFDM frame is generated, Inverse Fast Fourier Transform (IFFT) is performed on this OFDM frame, so data symbols are carried on orthogonal subcarriers. In order to avoid the Inter Symbol Interference (ISI) introduced by the channel a cyclic prefix is inserted at the front of each OFDM symbol. [23] At this point the PLCP frame is ready to be transmitted. 


\subsubsection{Channel Model}

The multipath channel model used in this research implements a simulation of a multipath Rayleigh fading propagation channel that can be used for mobile wireless communication systems and Additive White Gaussian Noise (AWGN) to simulate the propagation noise.

In multipath channels, signals are reflected at multiple places, so a signal travels to the receiver through multiple paths, and each of these paths have different lengths and time delays. In order to simulate the multipath channel effect on a signal a Multipath Rayleigh Fading Channel was used. Two effects was simulated using the Multipath Rayleigh Fading Channel: time selectivity of the channel due to motion (Doppler shift), and frequency selectivity due to resolvable multipath components (delay spreading). In order to simulate the Doppler shift an interpolated filtered Gaussian noise source was used. [24]

The details of the channel model are given later in the chapter.

\subsubsection{DSRC Receiver}

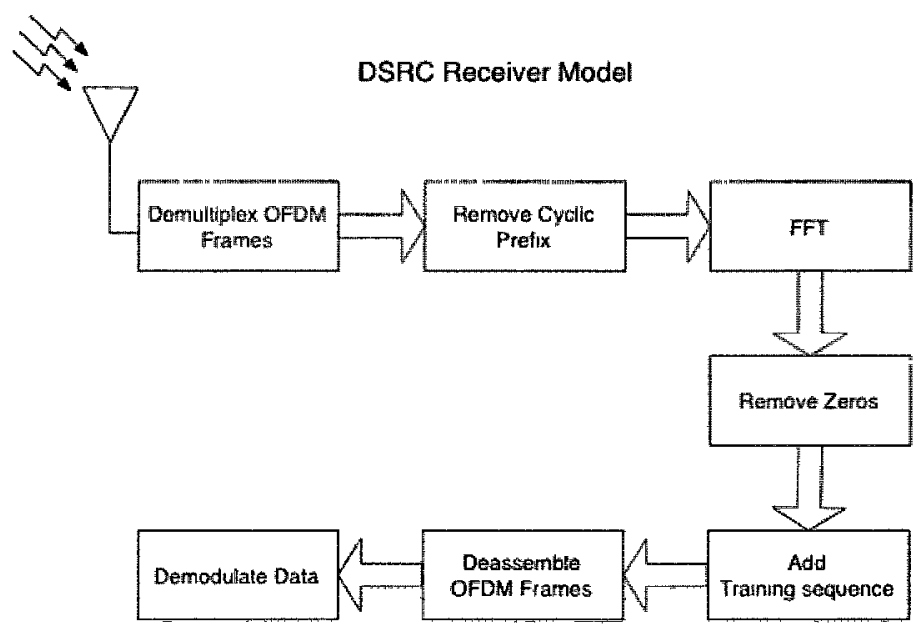

Figure 3.10: DSRC Receiver model 
Figure (3.10) shows the DSRC receiver processing blocks. After the packet is detected, the receiver demultiplex the received OFDM symbol, then the cyclic prefix is removed, which is used to determine the start of the OFDM symbol. After the received packet is corrected, it is converted from time domain to frequency domain using Fast Fourier Transform (FFT). After the packet is converted to frequency domain, the 12 zero padding that was added at the transmitter side will be removed, and then the training sequence is added to perform timing and frequency synchronization. 


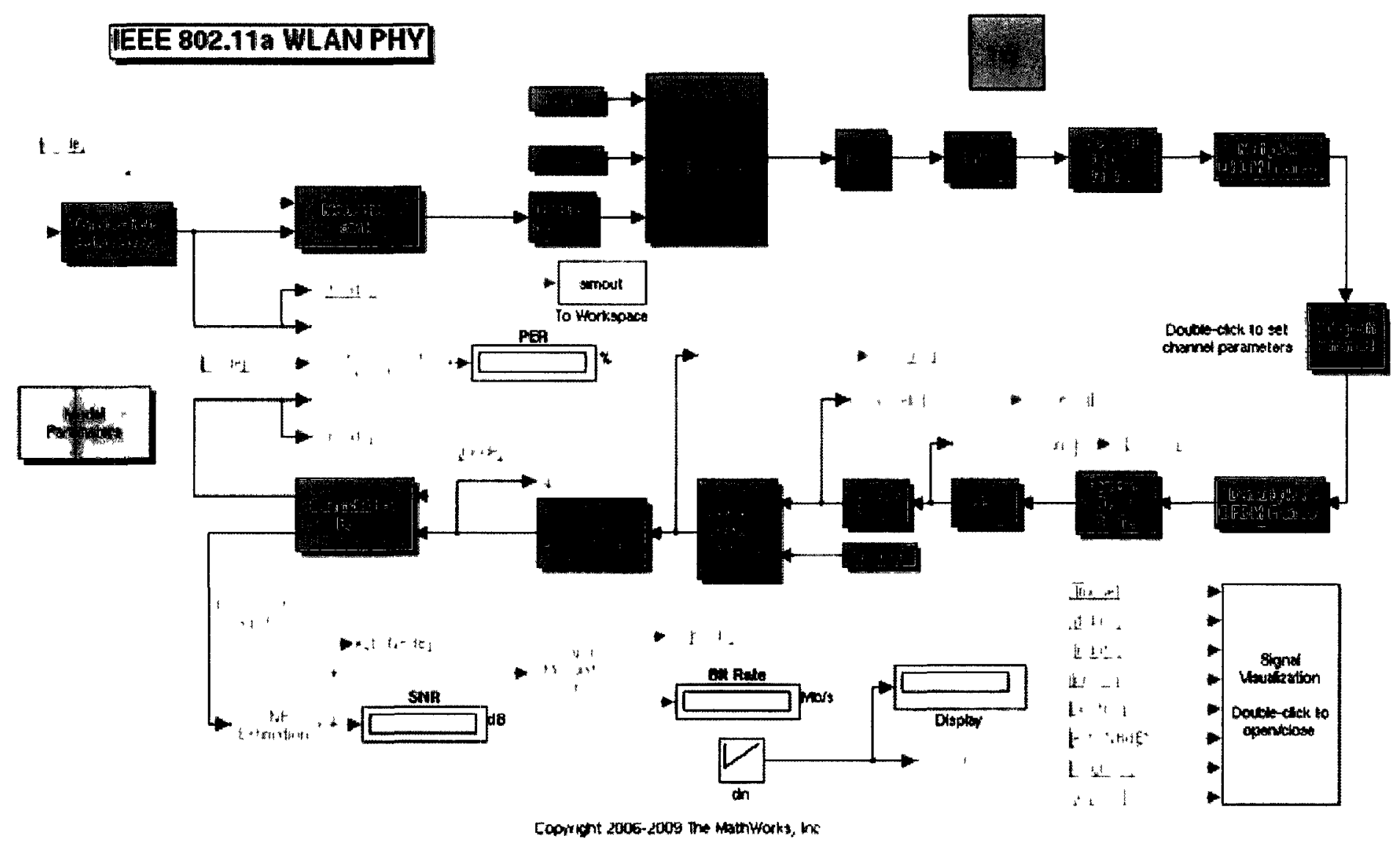

Figure 3.11: IEEE 802.11a Physical layer model [25] 
Afterwards, the received signal is disassembled to OFDM frames then demodulated. Finally the resulting bits are passed into a decoder and the CRC check is performed to determine whether there is bit error in the packet or not. Figure (3.11) shows the IEEE 802.11a model that was used in this research.

\subsection{Explanation of the developed SNR/Doppler Shift Generator model}

This section explains the model that has been developed and used in this thesis to generate SNR and Doppler shift values to be applied by the IEEE 802.11a model that was explained earlier. The main reason for the SNR/Doppler Shift Generator model is to study the effect of distance, speed and environment on the reliability of the DSRC wireless communication channel. Calculating SNR values at different distances between transmitter and receiver tests the change in distance factor. In order to generate the SNR values we need to calculate the transmitted power using equation 3.2, which is in $\mathrm{dBm}$, then calculating the received power using equation 3.4 , which is done by subtracting the Free Space Path Loss (FSPL), which was calculated using equation 3.3, from the transmitted power. The transmitted power and received power are constant for a certain transmitted power.

$$
\begin{gathered}
P_{t}=10 \log T_{x} \\
F S P L(d B)=20 \log (d)+20 \log (d)+32.45 \\
P r=P t-F S P L
\end{gathered}
$$

Using the received power value calculated before we can calculate the path loss value, which depends on the distance. There are two different ways of calculating 
the path-loss, which are single-slope and dual slope models [15]. The single-slope model usually is used for calculating the path-loss exponent for highways and rural environments. This model is represented in equation 3.5. This model has a path-loss exponent $\gamma$, standard deviation $\sigma$ and a reference distance between the transmitter and the receiver $d_{0}$. The standard deviation was used for applying Gaussian noise for generating SNR values $X_{\sigma}$.

Table 3.7: Path-loss exponents for different test environments [2] [26]

\begin{tabular}{|c|c|}
\hline Test Area & Path-loss Exponent \\
\hline Highway & $\gamma=1.9[27]$ \\
& $\gamma=1.85[28]$ \\
\hline Rural & $\gamma=1.79[28]$ \\
& $\gamma=2.3[27]$ \\
\hline Suburban & $\gamma_{1}=2.1, \gamma_{2}=3.8[15]$ \\
\hline Urban & $\gamma=1.61(\mathrm{LOS})[28]$ \\
& $\gamma=2.8(\mathrm{NLOS})[29]$ \\
\hline
\end{tabular}

Communications among cars is a new environment for channel modeling. Traditional propagation models typically assume that one if not both of the communicating antennas are well elevated above ground. In V2V both the transmit and receive antennas are low (between one and two meters above ground. At $5.9 \mathrm{GHz}$, there is not enough Fresnel clearance and the free space model cannot be applied even if the two cars are in open space outside the city. Since typically, there are no electromagnetic barriers among cars, many researchers suggested the use of two-ray model. In the two-ray model, the channel consists of two rays: a direct line of sight ray and a second ray reflected off the ground. Of course there could be other reflections from adjacent buildings and other objects but those are usually neglected in the two-ray model. The geometry of the model is well known, and it uses the antenna heights 
and the horizontal distance between the two cars to determine the differential delay between the two assumed rays. For certain antenna heights: $h_{T}$ and $h_{R}$ (transmitter and receiver antenna heights respectively), there is a critical distance known as the Fresnel Distance, $d_{F}=\left(4 h_{T} h_{R}\right) / \lambda$ where $\lambda$ is the carrier frequency wavelength in free space. At $d_{F}$ the differential delay between the two rays translate into $180^{\circ}$ phase shift, which allows the two rays to interfere with each other. When the distance between the transmitter and receiver $d \leq d_{F}$ the two rays do not interfer with each other and thisis known as the Fresnel clearance region. In this region, the path-loss of the signal is small and the signal strength decays at a low rate. Beyond $d_{F}$, however, the two rays interfer with each other and the signal strength decays at a faster rate. The two distance path-loss indices, $\gamma_{1}$ and $\gamma_{2}$, in the two regions are different and typically are determined empirically. Table 3.7 shows some typical empirical values for $\gamma_{1}$ and $\gamma_{2}$ in different environments.

$$
P(d)=P r-10 \lambda \log \left(d / d_{0}\right)+X_{\sigma}
$$

On the other hand dual-slope path-loss model is used for calculating the path-loss value for suburban and urban environments. We characterize this model by a pathloss exponent $\lambda$ and standard deviation $\sigma$. If the distance between the transmitter and the receiver is between the reference distance $d_{0}$ and critical distance $d_{F}$ then the model will use the first part of equation 3.6 and if the distance is greater than $d_{F}$ then the model will use the second part of the equation.

$$
P(d)= \begin{cases}P r-10 \lambda_{1} \log \left(d / d_{0}\right)+X_{\sigma_{1}} & \text { if } d_{0} \leq d \leq d_{F} \\ P r-10 \lambda_{1} \log \left(d_{F} / d_{0}\right)-10 \lambda_{2} \log \left(d / d_{F}\right)+X_{\sigma_{2}} & \text { if } d>d_{F}\end{cases}
$$

At the same time the change in the path-loss decreases the signal to noise ratio 
(SNR). According to the following equation (when $N_{0}=-99 d B m[30]$ ):

$$
S N R(d B)=P(d)-N_{0}
$$

The current research model uses equations (3.4 and 3.5) to calculate the path-loss, 100 different path-loss values are generated by generating $100 X_{\sigma}$ values, and then the resulting value is used to generate SNR values that is applied in the IEEE 802.11a model.

Because the speed of source $\left(v_{r}\right.$ positive if the receiver is moving towards the source) and the receiver ( $v_{s}$ positive if the source is moving away from the receiver) to the medium is lower than the velocity of the waves in medium $\left(c=3 \times 10^{8} \mathrm{~m} / \mathrm{sec}\right.$ ), the relationship between the emitted frequency $\left(f_{0}=5.9 \mathrm{GHz}\right)$ and the observed frequency $(f)$ is given by equation 3.8. For estimating the effect of the speed factor on the performance of the multipath channel, equation 3.8 was used to calculate the Doppler shift, which is calculated by subtracting the original frequency $\left(f_{0}\right)$ from the new calculated frequency $(f)$, equation 3.9. Figure 3.12 shows how SNR and Doppler shift values are generated in order to calculate the PER for the dual-slope path-loss model.

$$
\begin{gathered}
f=\left(\frac{c+v_{r}}{c+v_{s}}\right) f_{0} \\
\Delta f=f-f_{0}
\end{gathered}
$$

Testing the reliability of DSRC for different environments such as highways, urban, suburban, and rural environments, can be done by changing the path-loss exponents. Each test area has different path-loss exponents, such as, highways, rural, suburban and urban environments. These path-loss exponents values are represented in Table 3.7. 


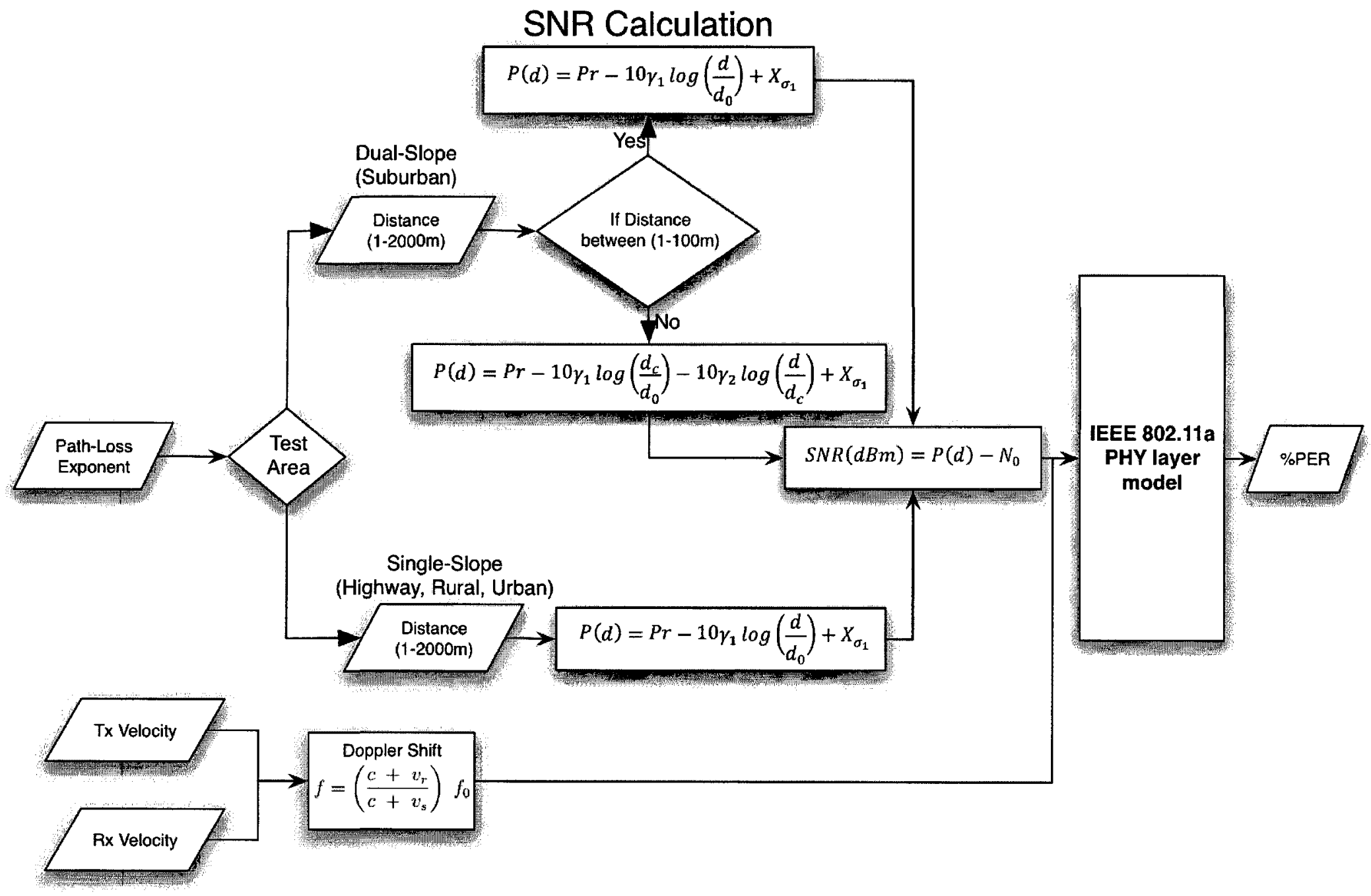

Figure 3.12: Flowchart of the SNR/Doppler shift Generator model 


\subsection{Explanation of experiments and system setup}

Table 3.8: Parameters for Dual-Slope model

\begin{tabular}{|c|c|}
\hline System Parameters & Description \\
\hline $\mathrm{dn}$ & Distance $(\mathrm{m})$ \\
\hline TxPower & Transmitted Power \\
\hline$\gamma_{1}$ & $\begin{array}{c}\text { Path-Loss exponent } \\
\left(d_{0} \leq d \leq d_{F}\right)\end{array}$ \\
\hline$\gamma_{2}$ & Path-Loss Exponent \\
\hline$\sigma_{1}$ & Variance \\
\hline$\sigma_{2}$ & Variance \\
\hline$d o$ & Reference Distance $(\mathrm{m})$ \\
\hline$d_{F}$ & Critical Distance $(\mathrm{m})$ \\
\hline$v r$ & Receiver Velocity $(\mathrm{Km} / \mathrm{h})$ \\
\hline$v c$ & Source Velocity $(\mathrm{Km} / \mathrm{h})$ \\
\hline
\end{tabular}

This section discusses the different system setups that have been used in this research. Figures (3.13 and 3.14), show connecting the SNR/Doppler Shift Generator to the multipath channel in the IEEE 802.11a WLAN PHY model. The SNR/Doppler Shift Generator model generates the SNR and Doppler shift values that are used to calculate the PER. The model uses multiple parameters in order to simulate different test environments and different vehicle speeds. These parameters are listed in Tables (3.8 and 3.9). 
Table 3.9: Parameters for Single-Slope model

\begin{tabular}{|c|c|}
\hline System Parameters & Description \\
\hline $\mathrm{dn}$ & Distance $(\mathrm{m})$ \\
\hline TxPower & Transmitted Power \\
\hline$\gamma_{1}$ & Path-Loss exponent \\
\hline$\sigma$ & Variance \\
\hline$d_{o}$ & Reference Distance $(\mathrm{m})$ \\
\hline$d_{F}$ & Critical Distance $(\mathrm{m})$ \\
\hline$v r$ & Receiver Velocity $(\mathrm{Km} / \mathrm{h})$ \\
\hline$v c$ & Source Velocity $(\mathrm{Km} / \mathrm{h})$ \\
\hline
\end{tabular}




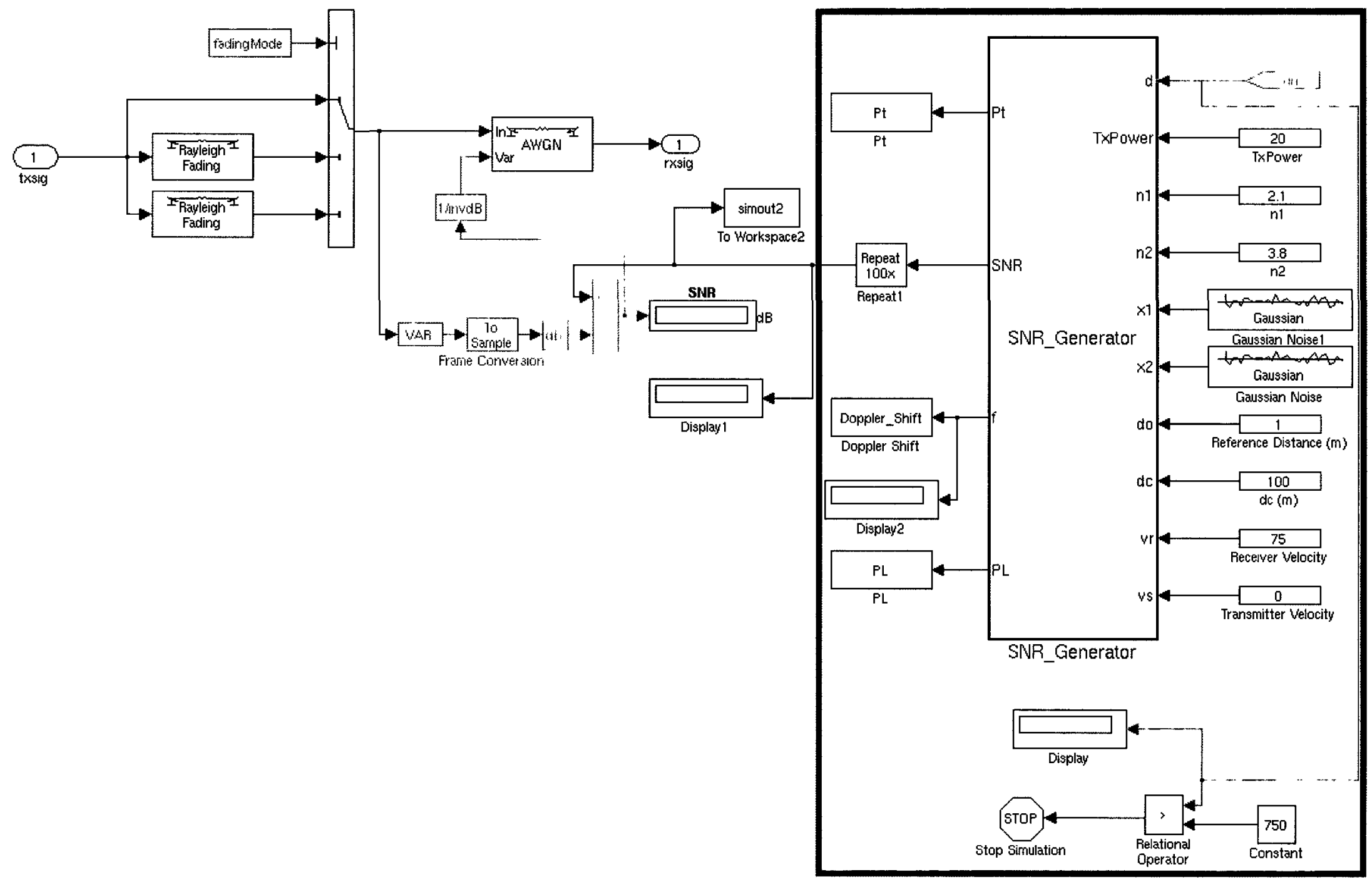

Figure 3.13: Multipath Channel including SNR generator (Dual-Slope Path-Loss calculation) 


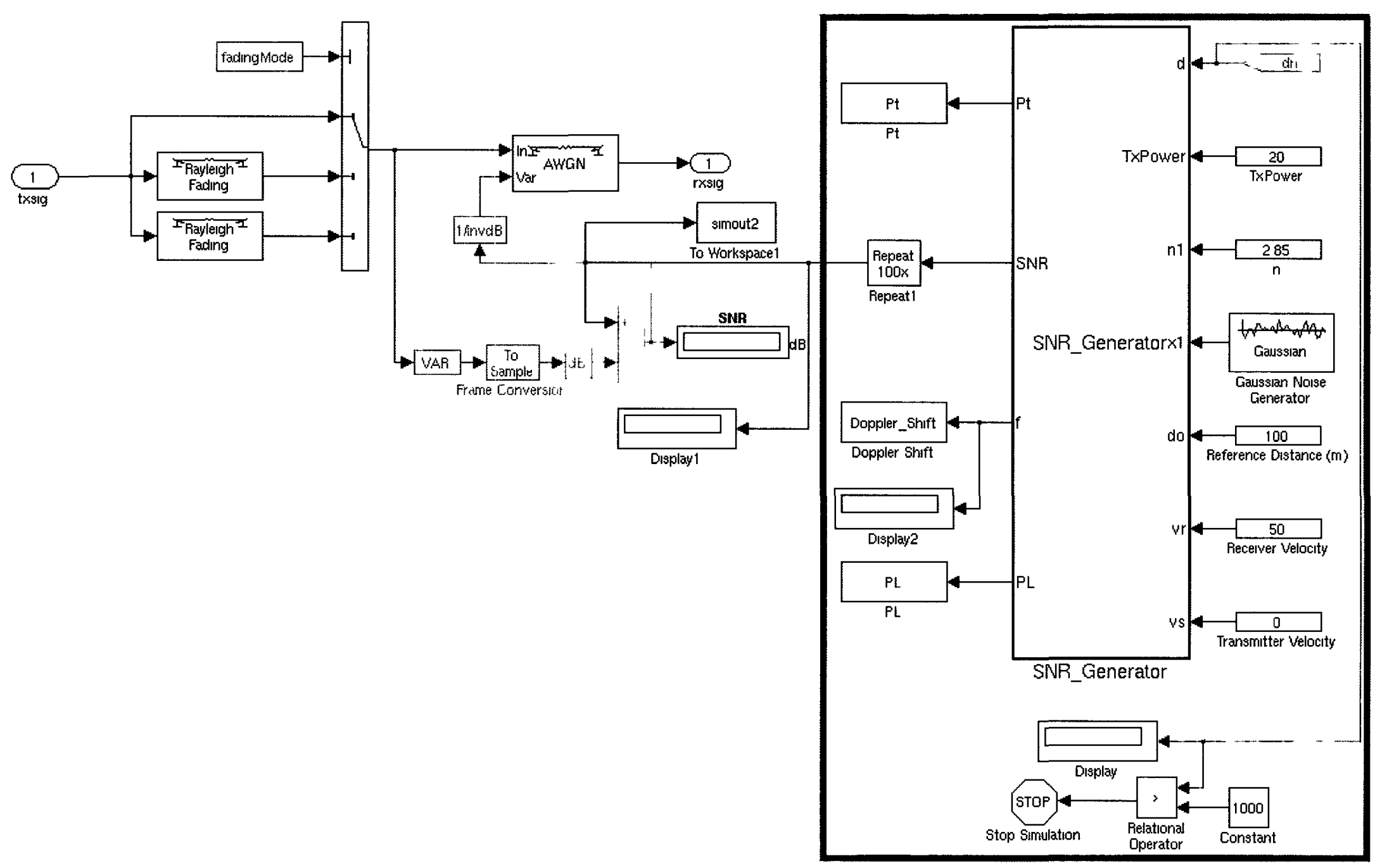

Figure 3.14: Multipath Channel including SNR generator (Single-Slope Path-Loss calculation) 


\subsection{Evaluating the DSRC for various parameters}

As was mentioned in the previous chapter, this research is aimed at determining the reliability of DSRC for $\mathrm{V} 2 \mathrm{~V}$ communications. The reliability was tested by changing multiple factors, such as, distance, speed, and test area. Four test environments have been considered in the course of this research, which are, highway, suburban, rural, and urban environments. For each test area, several pertinent parameters, explained in table (3.8 and 3.9), have been used. Some values have been common to all tests including: transmit power $(20 \mathrm{dBm}[31])$, receiver speed $(25,50 \mathrm{~km} / \mathrm{h})$, source speed $(0 \mathrm{~km} / \mathrm{h})$, and a reference distance $(100 \mathrm{~m}$ [32]). This section explains various simulated tests for various environments.

\subsubsection{Suburban Environments}

Table 3.10: Values used in Suburban test simulation

\begin{tabular}{|c|c|}
\hline System Parameters & Values \\
\hline $\mathrm{dn}$ & $1-1000 \mathrm{~m}$ \\
\hline$\gamma_{1}$ & 2.1 \\
\hline$\gamma_{2}$ & 3.8 \\
\hline$\sigma_{1}$ & 2.6 \\
\hline$\sigma_{2}$ & 4.4 \\
\hline$d o$ & $1 \mathrm{~m}$ \\
\hline$d_{F}$ & $100 \mathrm{~m}$ \\
\hline
\end{tabular}

Suburban environments usually refer to residential environments. Single houses are the usual type of houses that are found in suburbs. [2] The dual-slope propagation model is more practical to generate accurate results. [15] Tests that have been conducted to estimate the reliability of the IEEE 802.11a communication channel for 
V2V communications are listed in Table 3.10. A distance (1-1000 m) between the transmitter and the receiver was used. The reason that for suburban environments only a distance of $1000 \mathrm{~m}$ was used is that according to the results, after $1000 \mathrm{~m}$, the PER was $100 \%$ all time. Two values of path-loss exponents and standard deviation values have been used, $\lambda_{1}=2.1$ and $\lambda_{2}=3.8, \sigma_{1}=2.6$ and $\sigma_{2}=4.4$. [15]

\subsubsection{Highways Environments}

Table 3.11: Values used in Highway test simulation

\begin{tabular}{|c|c|}
\hline System Parameters & Values \\
\hline $\mathrm{dn}$ & $1-1200 \mathrm{~m}$ \\
\hline$\gamma$ & $1.85[28]$ \\
\cline { 2 - 2 } & $1.9[27]$ \\
\hline$\sigma$ & $2.3[28]$ \\
\hline
\end{tabular}

This test was simulated to determine the reliability the IEEE 802.11a communication channel for highway environments. The main reason for this test area, is to model vehicles which usually move with high speeds compared to other environments, and that makes it more important to have a reliable communication channel, in order to give the driver enough time to interact with road conditions and other any sudden changes in the road. For this test area, speeds of 25 and $50 \mathrm{~km} / \mathrm{h}$ were used. Other parameters used in this test are mentioned in Table 3.11. In highway environments (also in rural) a lower standard deviation value was used, because there are usually less nearby buildings compared to suburban and urban environments. [27] [33] 
Table 3.12: Values used in Urban test simulation

\begin{tabular}{|c|c|}
\hline System Parameters & Values \\
\hline \multirow{2}{*}{$\mathrm{dn}$} & $1-3000 \mathrm{~m}(\mathrm{LOS})$ \\
\cline { 2 - 2 } & $1-1200 \mathrm{~m}(\mathrm{NLOS})$ \\
\hline \multirow{2}{*}{$\gamma$} & $1.61(\mathrm{LOS})$ \\
\cline { 2 - 2 } & $2.8(\mathrm{NLOS})$ \\
\hline \multirow{2}{*}{$\sigma$} & $8(\mathrm{LOS})$ \\
\cline { 2 - 2 } & $4.4(\mathrm{NLOS})$ \\
\hline
\end{tabular}

\subsubsection{Urban Environments}

Urban environments usually refer to cities with high buildings and high building density. For this test area, other parameters have been used to simulate the reliability of the IEEE 802.11a communication channel. These values are mentioned in Table 3.12. In urban area test, two factors were used for determining which values of path-loss exponent, standard deviation, and distance to be used, which are Line-Of-Sight (LOS) and Non-Line-Of-Sight (NLOS). These values were, LOS $\lambda=1.61, \sigma=8$ [28], and $d=1$ to $3000 m$ was used and for NLOS $\lambda=2.8, \sigma=4.4$ [29], and $d=1$ to $1200 m$.

\subsubsection{Rural Environments}

Table 3.13: Values used in Rural test simulation

\begin{tabular}{|c|c|}
\hline System Parameters & Values \\
\hline $\mathrm{dn}$ & $1-1200 \mathrm{~m}$ \\
\hline \multirow{2}{*}{$\gamma$} & $1.79(\mathrm{LOS})[28]$ \\
\cline { 2 - 2 } & $2.3(\mathrm{NLOS})[27]$ \\
\hline$\sigma$ & $2.7[28]$ \\
\hline
\end{tabular}


Rural area was last test area that was simulated in this research. Values in Table 3.13 were used for this test. The distance ranged betwee $\gamma_{1} \mathrm{~m}$ to $1200 \mathrm{~m}$, for the same reason of the suburban environments, which was beyond $1200 \mathrm{~m}$ the PER was $100 \%$ all the time.

\subsubsection{Delay spread}

Another factor needs to be tested, is the effect of the delay spread on the DSRC communication channel. In telecommunications the delay spread is a way of measuring the multipath effect of a channel, which is the difference between the arrival time of the first multipath component and the last multipath component of a signal to the destination. In order to test the effect of the delay spread on the DSRC communication channel, four tests have been conducted for each environments. Each of these tests uses different delay spread value, which are:

- Flat fading $(0 \mu \mathrm{sec})$.

- Dispersive fading with $0.1,0.5,1 \mu$ sec delay spreads.

\subsubsection{Delay time}

From Table 3.6, the maximum delay time for a reliable connection is 0.1 seconds and it should cover a distance over 150 meters for most applications. The delay time was calculated using equation 3.13, which uses the Packet Error Rate (PER) and the minimum delay (MD) which are calculated using equations (3.10 and 3.11) respectively. Table 3.14 was used to calculate the worst case analysis PER for different packet sizes $(\mathrm{N}) .[35][20]$

$$
P E R=1-(1-B E R)^{N}
$$


Table 3.14: Constants used to calculate delay time

\begin{tabular}{|c|l|c|}
\hline Symbol & Definition & Value \\
\hline$T_{\text {SLOT }}$ & A slot time. & $9 \mu \mathrm{sec}$ \\
\hline$T_{D I F S}$ & DIFS time & $34 \mu \mathrm{sec}$ \\
\hline$C W_{\text {min }}$ & Minimum back off window size & 15 \\
\hline$T_{P}$ & Transmission time of the physical preamble & $16 \mu \mathrm{sec}$ \\
\hline$T_{P H Y}$ & Transmission time of the PHY header & $4 \mu \mathrm{sec}$ \\
\hline$T_{H D A T A}$ & $\begin{array}{l}\text { Transmission time of MAC overhead. MAC overhead in } \\
\text { bytes, i.e., 28 bytes }\end{array}$ & $0.41 \mu \mathrm{sec}$ \\
\hline$T_{D A T A}$ & $\begin{array}{l}\text { Transmission time for the payload in } \mu \mathrm{sec} \text { and depends on the } \\
\text { packet size and data rate }\end{array}$ \\
\hline$\tau$ & Propagation delay & $1 \mu \mathrm{sec}$ \\
\hline$T_{S Y M}$ & Symbol interval & $4.1 e-17$ \\
\hline$T_{P \text { Preamable }}$ & PLCP preamble duration & $5.9 e-17$ \\
\hline$T_{\text {Siganl }}$ & Duration of the Signal BPSK-OFDM symbol & $4.1 e-17$ \\
\hline
\end{tabular}




$$
M D=T_{P}+T_{P H Y}+T_{H_{D A T A}}+T_{D A T A}+T_{D I F S}+\tau+\left(\frac{C W_{\min } T_{S L O T}}{2}\right)
$$

Time that is needed by DSRC system to generate a message and send it over the communication channel is calculated using equation 3.12 .

$$
\begin{gathered}
T_{D A T A}=T_{\text {Preamable }}+T_{\text {Signal }}+\frac{16+8 \times \text { PacketLength }+6}{\text { DataRate }}+\frac{T_{S} Y M}{2} \\
\text { Delaytime }=\frac{1}{1-P E R} M D
\end{gathered}
$$




\section{Chapter 4}

\section{Performance of V2V DSRC Network}

\subsection{Background}

For V2V critical communication a high data rate and low number of lost messages are

required, especially at high vehicle speeds and critical conditions, such as potential accidents. The DSRC physical layer has been simulated using IEEE 802.11a Physical layer model available in MatLab v 7.9.0 (R2009b).

So in this research, the criterion used to determine at what distance the communication medium is not reliable for $\mathrm{V} 2 \mathrm{~V}$ communications was to test when $90 \%$ of the 10,000 messages that have been sent from the source arrived to the destination for each distance. In all the simulated tests that were done in this research, the average PER, BER, Bit Rate was calculated to generate all results figures. Bit error rate (BER) was used to measure the packet performance. Adaptive modulation and coding was considered when obtaining the performance curves. This chapter discusses some test results that have been collected for all test environments; other figures for all tests are also available in Appendix A. 


\subsection{Packet Size and delay spread Effect}

This section discusses the effect of changing the packet size and delay spread on the DSRC communication channel for few environments and vehicle speeds. Figure 4.1 shows the effect of changing the delay spread for a fixed packet size at 25 and $50 \mathrm{~km} / \mathrm{h}$ speeds. It is clear from the figure that delay times for low delay spreads such as flat fading (i.e. $0 \mu \mathrm{sec}$ ), $0.1 \mu \mathrm{sec}$, and $0.5 \mu \mathrm{sec}$, but delay time increases dramatically for very high delay spread $(1 \mu \mathrm{sec})$. These values was used as a lookup table to generate delay times for different environments.

The effect of using packet size of the five DSRC applications discussed in table 3.5 is demonstrated in figure 4.2 , which shows the increase in delay time over distance for suburban environment with flat fading and vehicle speed $25 \mathrm{Km} / \mathrm{H}$. For all these applications the maximum allowed delay time is $0.1 \mu \mathrm{sec}$.

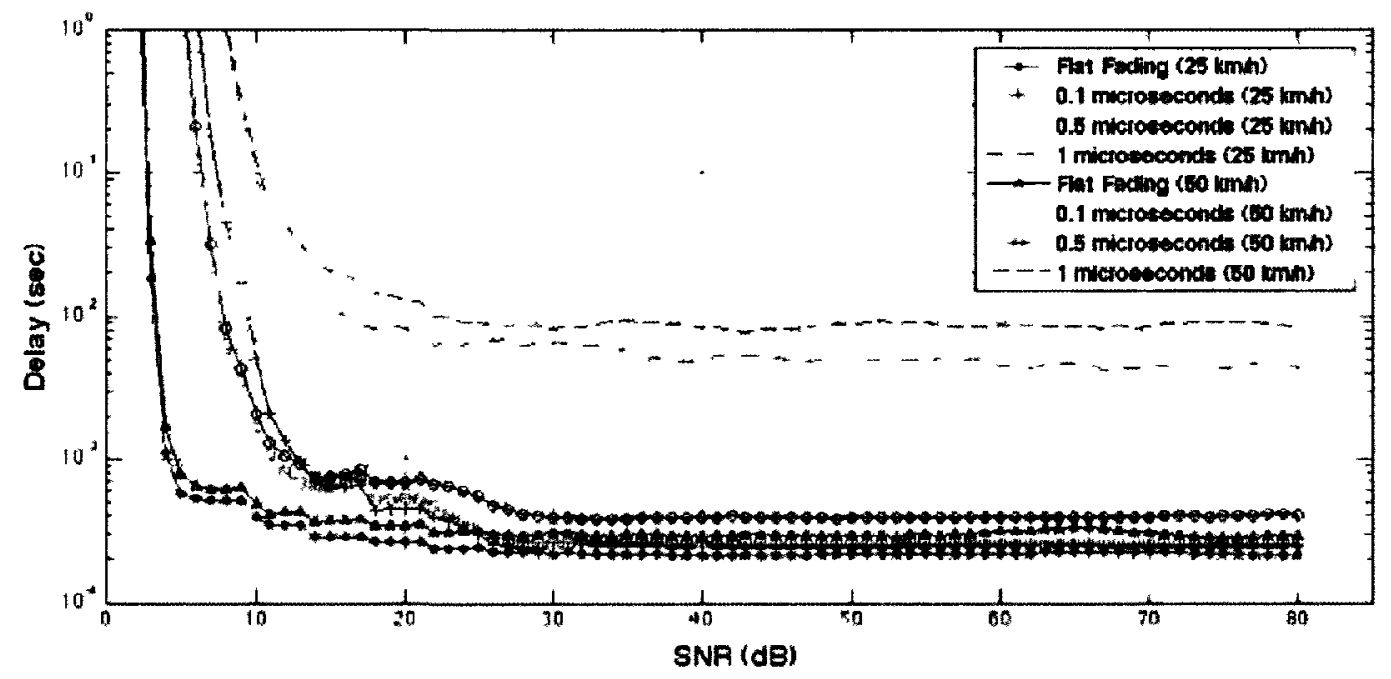

Figure 4.1: Effect of delay spread on the Delay Time at 25 and $50 \mathrm{~km} / \mathrm{h}$ )

So from the figure we can conclude that for these parameters the maximum distance that the DSRC connection can provide a reliable communication is between 210 $\mathrm{m}$ and $240 \mathrm{~m}$. The effect of applying a higher delay spread is shown in figure 4.3 for same environment used to generate figure 4.2. It is clear from figure 4.3 that distance 
for an acceptable delay tıme decreases to between $175 \mathrm{~m}$ and $220 \mathrm{~m}$

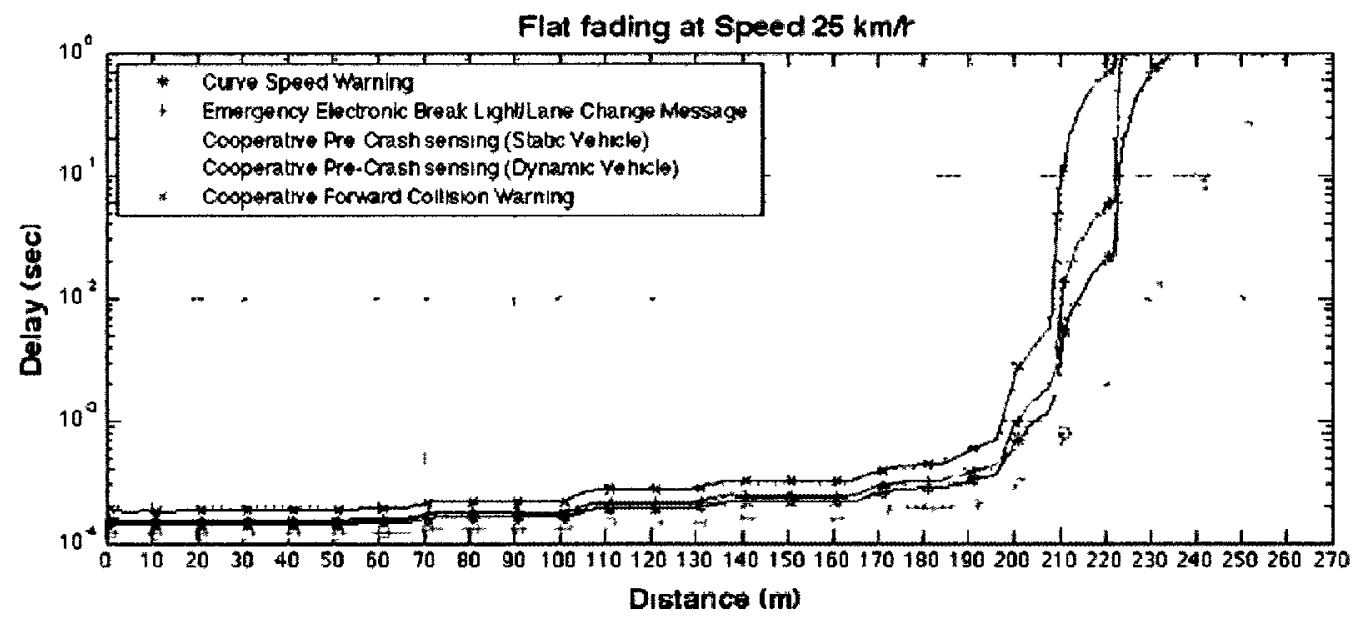

Figure 4.2: Effect of packet size on the Delay Time for suburban environment and flat fading at $25 \mathrm{~km} / \mathrm{h}$

Another example of the effect of packet size and delay spread on the reliability of DSRC communication is demonstrated in figures (44 and 45) In both figures rural environment was simulated for delay spreads $01 \mu \mathrm{sec}$ and $1 \mu \mathrm{sec}$ respectively and speed $50 \mathrm{~km} / \mathrm{h}$ was used For lower delay spread the distance can go up to $650 \mathrm{~m}$ for cooperative forward collision warning application which is higher than the required value $(150 \mathrm{~m})$ and that makes it acceptable for that simulated applications, but when we increase delay spread to $1 \mu \mathrm{sec}$ we notıce that delay time starts at a value higher than the acceptable value $\left(\begin{array}{lll}0 & 1 \mathrm{sec}\end{array}\right)$

Figure 46 shows simulation result for same environment but at speed $25 \mathrm{~km} / \mathrm{h}$ and it is noticed that the distance that a reliable communication for that application at $25 \mathrm{~km} / \mathrm{h}$ is about $200 \mathrm{~m}$ So in this case DSRC is not sultable for cooperative forward collisıon warning applicatıon at $50 \mathrm{~km} / \mathrm{h}$ 


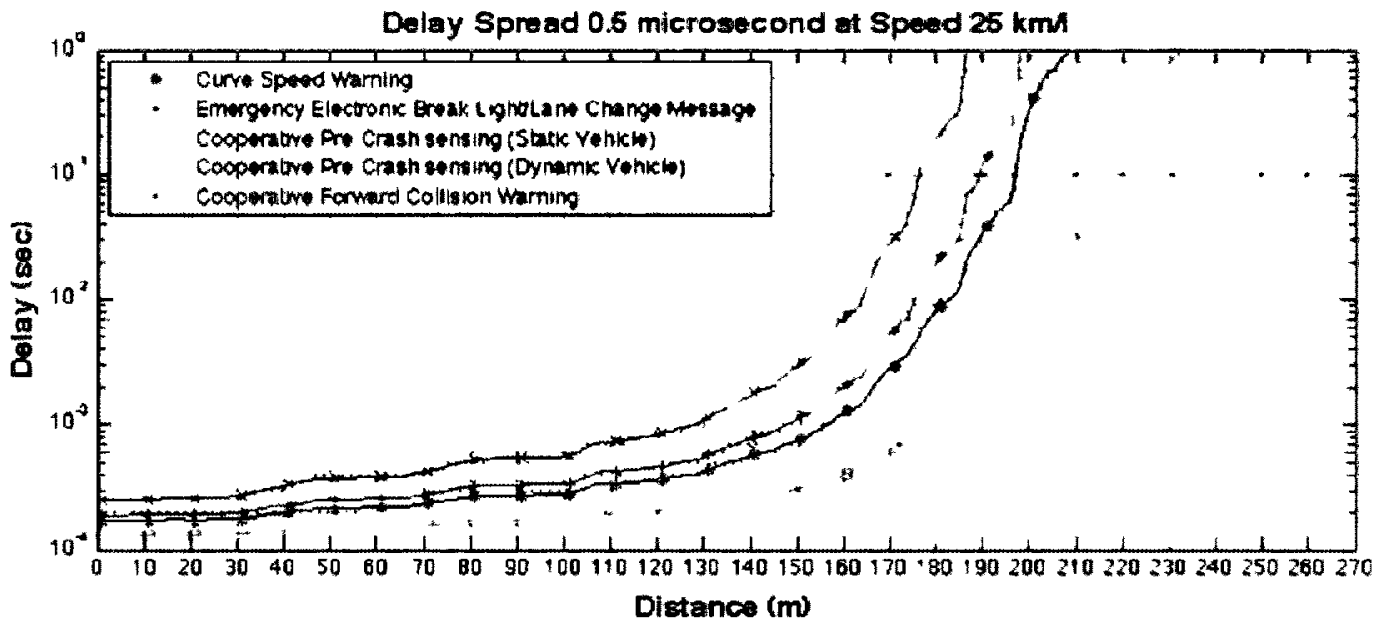

Figure 4.3: Effect of packet size on the Delay Time for suburban environment and $05 \mu \mathrm{sec}$ at $25 \mathrm{~km} / \mathrm{h}$ )

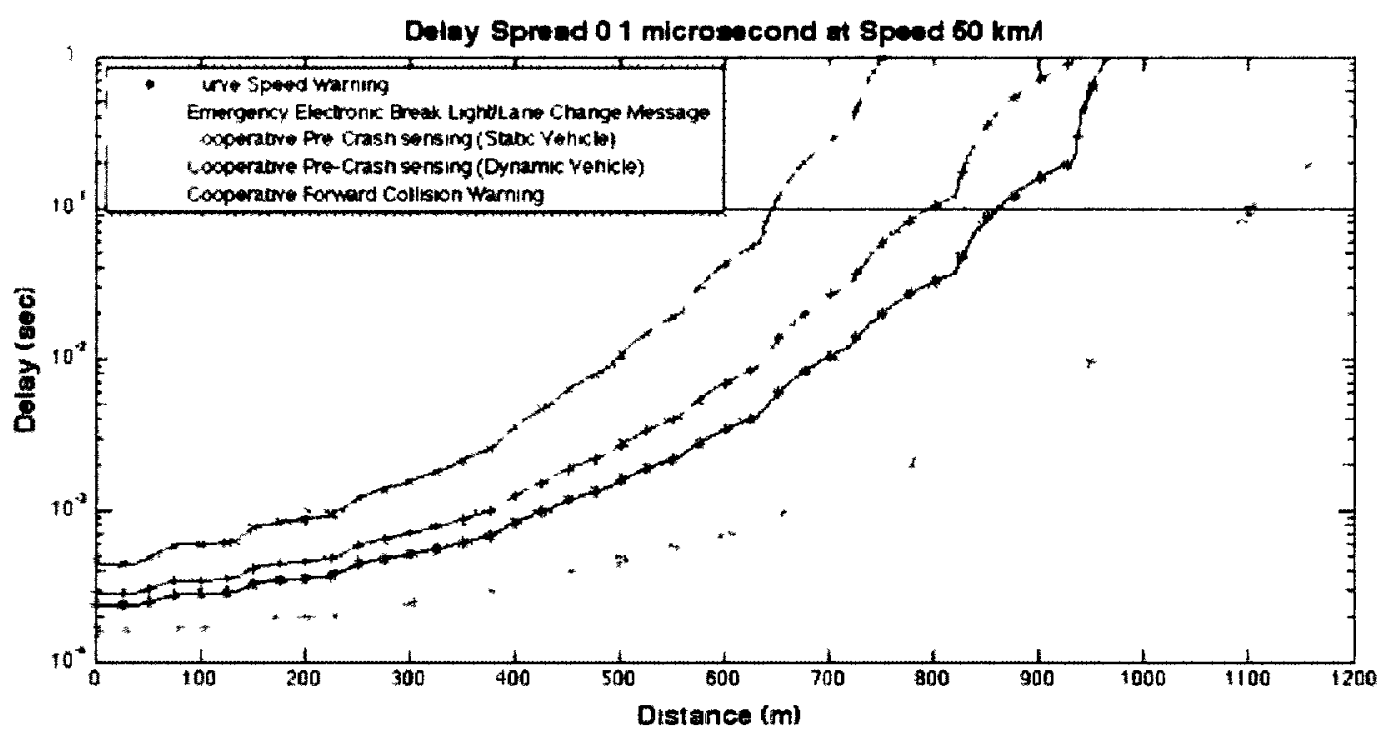

Figure 4.4: Effect of packet size on the Delay Time for rural environment and 01 $\mu \mathrm{sec}$ at $50 \mathrm{~km} / \mathrm{h}$ 


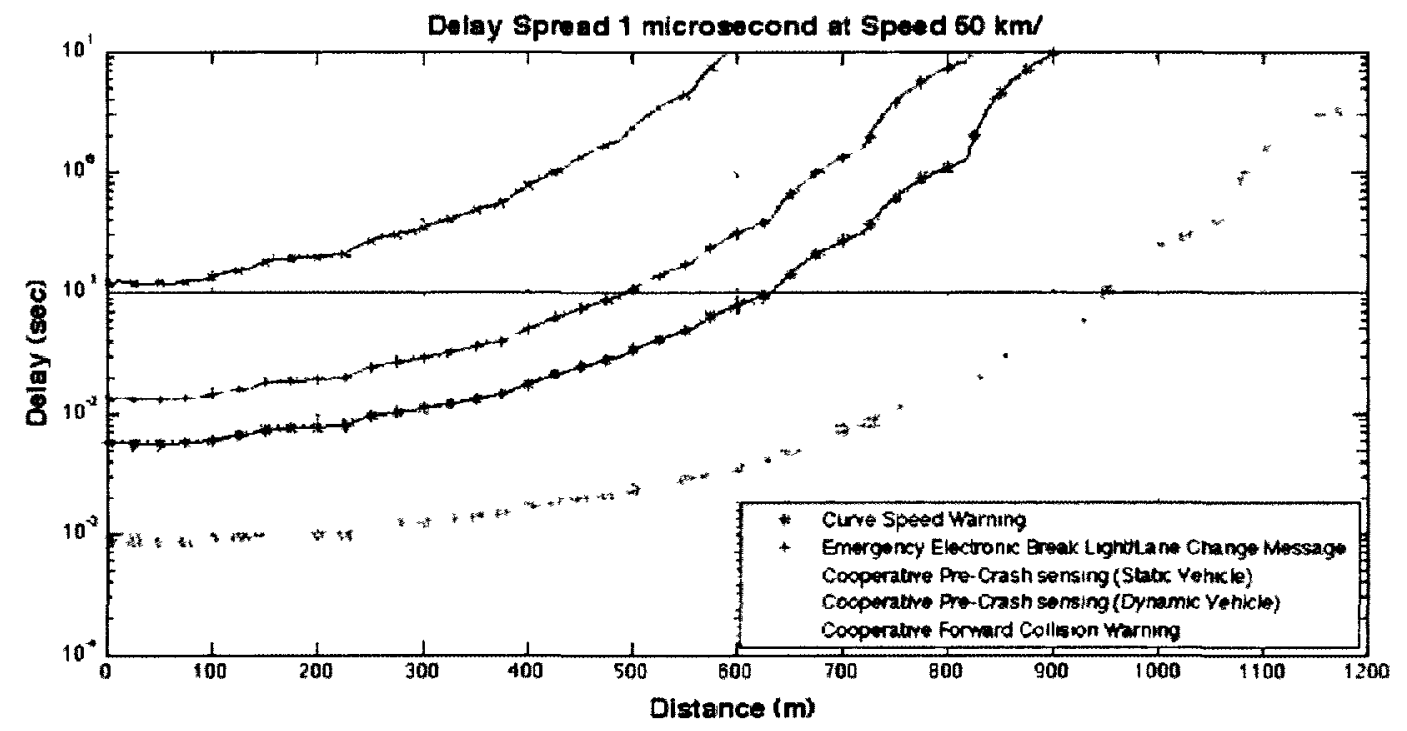

Figure 4.5: Effect of packet size on the Delay Time for rural environment and 1 $\mu \mathrm{sec}$ at $50 \mathrm{~km} / \mathrm{h}$

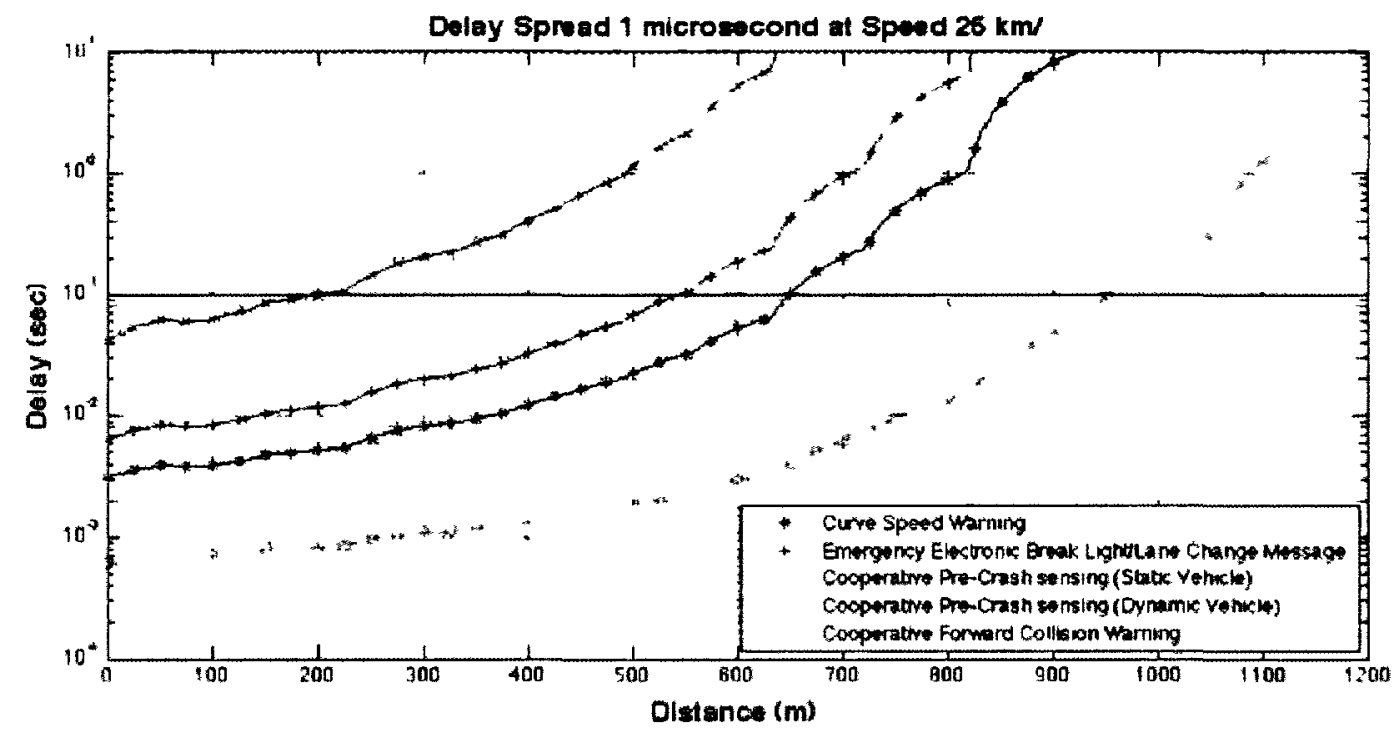

Figure 4.6: Effect of packet size on the Delay Time for rural environment and 1 $\mu \mathrm{sec}$ at $25 \mathrm{~km} / \mathrm{h}$ 


\subsection{Suburban Environment}

As was mentioned in the previous chapter, the suburban environment test was simulated using the Dual-Slope Path-Loss propagation model, which uses two path-loss exponents (2.1 and 3.8) and two standard deviations $(2.6,4.4)$. Figure 4.7, shows the effect of changing distance and speed on the quality of the received data. For the same test the relationship between SNR and BER was demonstrated in figure 4.8.

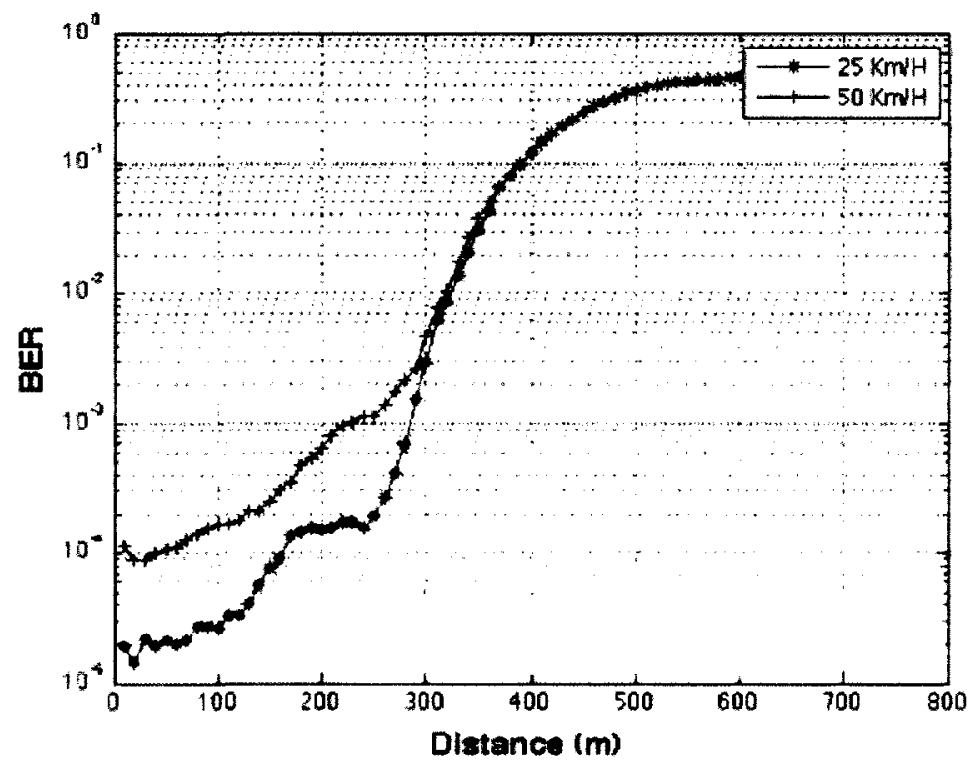

Figure 4.7: BER vs. Distance $(m)$ for Suburban environments at different speeds

It was found that although the model used AMC, the BER did not have an instantaneous drop when changing between modulation modes. The explanation of that smooth change in BER throughout the test was because, in order to calculate the BER at each distance, the model used a random shadowing value $\left(X_{\sigma}\right)$, referring to equation'3.6, and at certain distances the SNR value that was generated fluctuate between two different modulation thresholds.

Figure 4.9 demonstrates the different modulations and coding that are used in the 802.11a model by comparing the effect of SNR on the \%PER for vehicle at $50 \mathrm{Km} / \mathrm{h}$. 


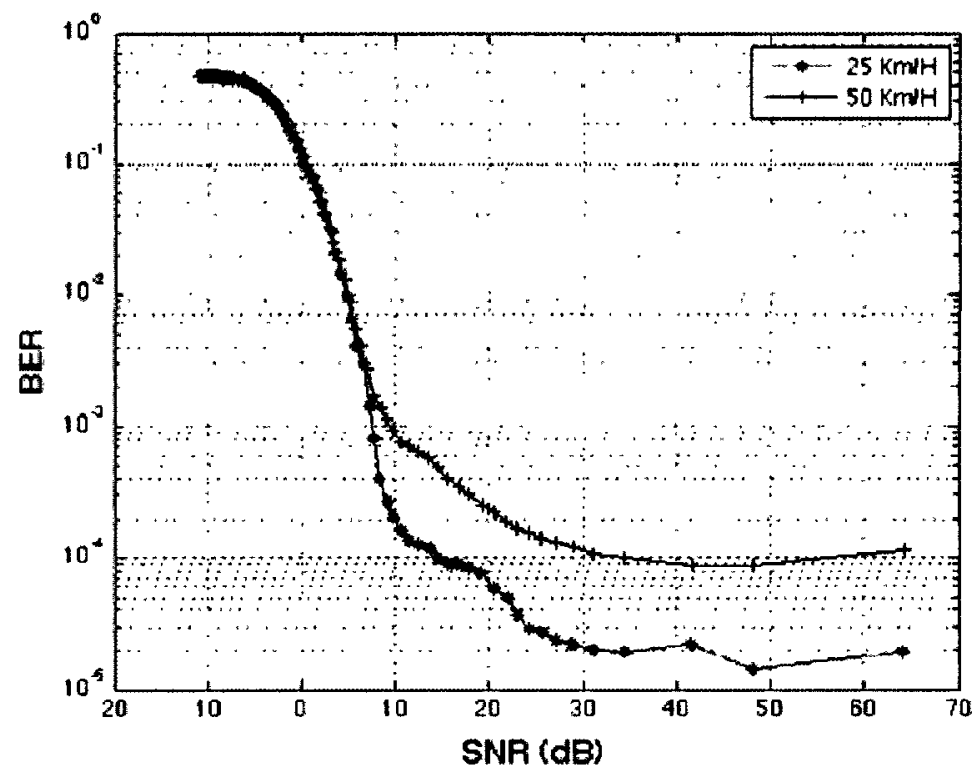

Figure 4.8: SNR (dB) vs. Distance $(m)$ for Suburban environments at different speeds

Also it can be concluded from figure 4.11 that the IEEE 802.11a communication channel can be reliable up to $175 \mathrm{~m}$ for different applications (different packet sizes), because after that distance the delay time starts to increase over the required limit (0.1 seconds). 


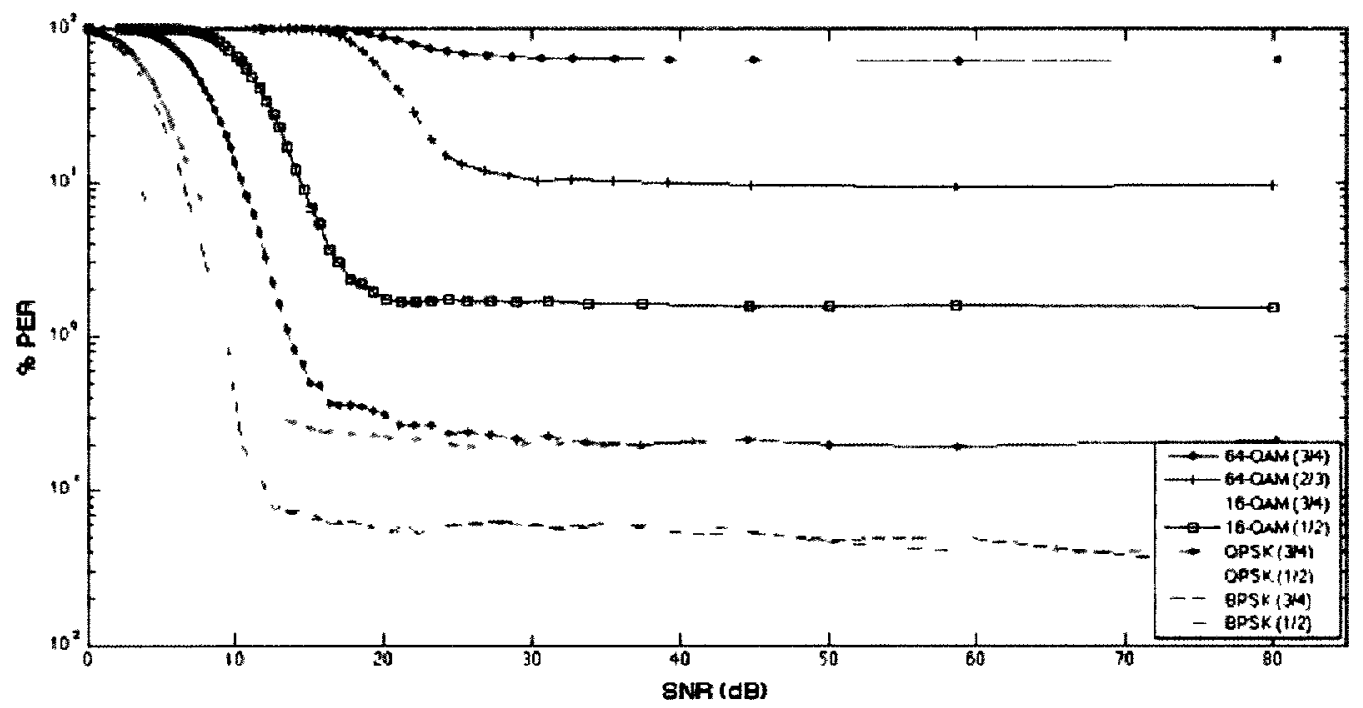

Figure 4.9: \%PER vs SNR for Different AMC

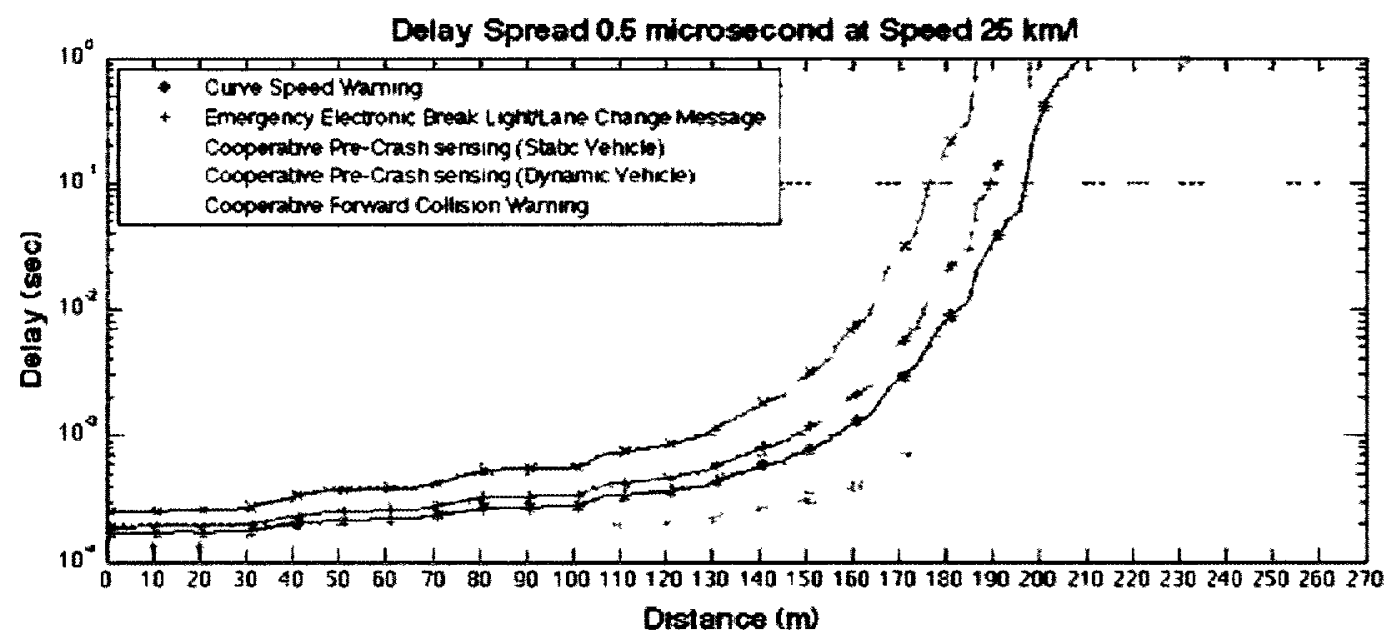

Figure 4.10: Delay time (sec) vs Dsitance for different applications 


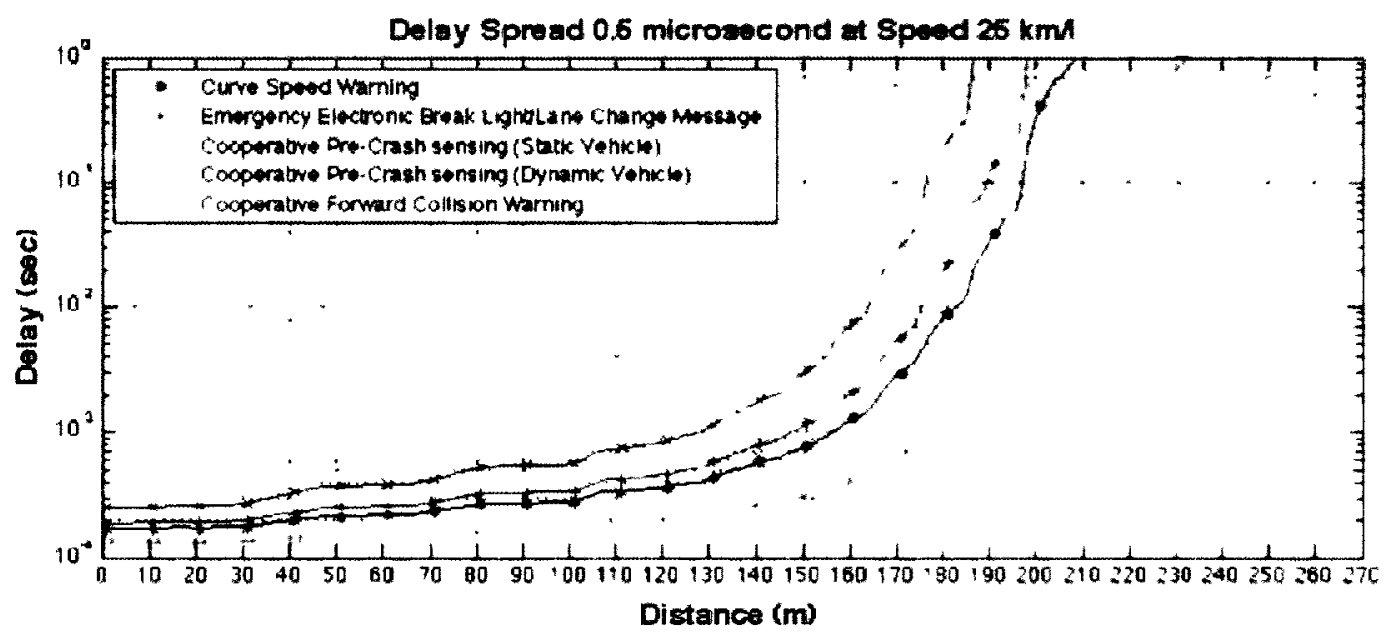

Figure 4.11: Delay time (sec) vs. Dsitance for different applications 


\subsection{Highway Environment}

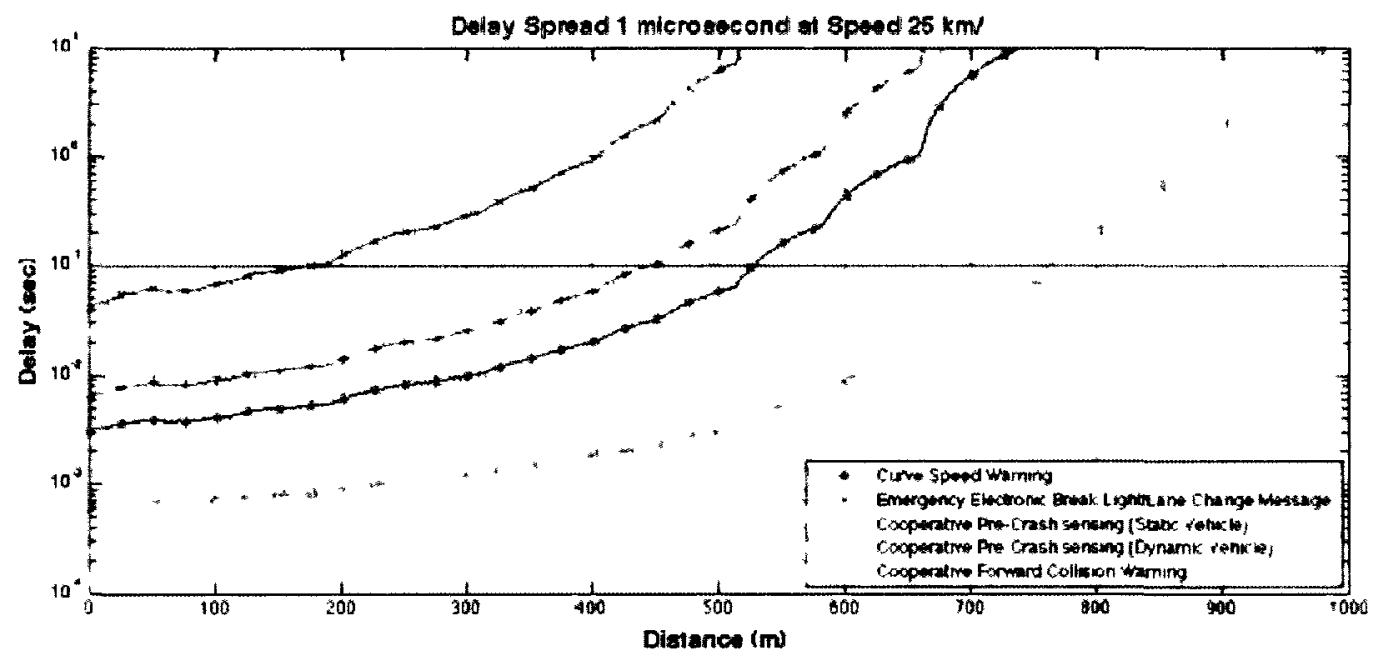

Figure 4.12: Delay time vs. Distance $(\mathrm{m})$ for multiple packet sizes at $25 \mathrm{~km} / \mathrm{h}$

For highway environment as it is known, usually vehicles drive with high speeds between $100-120 \mathrm{~km} / \mathrm{h}$. This test concentrated on 25 and $50 \mathrm{~km} / \mathrm{h}$ speed difference between two vehicles, to test the effect of higher speed on the reliability of the IEEE 802.11a communication channel. Figure 4.12 show that at speed $25 \mathrm{~km} / \mathrm{h}$, all the five applications pass the distance and delay time requirement $(0.1 \mathrm{sec}$ and $150 \mathrm{~m})$ on the other hand, figure 4.13 shows that for cooperative forward collision warning at speed $50 \mathrm{~km} / \mathrm{h}$ doesnt pass the requirement which means that DSRC communication channel is not practical for that application at higher speeds.

\subsection{Urban Environment}

For urban environments, two types of tests were simulated, with LOS and with NLOS. In this environment it was found that the reliable distance when there is LOS is between 400 and $2000 \mathrm{~m}$ which means it is acceptable for all our applications. On the other hand, when there was no line of sight the distance went down dramatically 


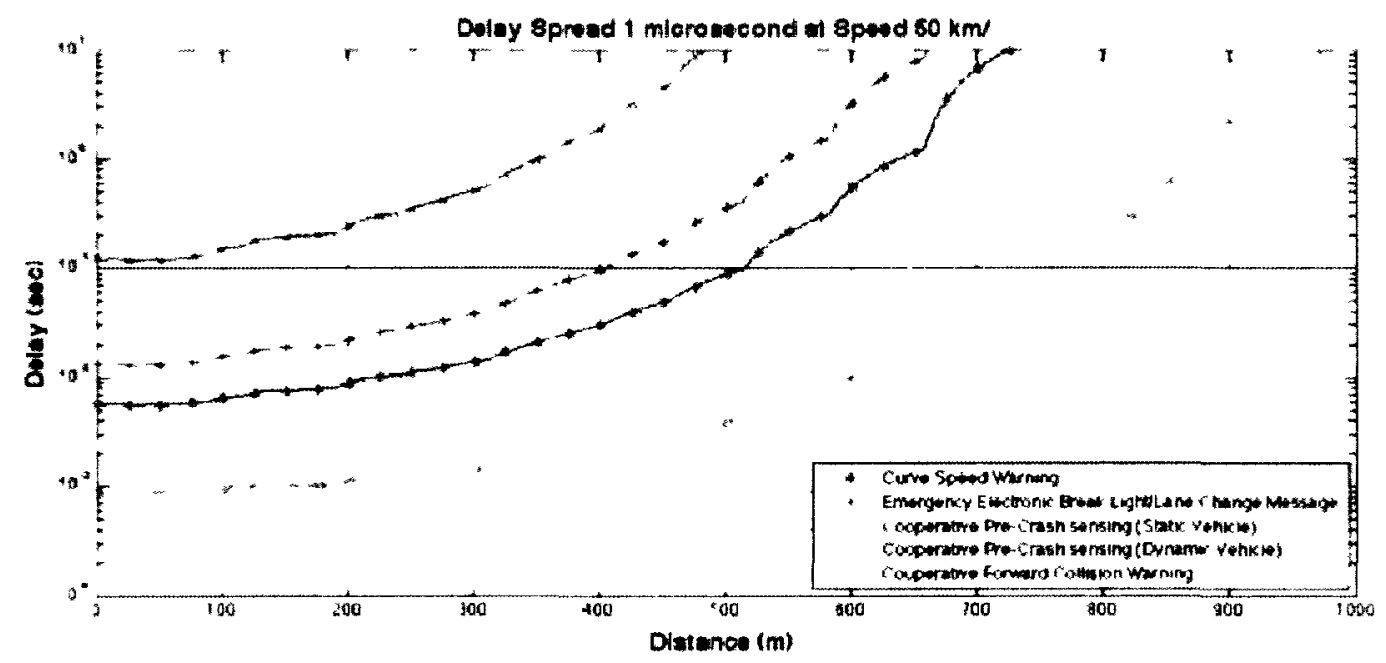

Figure 4.13: Delay tıme vs. Distance $(\mathrm{m})$ for multiple packet sizes at $50 \mathrm{~km} / \mathrm{h}$

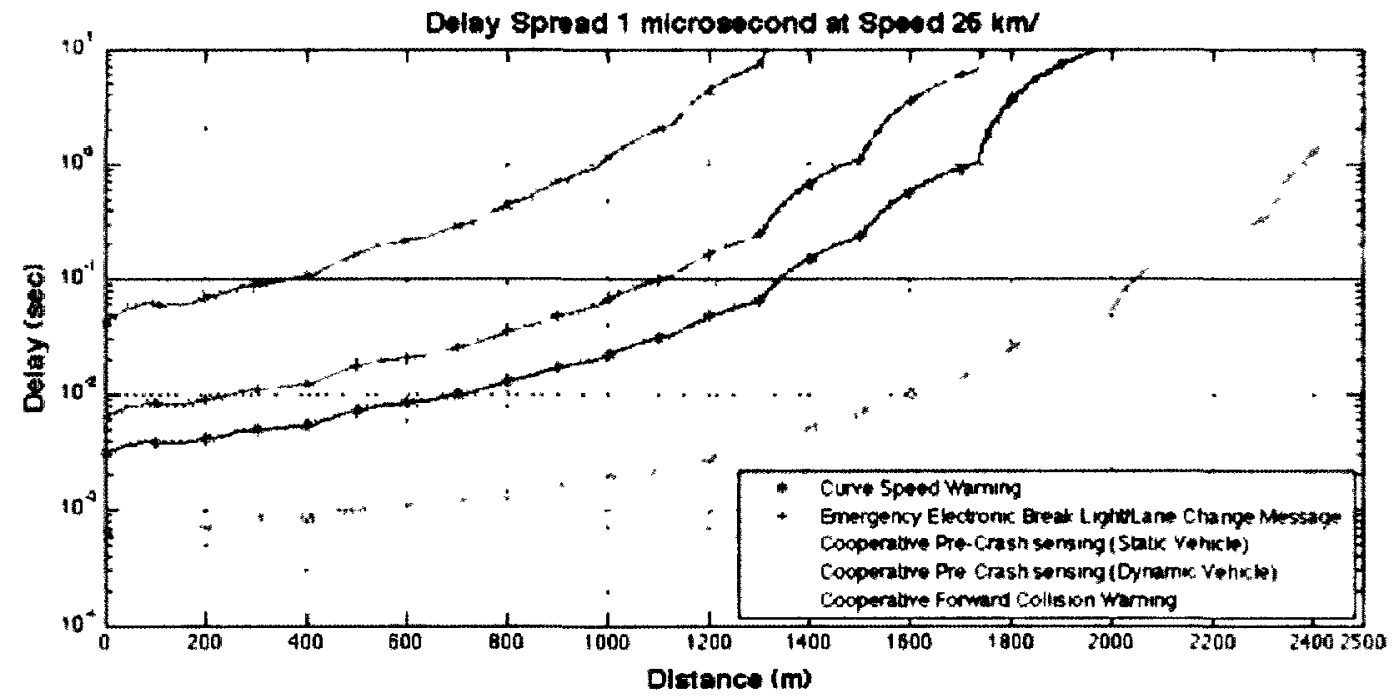

Figure 4.14: Delay time vs. Distance $(\mathrm{m})$ in urban areas (LOS) for $25 \mathrm{~km} / \mathrm{h}$ 
to between 30 and $110 \mathrm{~m}$ and that makes DSRC communications in urban areas not very practical when there is NLOS The reason for that big difference is that in urban environments buildings will act like a tunnel and that will increase the signal power, which means that it will travel for a longer distance. Figure (4.14 and 4.15) shows the difference in distance between the two tests at $25 \mathrm{~km} / \mathrm{h}$ speed.

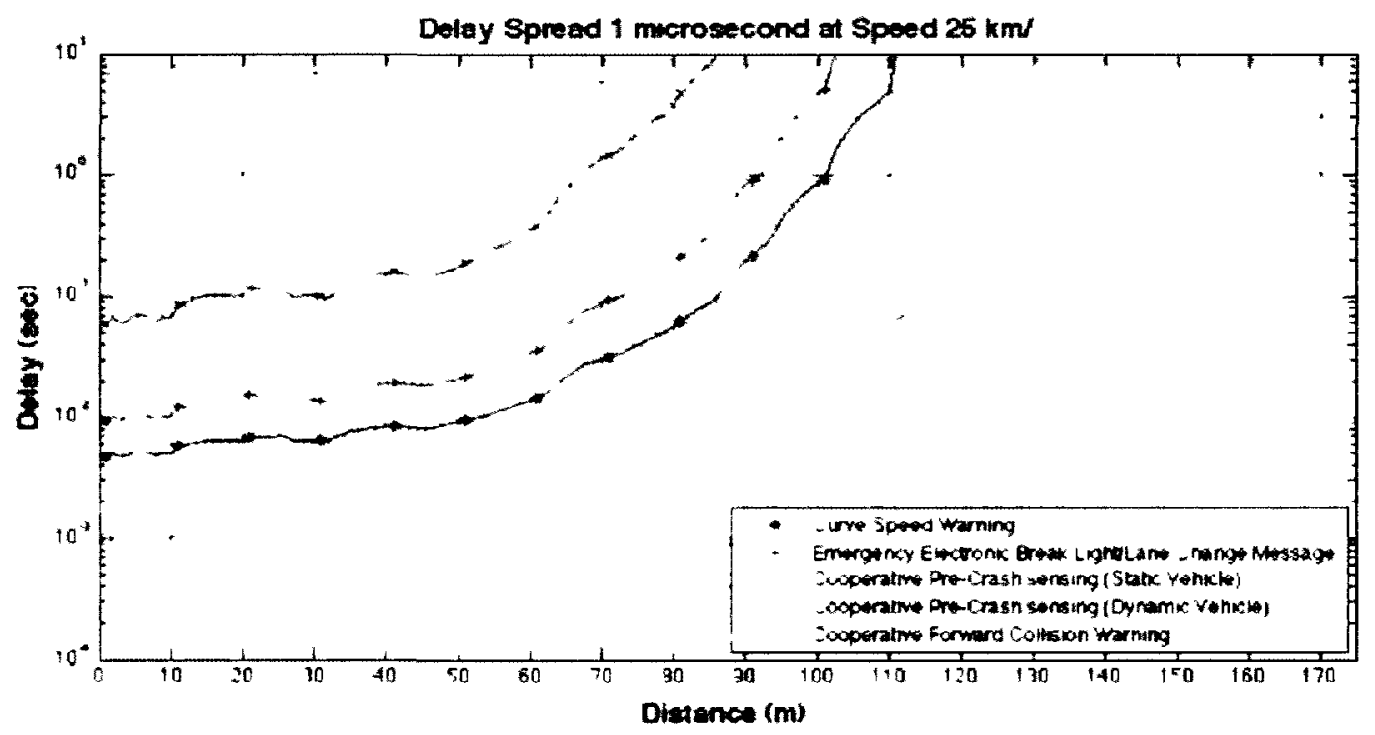

Figure 4.15: Delay time vs. Distance (m) in urban areas (NLOS) for $25 \mathrm{~km} / \mathrm{h}$

\subsection{Rural Environment}

This section discusses the last type of environment that was tested in this research, which was rural environment. For this environment two types of path-loss exponents were used which are 1.79 and 2.3 and they represent LOS and NLOS cases respectively. As discusses in the case of urban environments, there was a very big difference in performance between when there was LOS and NLOS. Figure 4.16 show that the for rural areas at speed $25 \mathrm{~km} / \mathrm{h}$ with LOS the maximum accepted distance range between 1075 and $1450 \mathrm{~m}$ which is almost 10 times higher than the minimum required 
distance.

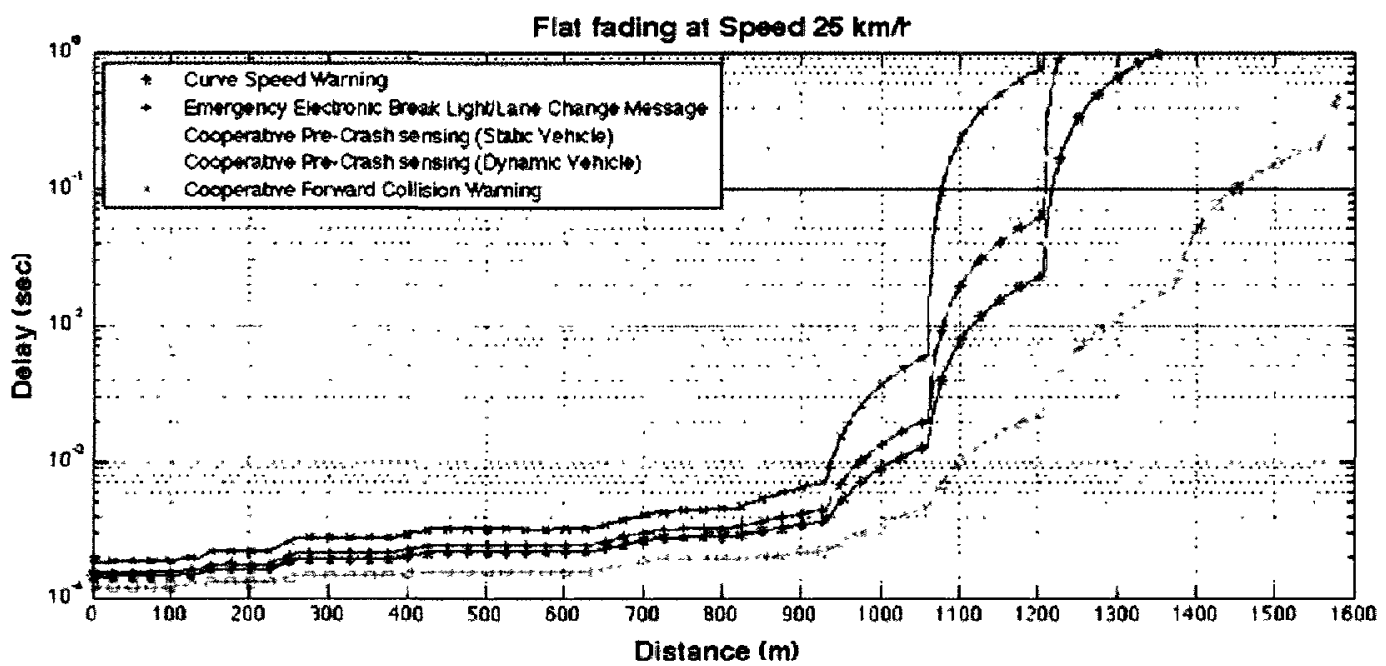

Figure 4.16: Delay time vs. Distance in rural areas (LOS) at $25 \mathrm{~km} / \mathrm{h}$

In the other test,figure 4.17 , which was the case NLOS, effective distance move down to between 225 and $285 \mathrm{~m}$, these results can get us to a conclusion that DSRC is practical for $\mathrm{V} 2 \mathrm{~V}$ communication in rural areas. 


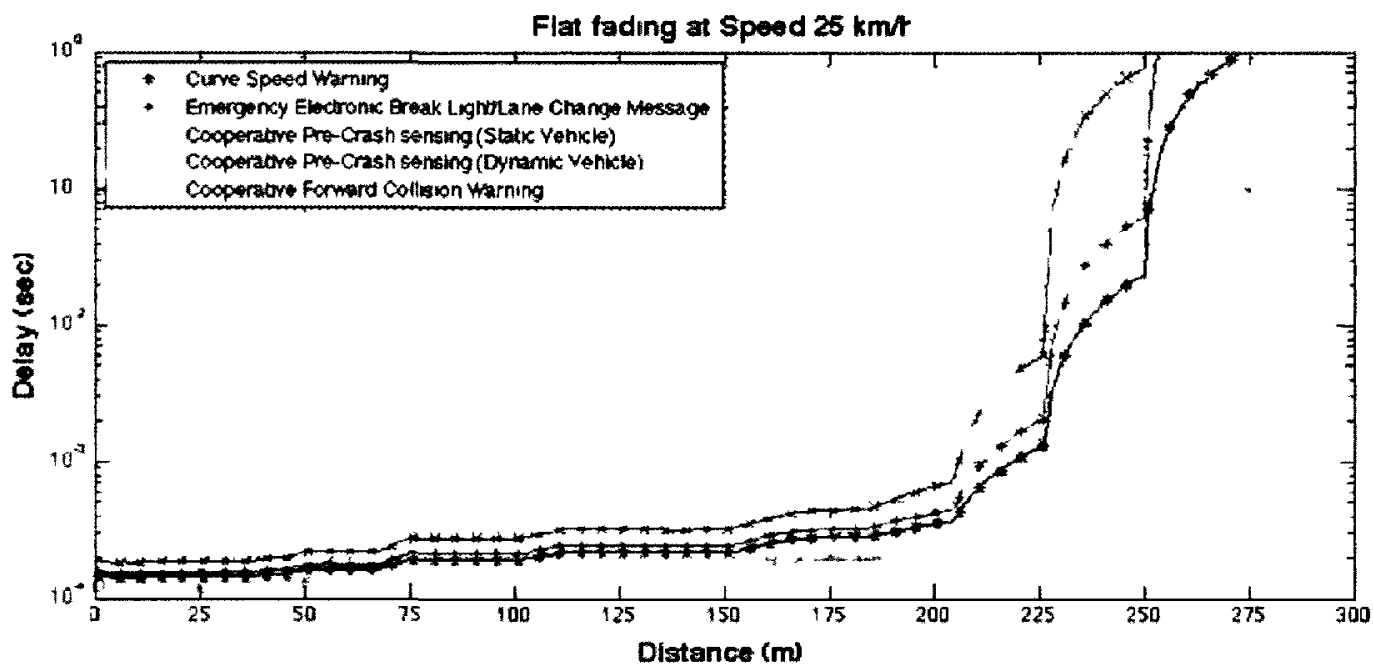

Figure 4.17: Delay time vs Distance in rural areas (NLOS) at $25 \mathrm{~km} / \mathrm{h}$ 


\section{Chapter 5}

\section{Conclusions and Recommendations for Future Research}

\subsection{Conclusions}

As intelligent transportation systems ITS advance, they require higher safety applications in order to reduce number of accidents, which results in reducing number of fatalities or injuries caused by accidents. Also the advancements in ITS reduce the costs occurred from accidents. V2V communication is a vital application of ITS in order to allow vehicles to exchange vehicles or roads information with surrounding vehicles or infrastructure.

This thesis provides a comprehensive study of the $5.9 \mathrm{GHz}$ DSRC wireless communication, which is assigned for vehicular applications, and identified the challenges that exist in various vehicular environments. Several studies have been conducted by other researchers to calculate the path-loss exponent for different environments on DSRC communication between two terminals. The DSRC physical layer was evaluated in this thesis using the previous path-loss exponents, and multiple tests were simulated in this thesis for rural, highway, urban and suburban areas.

In environments with low path-loss exponents, such as rural, highway and urban 
(with LOS) environments, and lower vehicle speed $(25-50 \mathrm{Km} / \mathrm{H})$, the DSRC showed a high reliability for longer distances compared to environments with high path-loss exponents, such as urban (with NLOS) and suburban environments. For higher vehicle speeds $(50 \mathrm{Km} / \mathrm{H})$, all tests showed a large drawback in the reliability of DSRC. The effect of delay spread was also simulated in this thesis, and it was concluded that at low delay spreads $(0.1 \mu \mathrm{sec}$ and $0.5 \mu \mathrm{sec})$ the effect of the delay spread was not very noticeable. But at higher delay spreads $(1 \mu \mathrm{sec})$ the BER increased compared to the other cases, which made DSRC not practical for some applications in some cases, e.g. urban (NLOS) and suburban.

Finally, it can be concluded that at higher vehicle speeds, delay spread, and pathloss exponents, certain changes need to be taken into account when designing the MAC layer for DSRC networks, and some recommendations are discussed in the next section.

\subsection{Recommendations for Future Research}

This research concentrated on evaluating the performance of the DSRC physical layer. As DSRC is still under development, there is lots of work to be done on it. This section discusses some of the future research recommendations that can be done based on this thesis.

As was mentioned in table (3.3), the required packet size for most types of communications are smaller than the OFDM frame size that is used by DSRC physical layer. So in order to reduce the bit error rate (BER) at low distances, high AMC, a medium access control (MAC) layer can be developed to send multiple messages in the same OFDM frame, or to repeat the same message multiple times in the same OFDM frame. Another enhancement on the DSRC model is to find the optimum SNR threshold values to achieve the highest performance of the system. 
One last recommendation that can be considered while developing inter-vehicle communication (IVC) network is the way of communication that will be used. There are two ways of communications, which are, Vehicle-to-Vehicle (V2V) or Vehicle-toInfrastructure (V2I). The system can be developed in order to accommodate both ways of communications. V2V communication can be considered the primary way of communication but in case that there was no other vehicles in the range of the transmitting vehicle, then the V2I communication can take place in order to deliver the road information to other vehicles. 


\section{Appendix A}

\section{Extra Test Results}

\section{A.1 Suburban Environments}

Table A.1: Values used to generate results for Suburban Environments Test

\begin{tabular}{|c|c|}
\hline System Parameters & Values \\
\hline$\gamma_{1}$ & 2.1 \\
\hline$\gamma_{2}$ & 3.8 \\
\hline$\sigma_{1}$ & 2.6 \\
\hline$\sigma_{2}$ & 4.4 \\
\hline
\end{tabular}


Flat fading at Speed $50 \mathrm{~km} / \mathrm{r}$

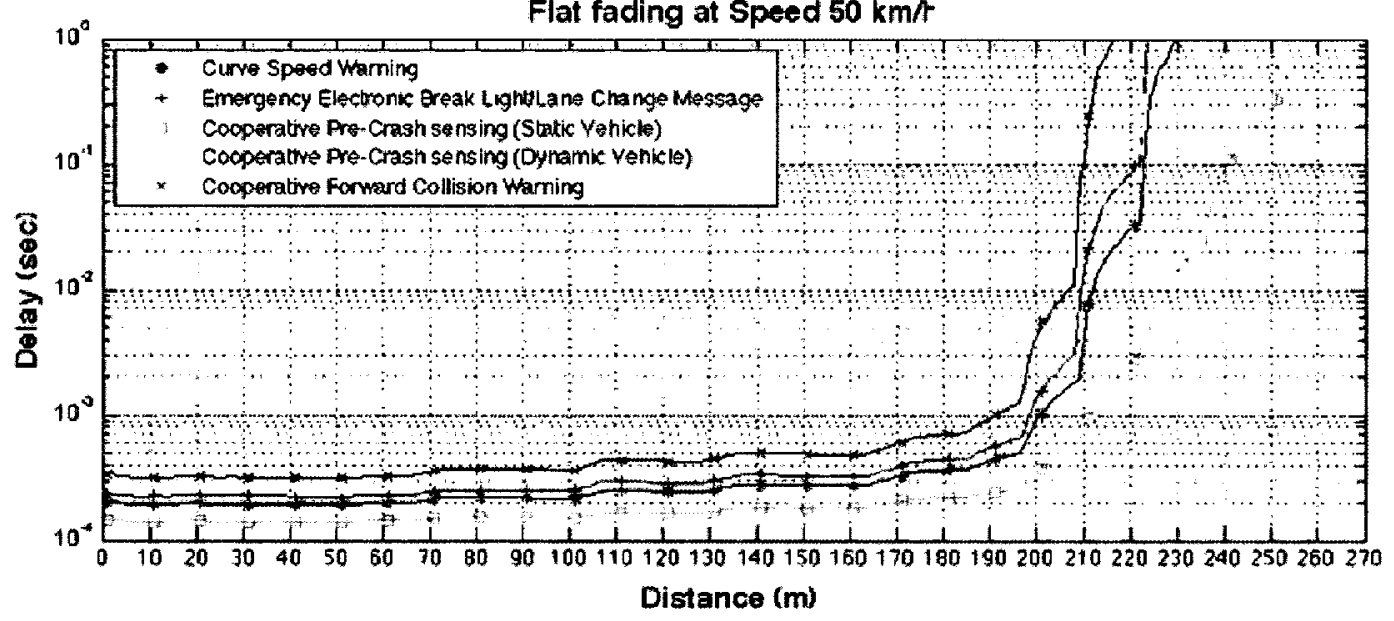

Figure A.1: Delay time vs. Distance for Suburban environment with flat fading at $50 \mathrm{~km} / \mathrm{h}$

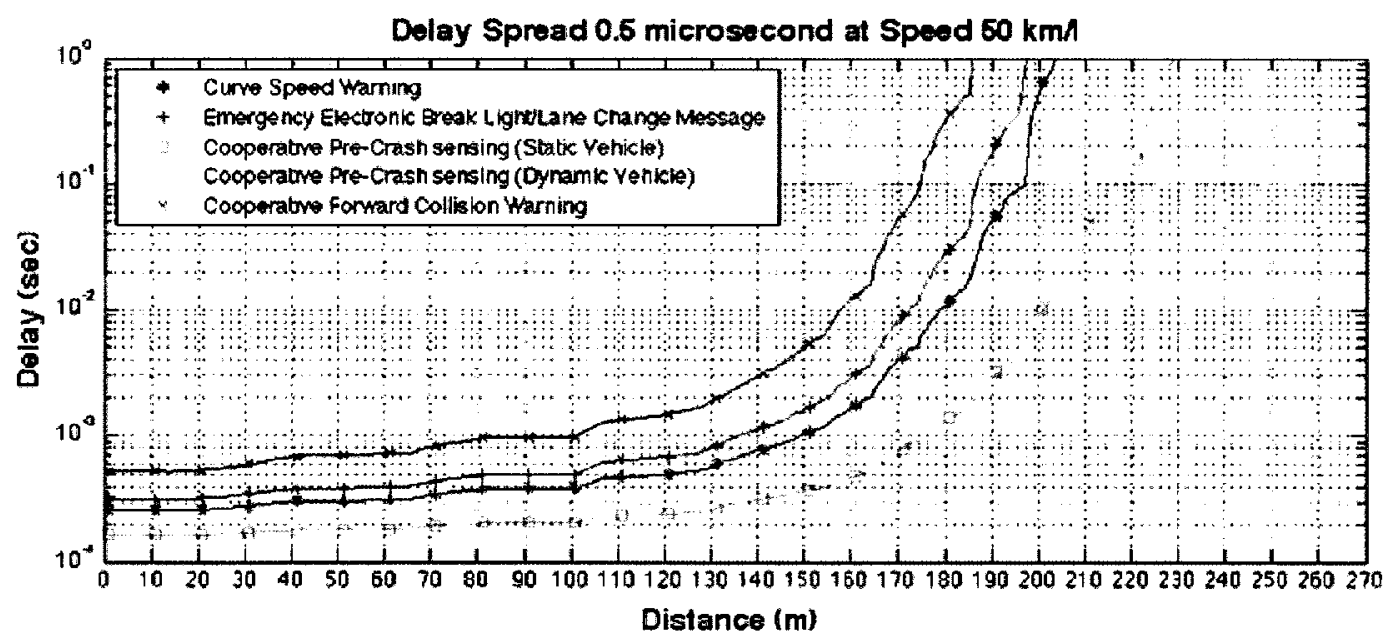

Figure A.2: Delay time vs. Distance for Suburban environment with $0.5 \mu \mathrm{sec}$ at 50 $\mathrm{km} / \mathrm{h}$ 


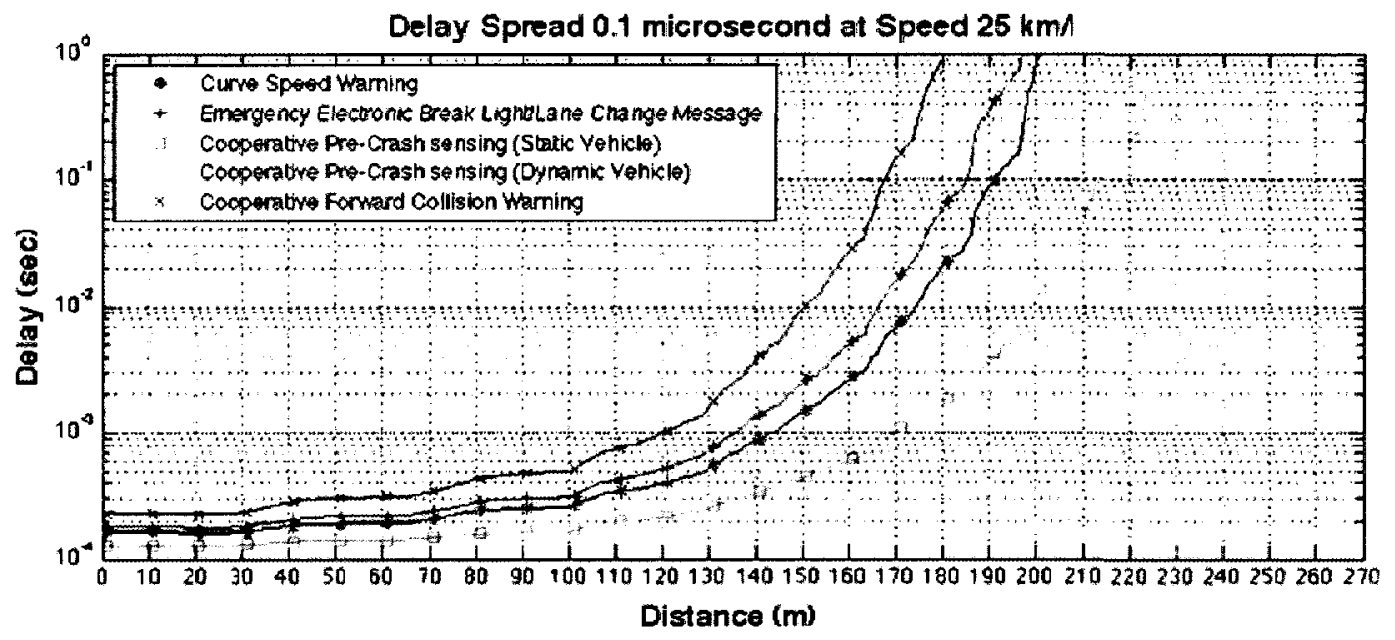

Figure A.3: Delay time vs. Distance for Suburban environment with $0.1 \mu$ sec at 25 $\mathrm{km} / \mathrm{h}$

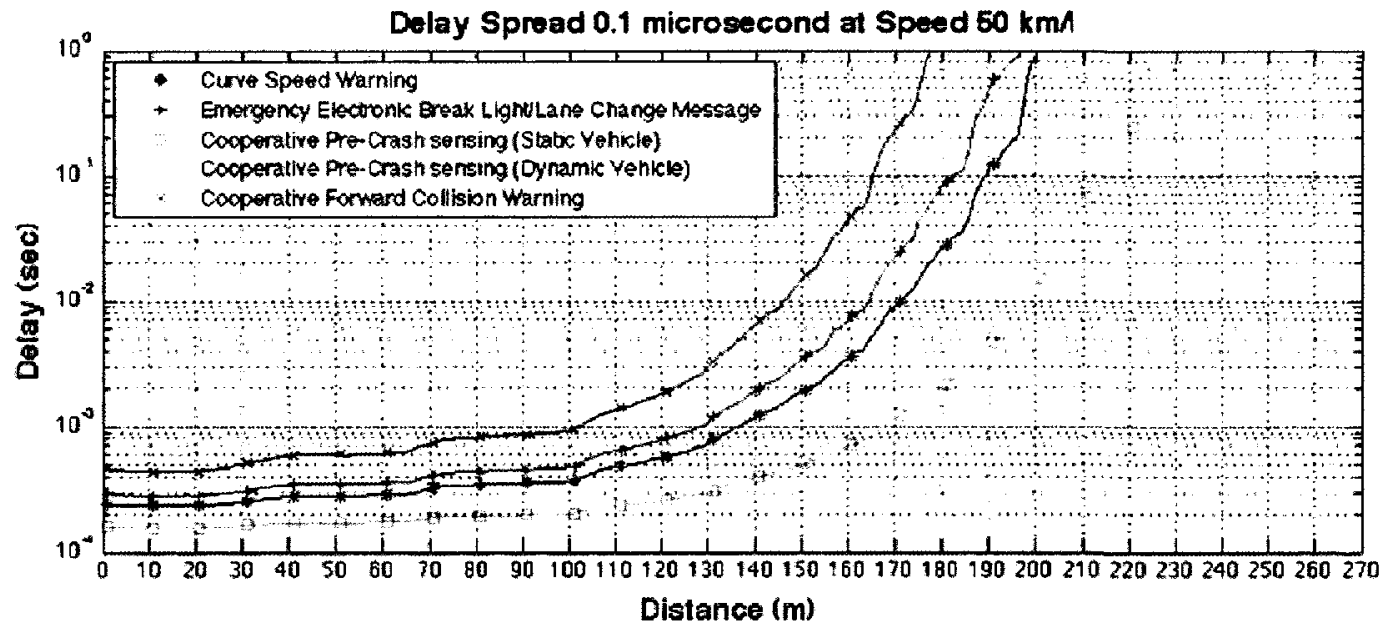

Figure A.4: Delay time vs. Distance for Suburban environment with $0.1 \mu$ sec at 50 $\mathrm{km} / \mathrm{h}$ 


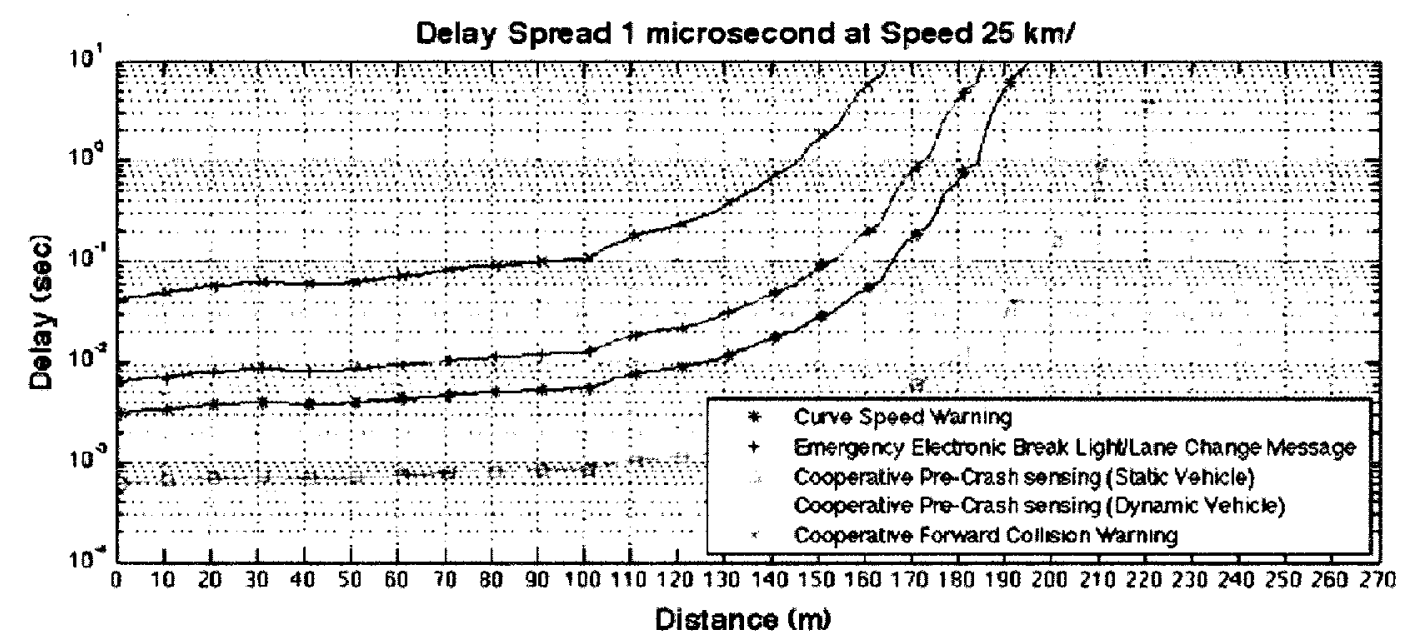

Figure A.5: Delay time vs. Distance for Suburban environment with $1 \mu$ sec at 25 $\mathrm{km} / \mathrm{h}$

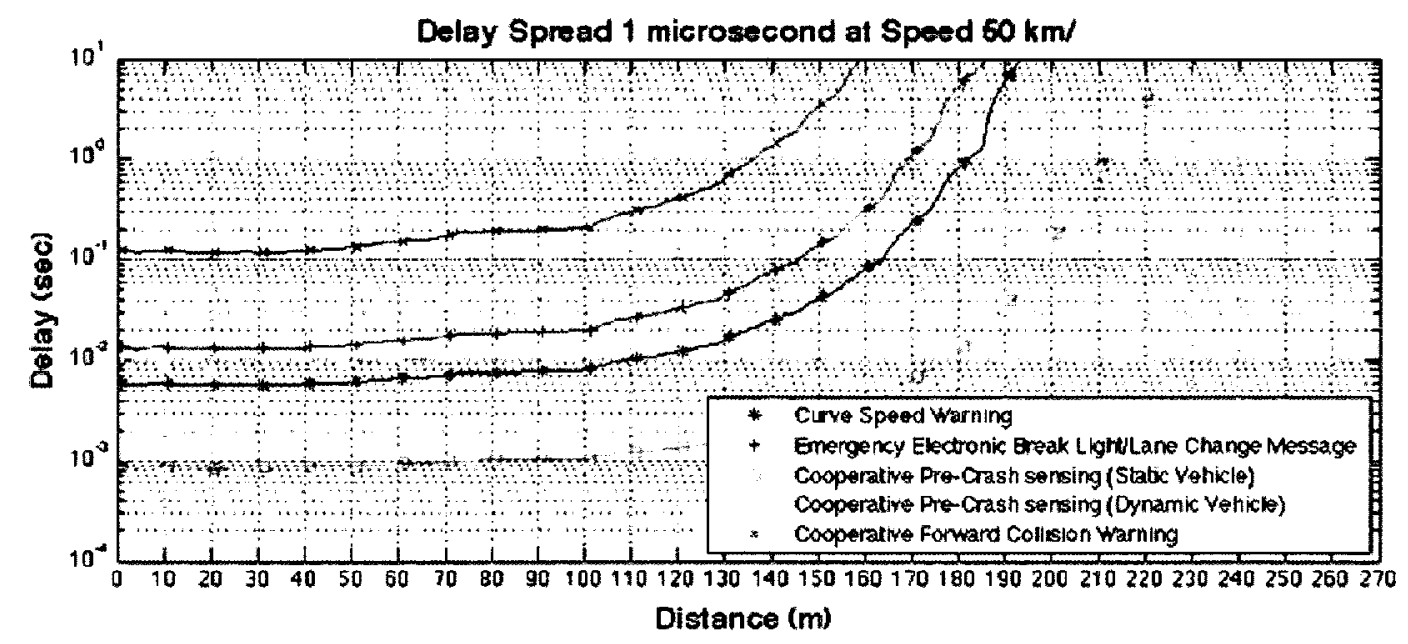

Figure A.6: Delay time vs. Distance for Suburban environment with $1 \mu$ sec at 50 $\mathrm{km} / \mathrm{h}$ 


\section{A.2 Highway Environments}

\section{A.2.1 Test 1}

Table A.2: Values used to generate results for Test 1 for Highway Environments

\begin{tabular}{|c|c|}
\hline System Parameters & Values \\
\hline$\gamma$ & 1.9 \\
\hline$\sigma$ & 2.3 \\
\hline
\end{tabular}

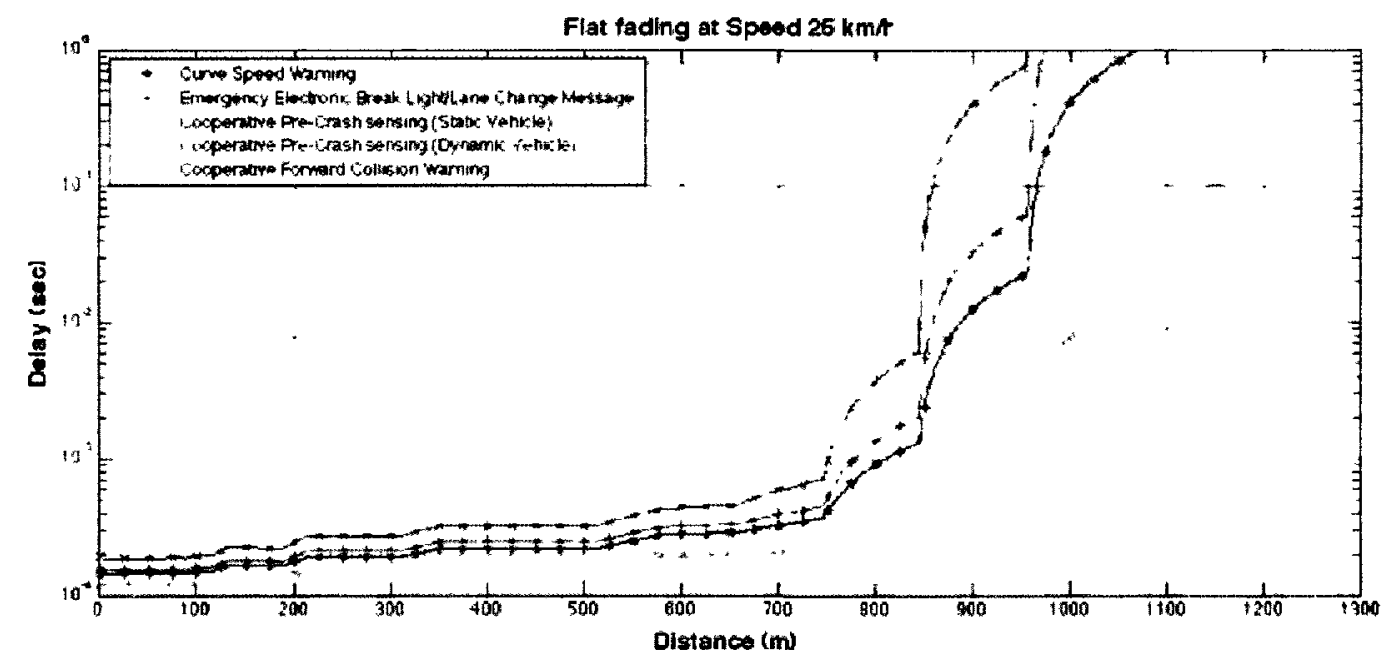

Figure A.7: Delay time vs. Distance for Highway environment with flat fading at $25 \mathrm{~km} / \mathrm{h}$ 


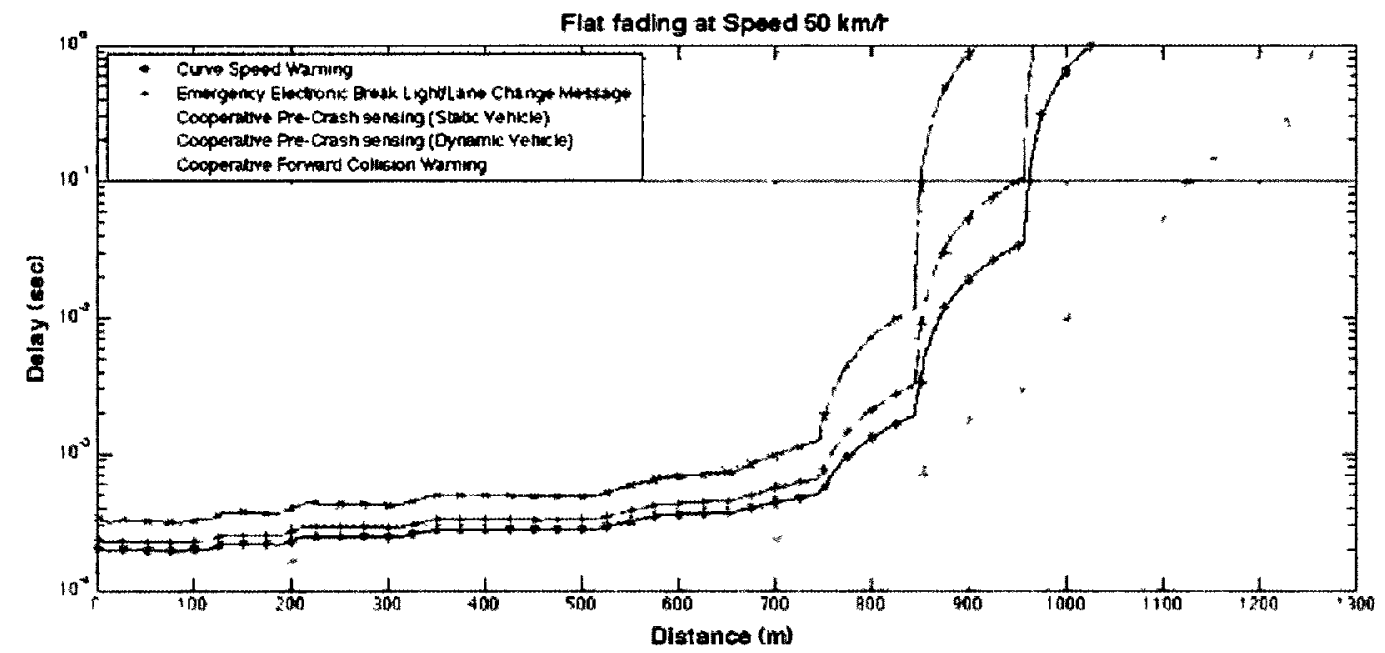

Figure A.8: Delay tıme vs Distance for Highway environment with flat fadıng at $50 \mathrm{~km} / \mathrm{h}$

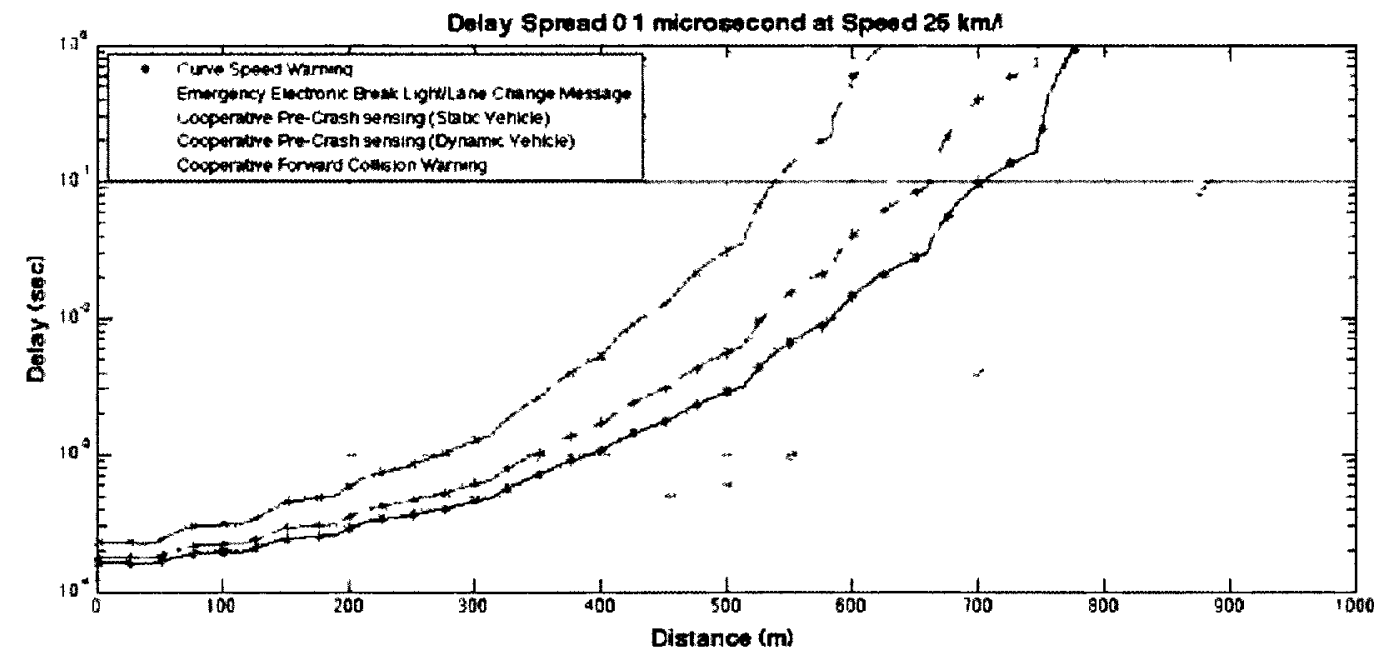

Figure A.9: Delay tıme vs Distance for Highway envıronment with $01 \mu \mathrm{sec}$ at 25 $\mathrm{km} / \mathrm{h}$ 


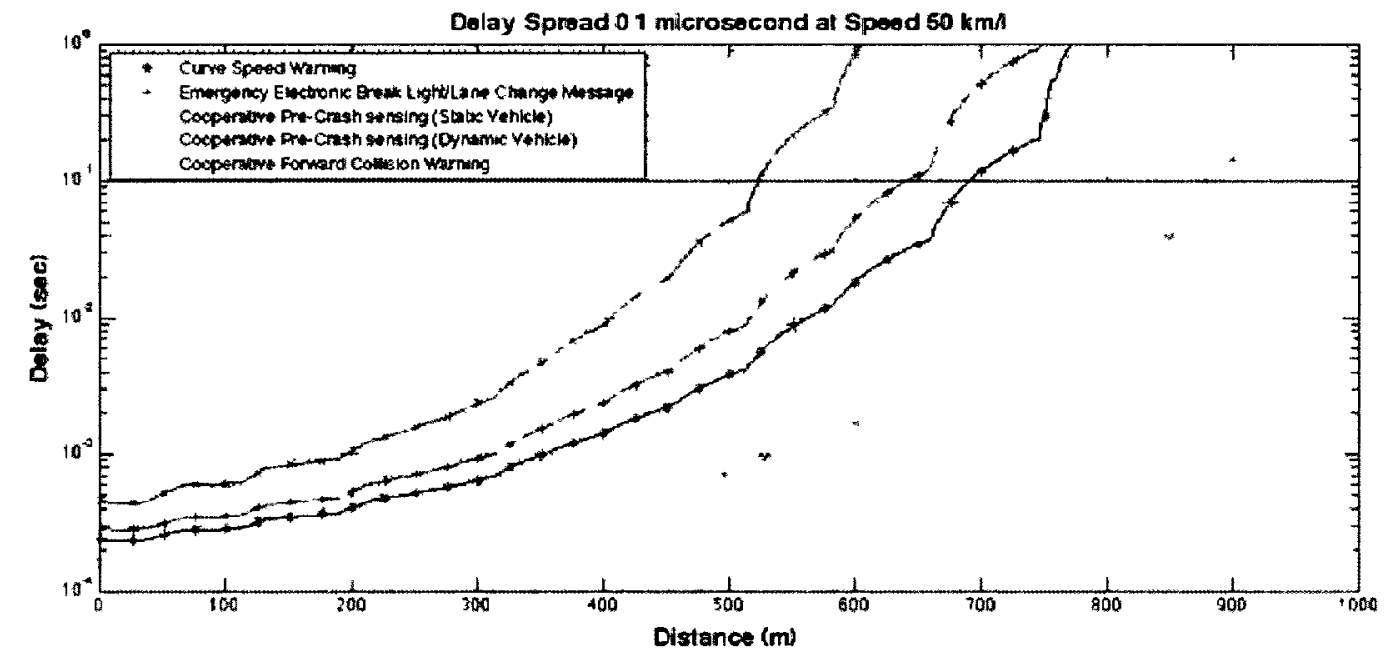

Figure A.10: Delay time vs Distance for Highway environment with $01 \mu \mathrm{sec}$ at 50 $\mathrm{km} / \mathrm{h}$

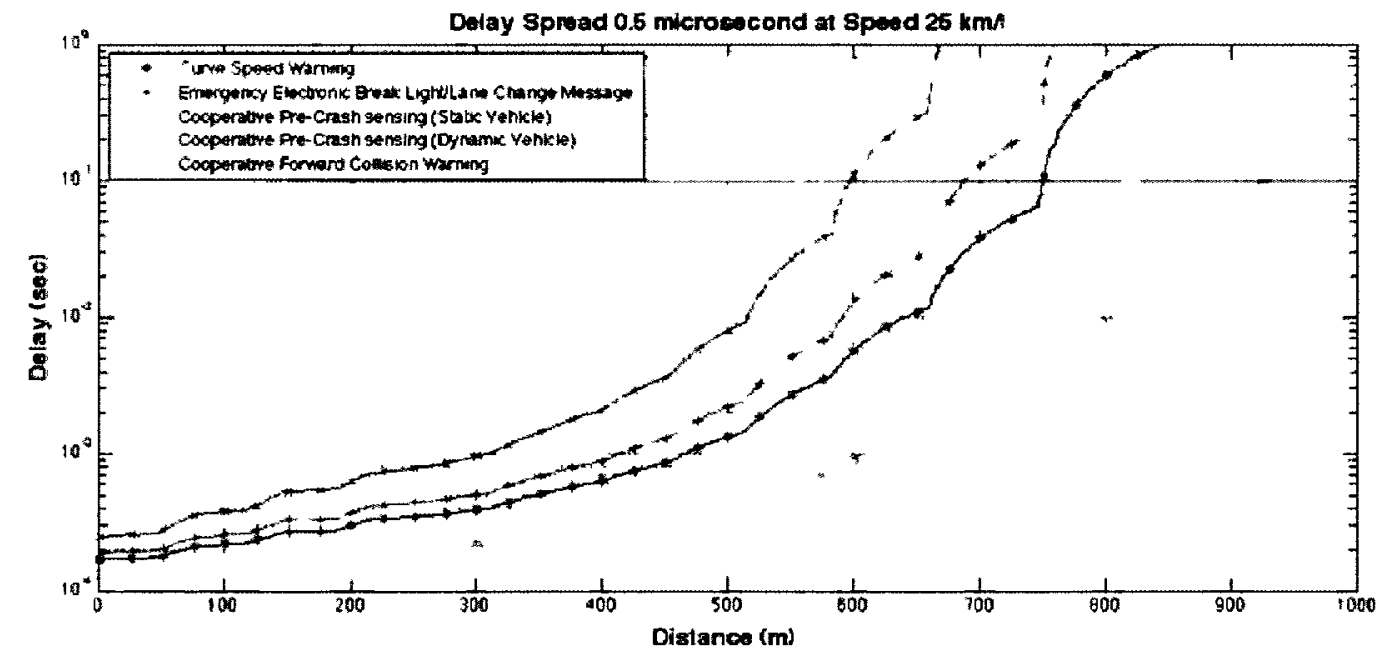

Figure A.11: Delay time vs Distance for Highway environment with $05 \mu$ sec at 25 $\mathrm{km} / \mathrm{h}$ 


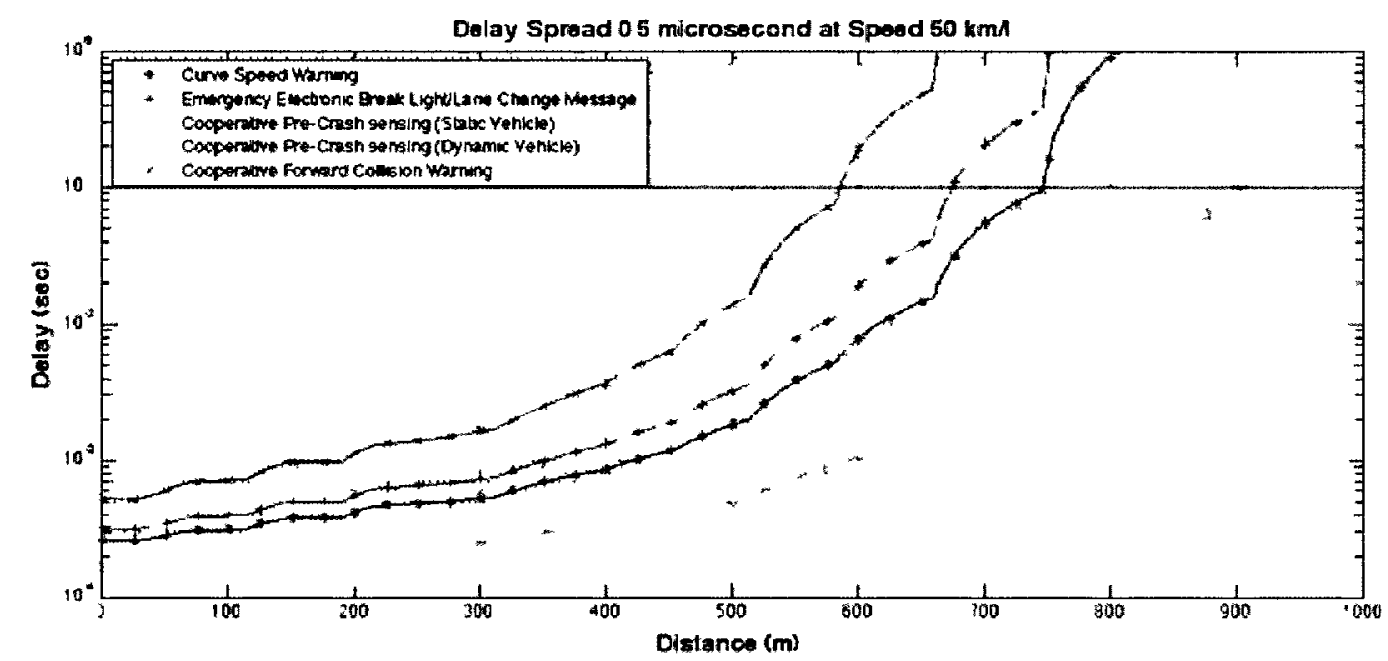

Figure A.12: Delay time vs Distance for Highway environment with $05 \mu$ sec at 50 $\mathrm{km} / \mathrm{h}$

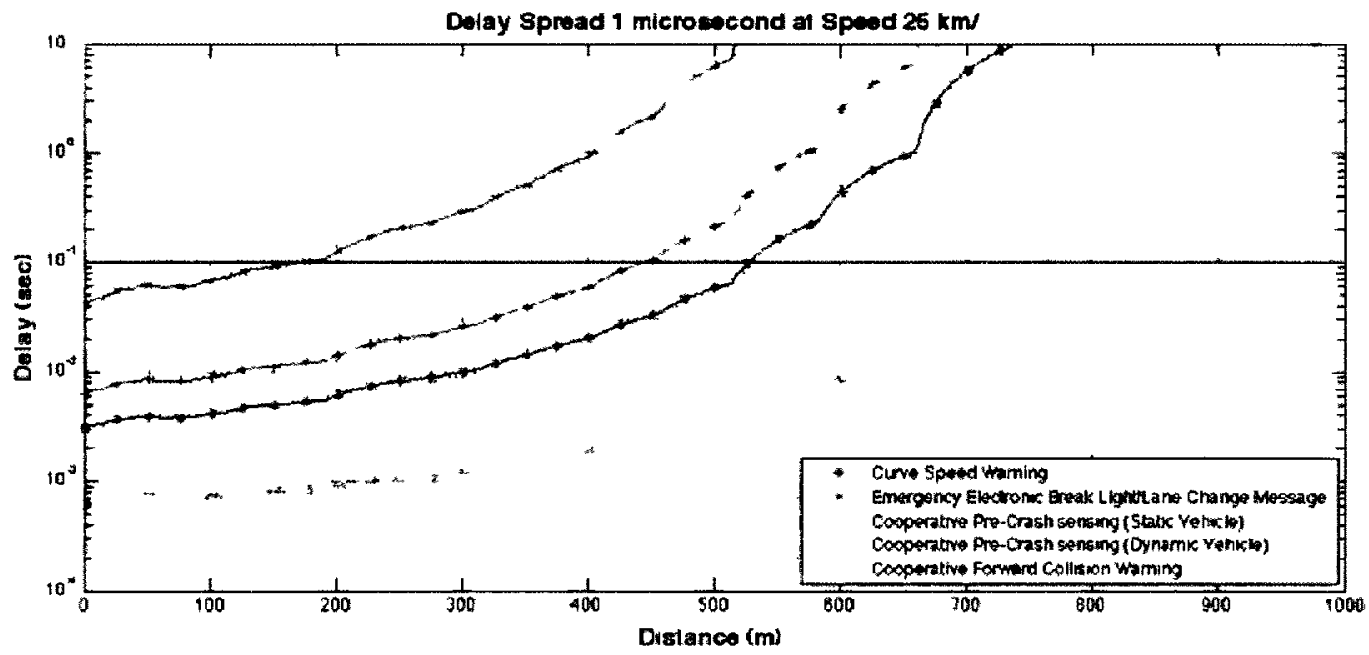

Figure A.13: Delay time vs Distance for Highway environment with 1 musec at $25 \mathrm{~km} / \mathrm{h}$ 


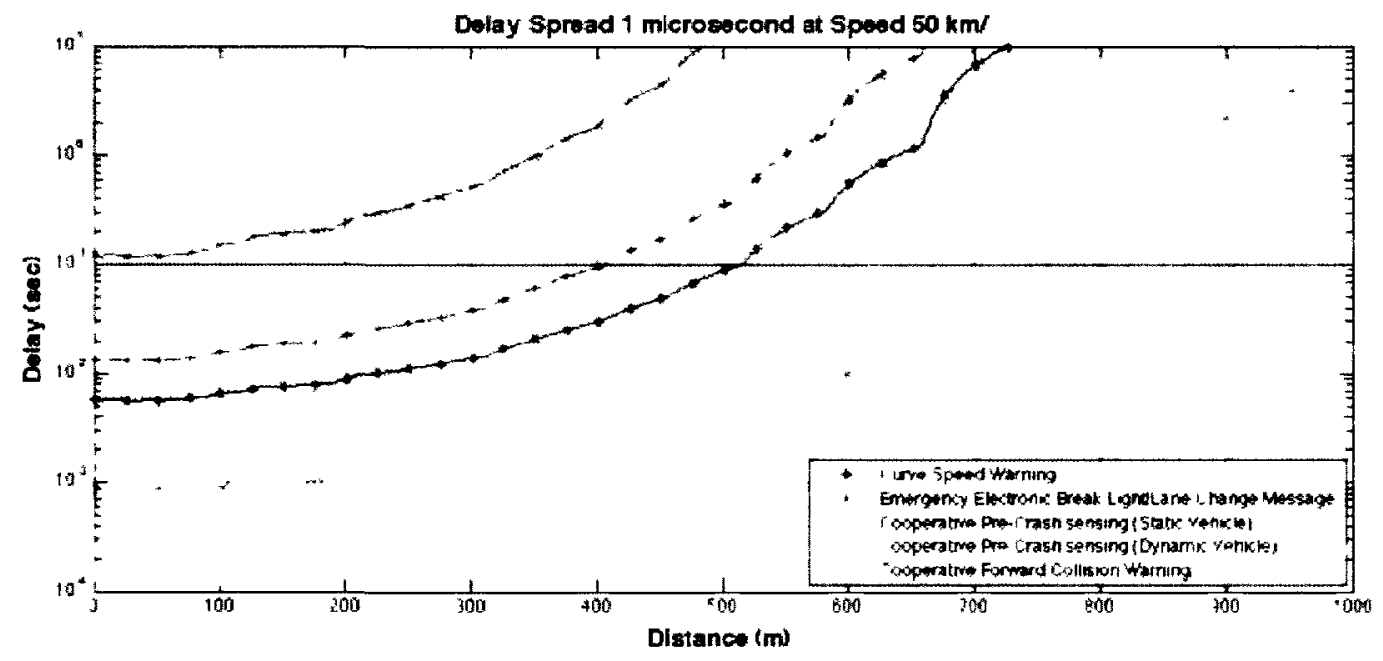

Figure A.14: Delay time vs. Distance for Highway environment with $1 \mu$ sec at 50 $\mathrm{km} / \mathrm{h}$ 


\section{A.2.2 Test 2}

Table A.3: Values used to generate results for Test 2 for Highway Environments

\begin{tabular}{|c|c|}
\hline System Parameters & Values \\
\hline$\gamma$ & 1.85 \\
\hline$\sigma$ & 2.3 \\
\hline
\end{tabular}

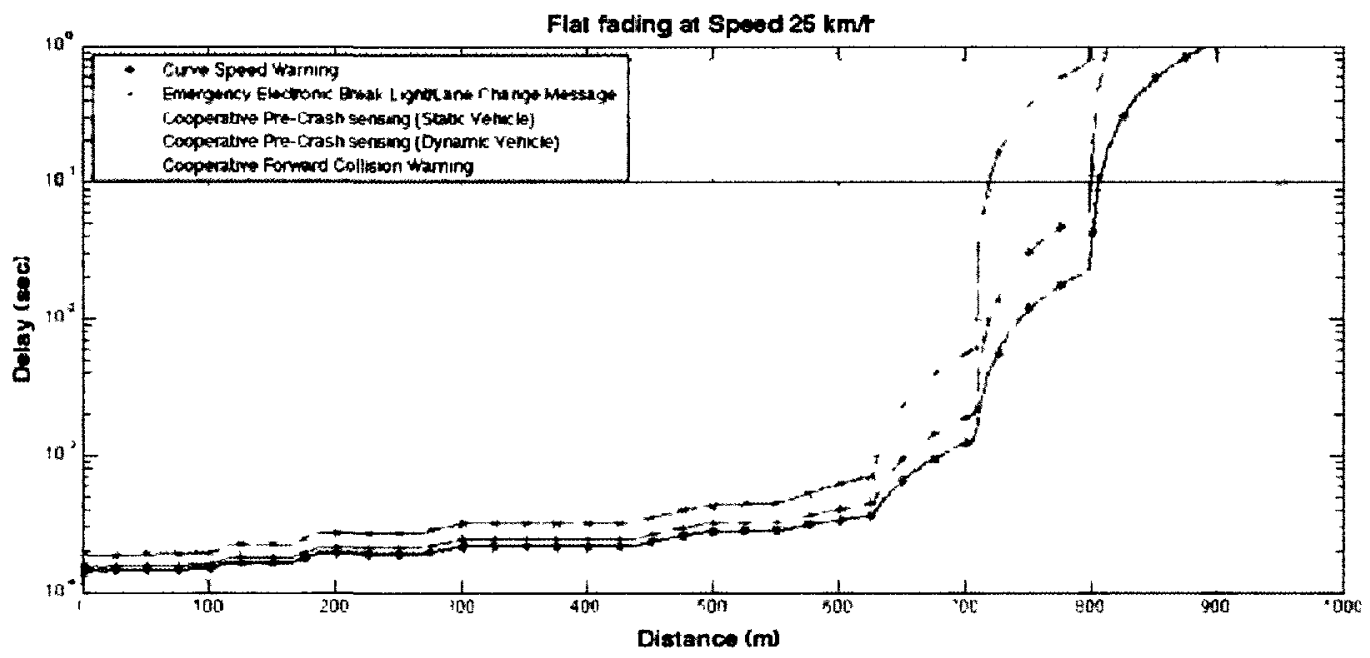

Figure A.15: Delay time vs. Distance for Highway environment with flat fading at $25 \mathrm{~km} / \mathrm{h}$ 


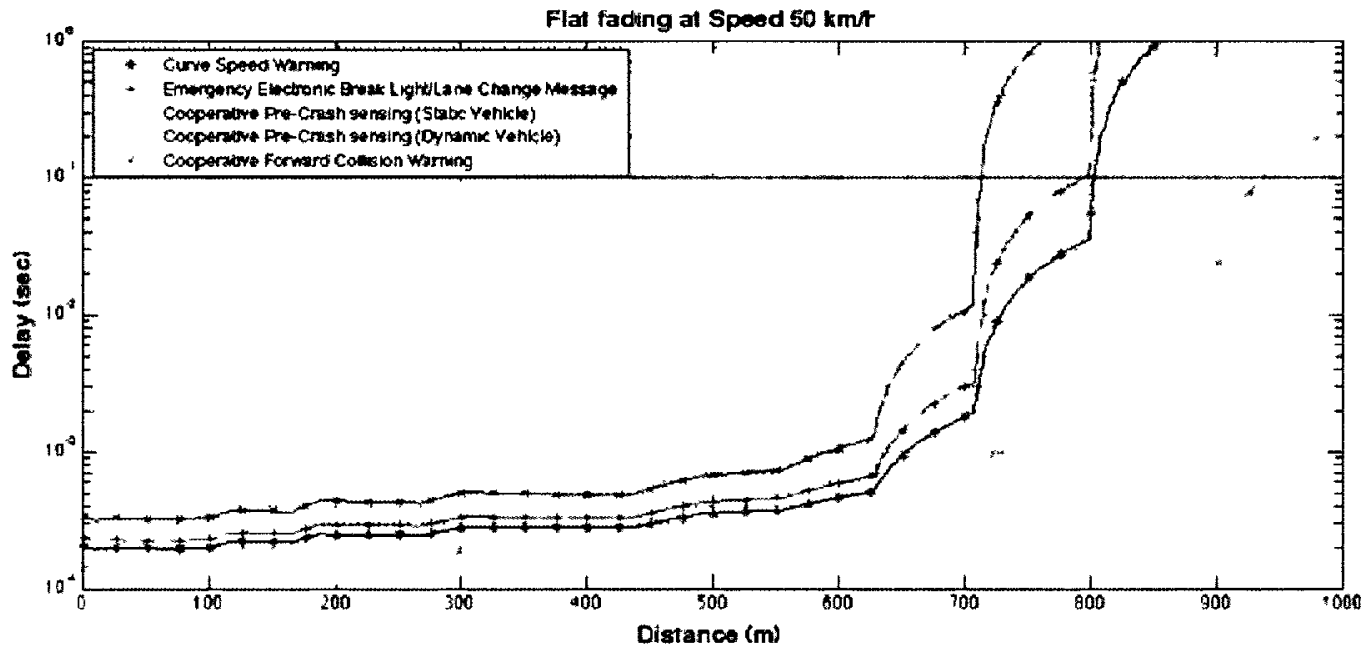

Figure A.16: Delay time vs Distance for Highway environment with flat fadıng at $50 \mathrm{~km} / \mathrm{h}$

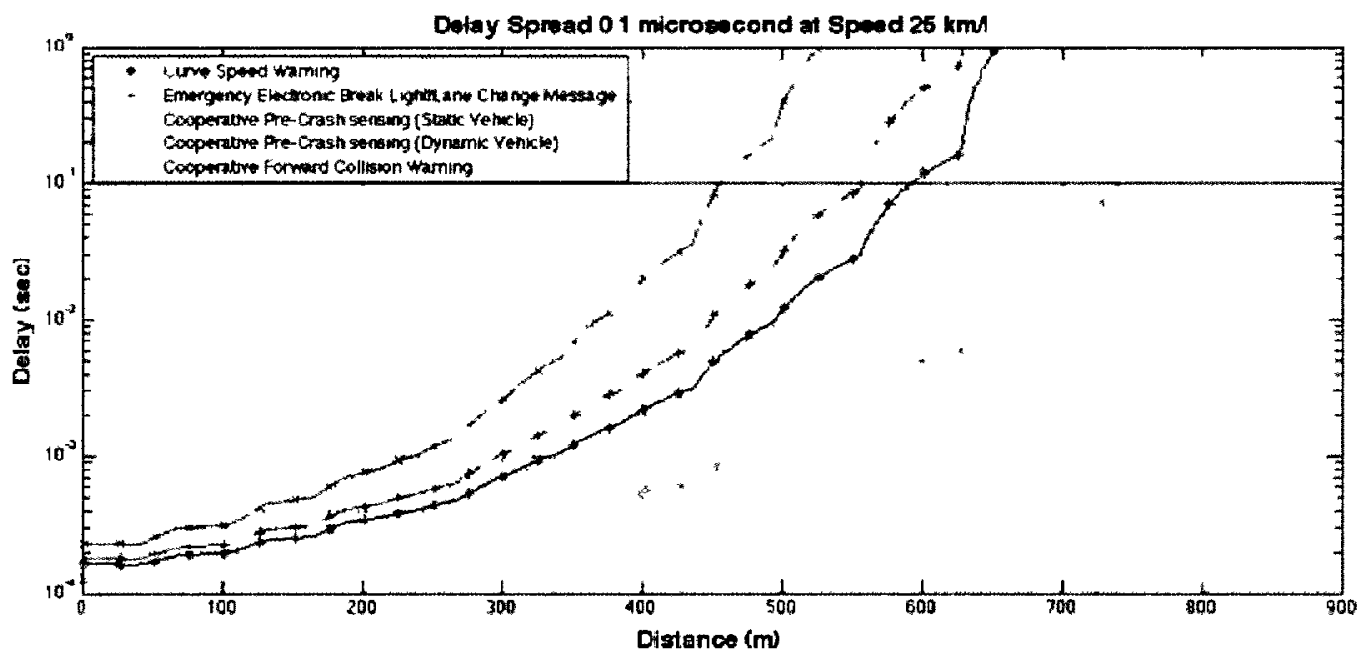

Figure A.17: Delay tıme vs Distance for Highway environment with $01 \mu$ sec at 25 $\mathrm{km} / \mathrm{h}$ 


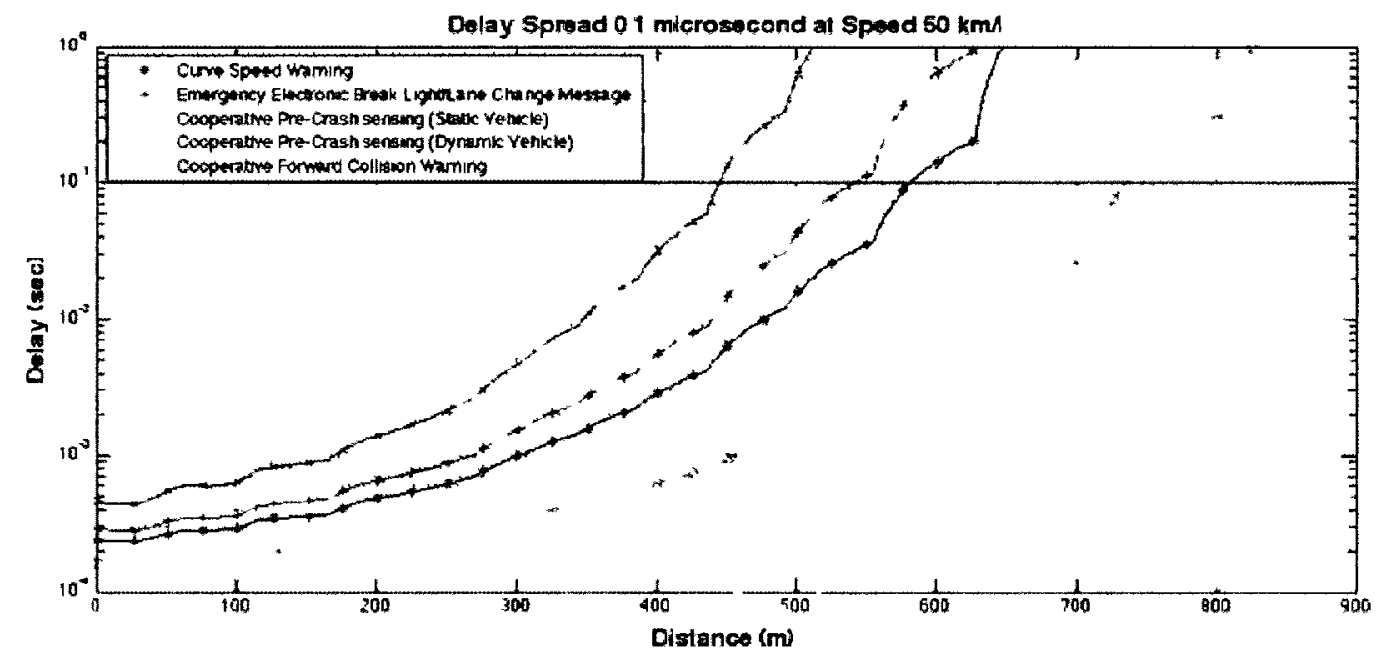

Figure A.18: Delay time vs Distance for Highway environment with $01 \mu$ sec at 50 $\mathrm{km} / \mathrm{h}$

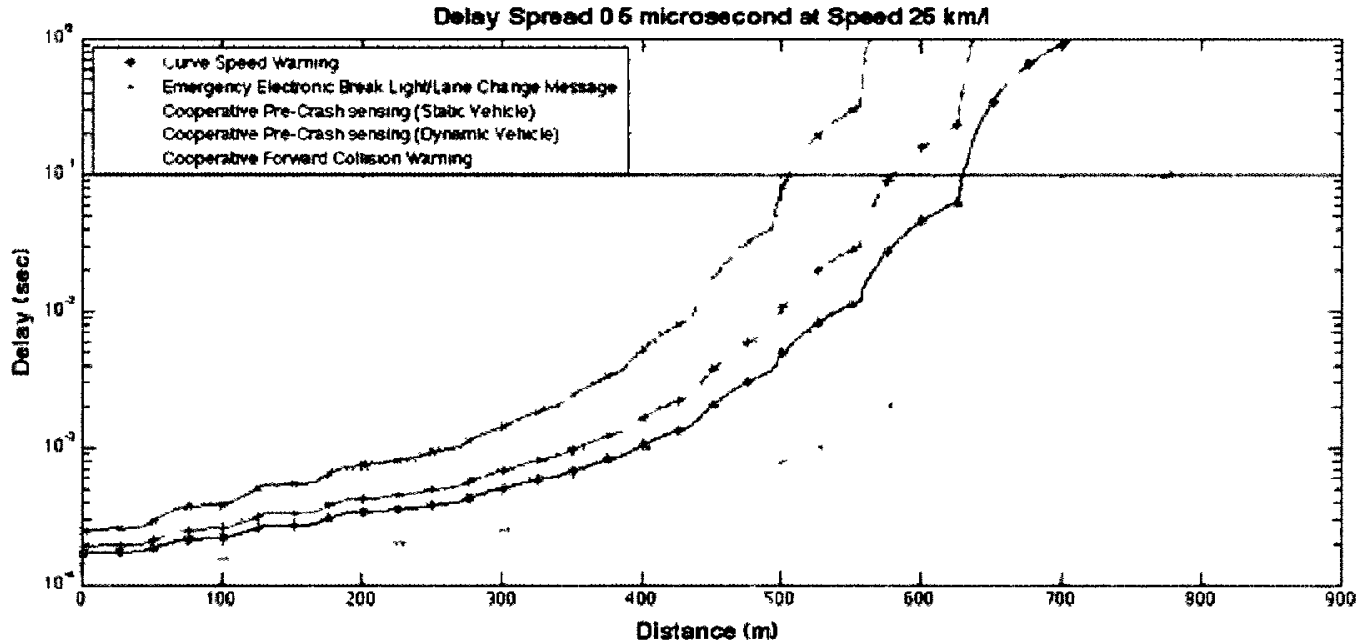

Figure A.19: Delay time vs Distance for Highway environment with $05 \mu$ sec at 25 $\mathrm{km} / \mathrm{h}$ 


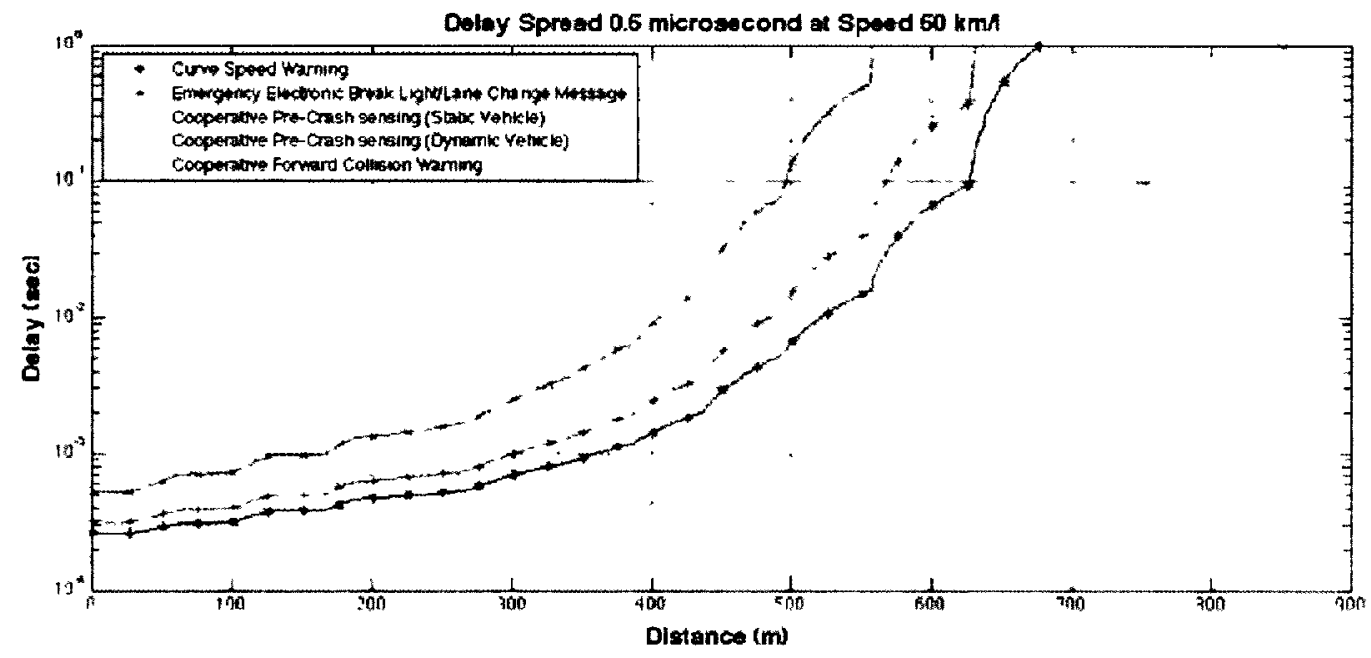

Figure A.20: Delay time vs. Distance for Highway environment with $0.5 \mu$ sec at 50 $\mathrm{km} / \mathrm{h}$ 


\section{A.3 Urban Environments}

\section{A.3.1 Test 1 (LOS)}

Table A.4: Values used to generate results for Test 1 for Urban (LOS) Envıronments

\begin{tabular}{|c|c|}
\hline System Parameters & Values \\
\hline$\gamma$ & 161 \\
\hline$\sigma$ & 8 \\
\hline
\end{tabular}

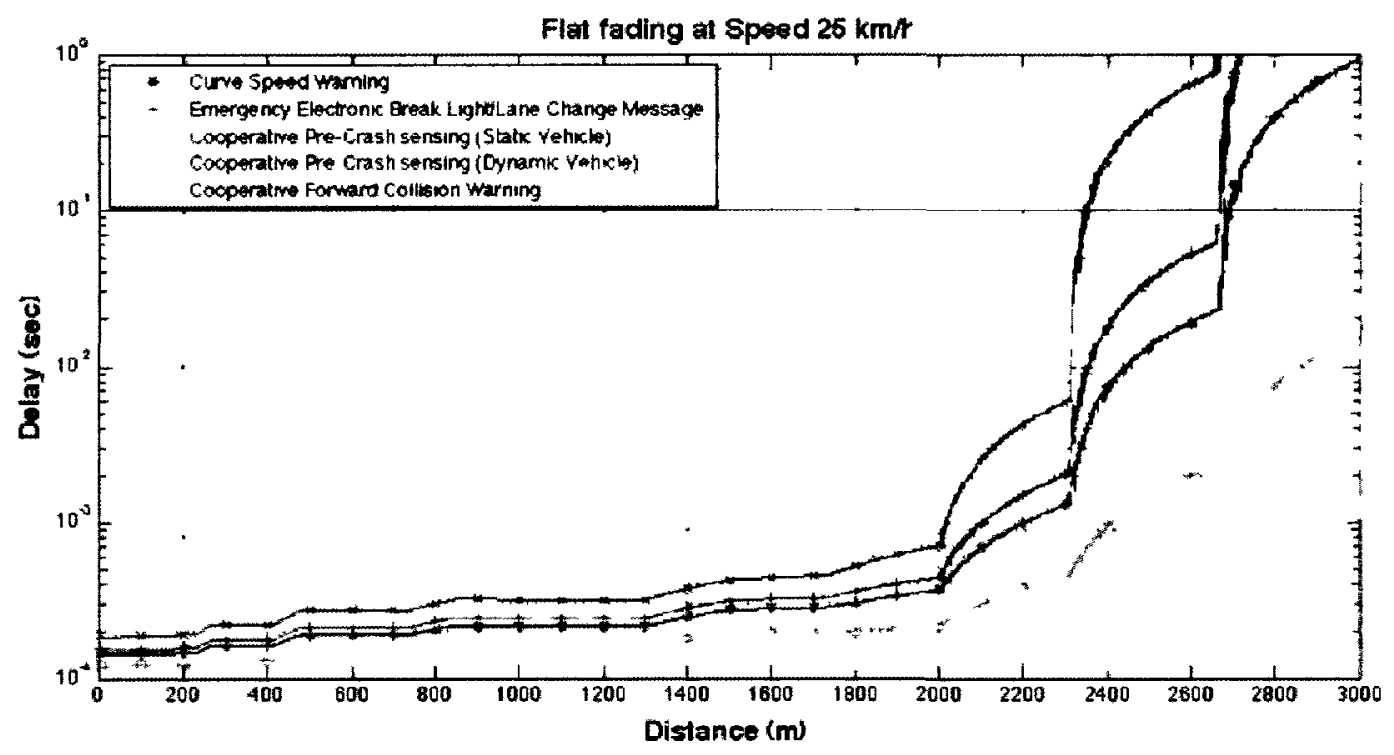

Figure A.21: Delay time vs. Distance for Urban environment with flat fading at 25 $\mathrm{km} / \mathrm{h}$ 


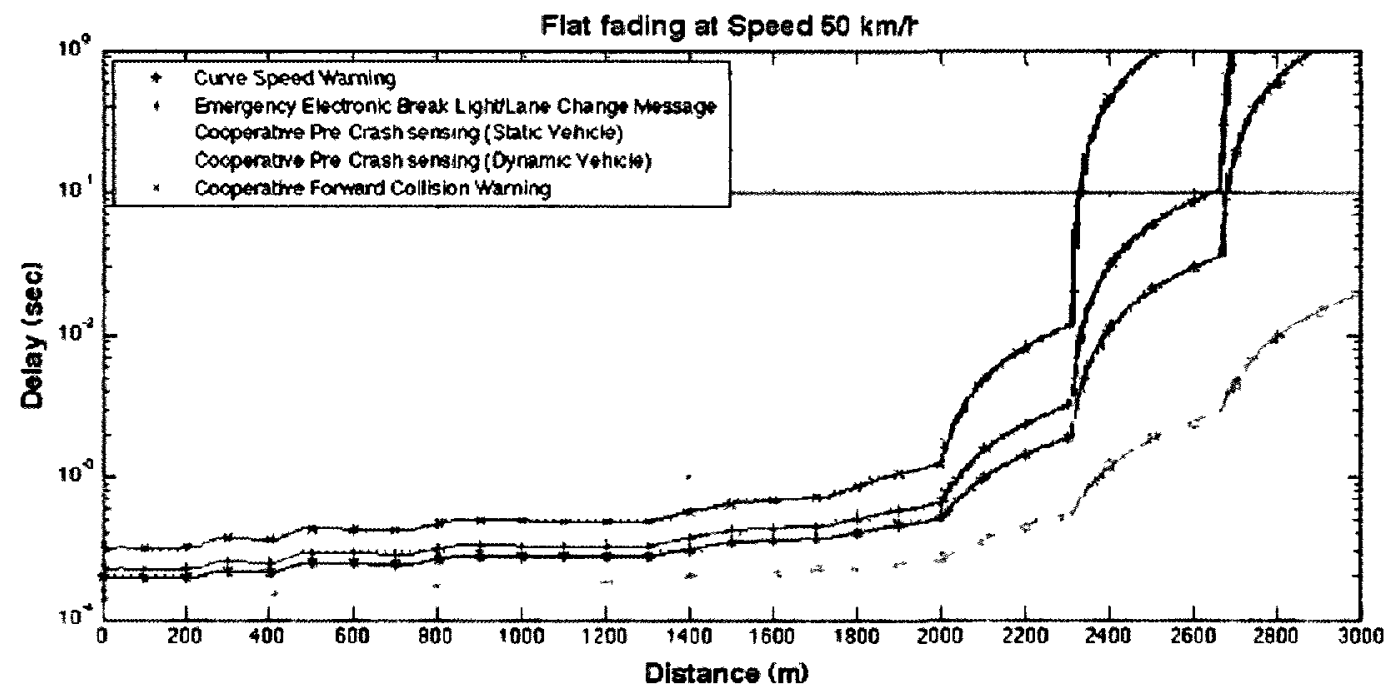

Figure A.22: Delay time vs Distance for Urban environment with flat fading at 50 $\mathrm{km} / \mathrm{h}$

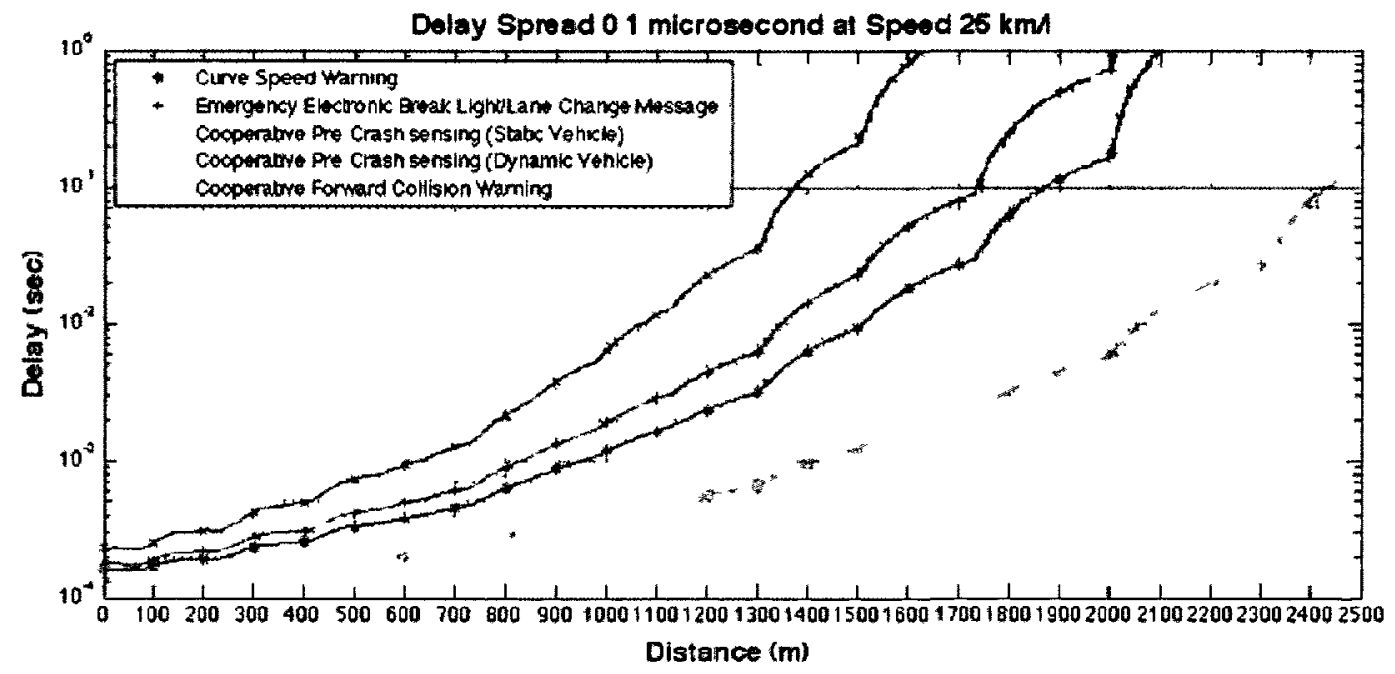

Figure A.23: Delay time vs Distance for Urban environment with $01 \mu$ sec at 25 $\mathrm{km} / \mathrm{h}$ 


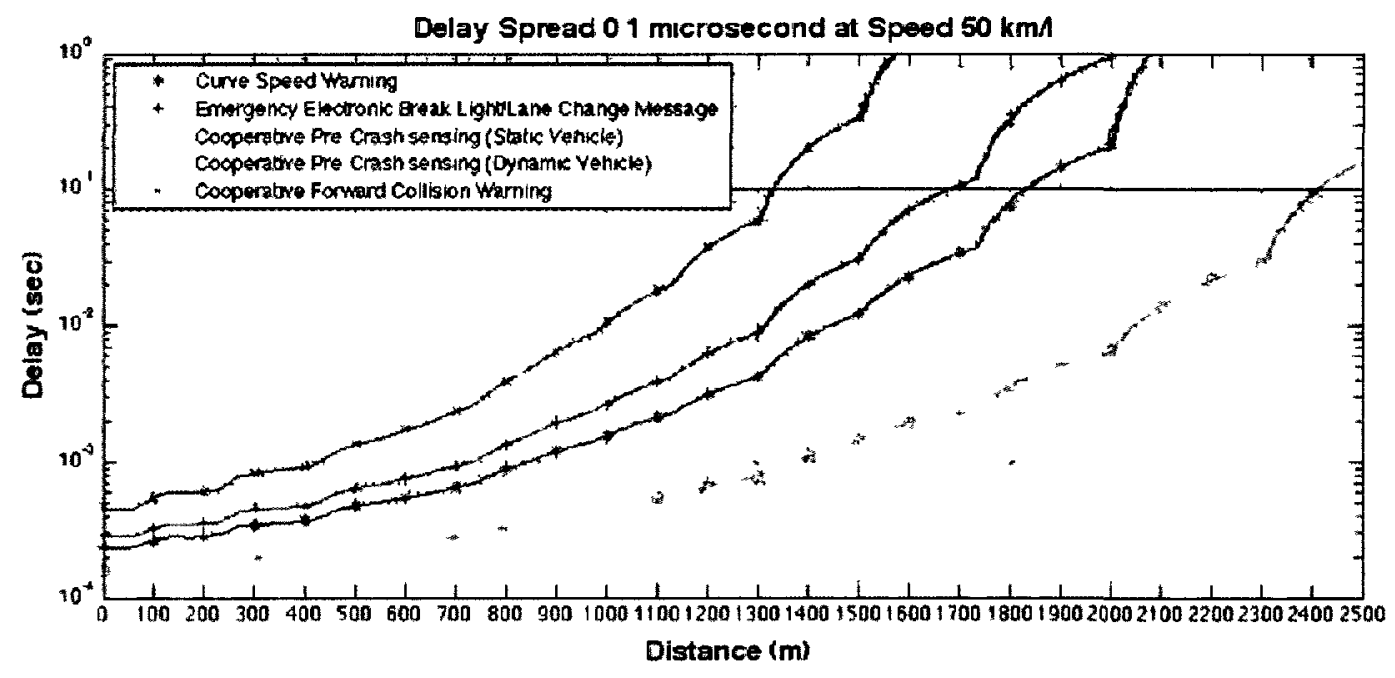

Figure A.24: Delay time vs Distance for Urban environment with $01 \mu$ sec at 50 $\mathrm{km} / \mathrm{h}$

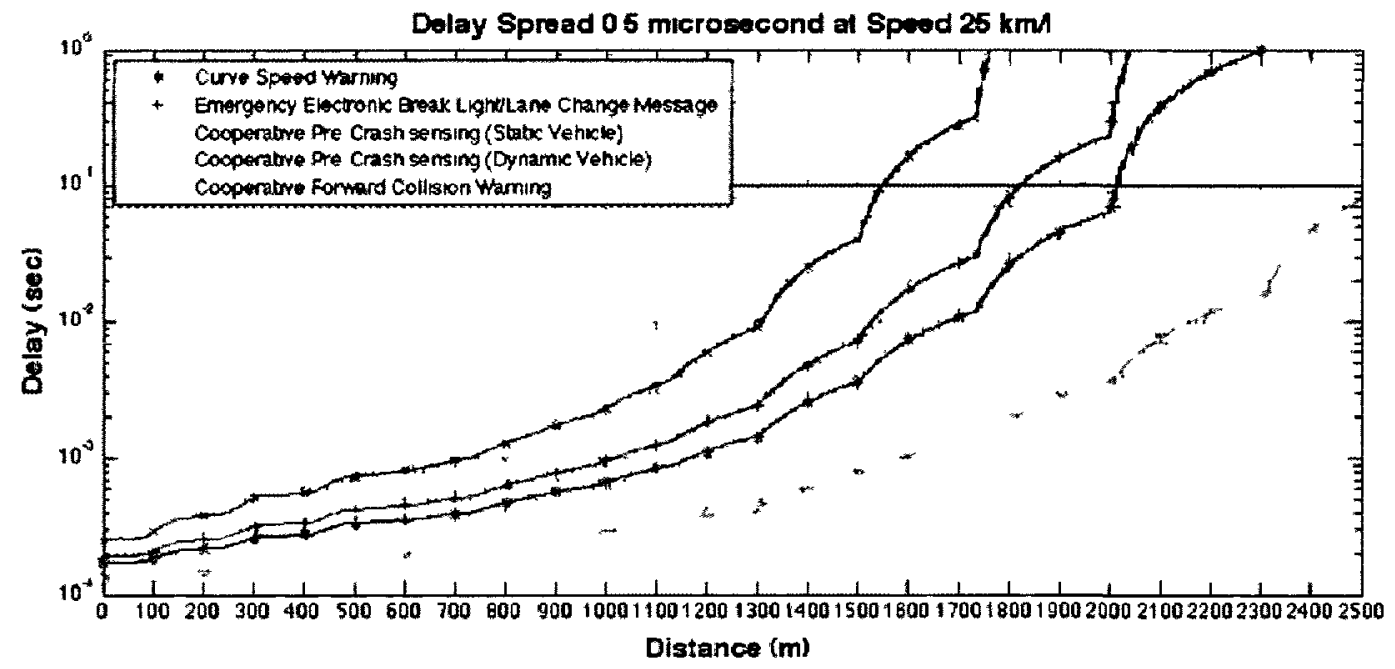

Figure A.25: Delay time vs Distance for Urban environment with $05 \mu$ sec at 25 $\mathrm{km} / \mathrm{h}$ 


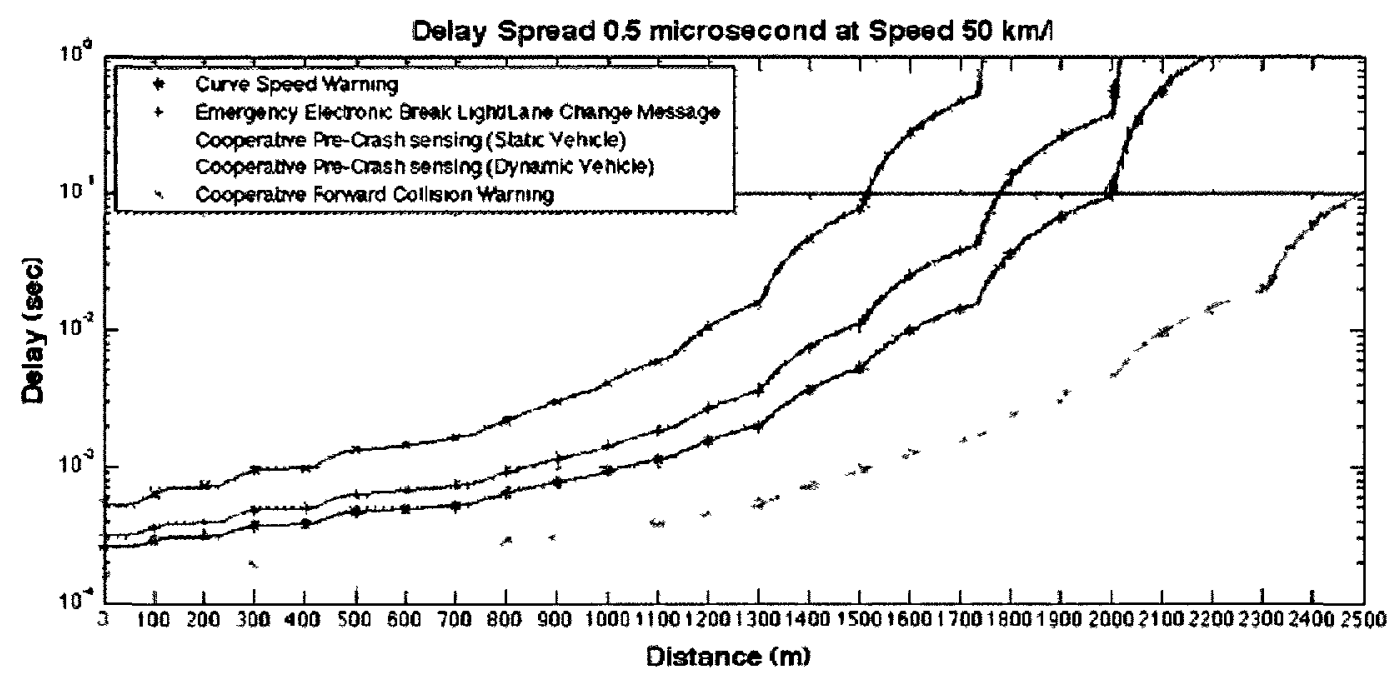

Figure A.26: Delay time vs Distance for Urban environment with $05 \mu$ sec at 50 $\mathrm{km} / \mathrm{h}$

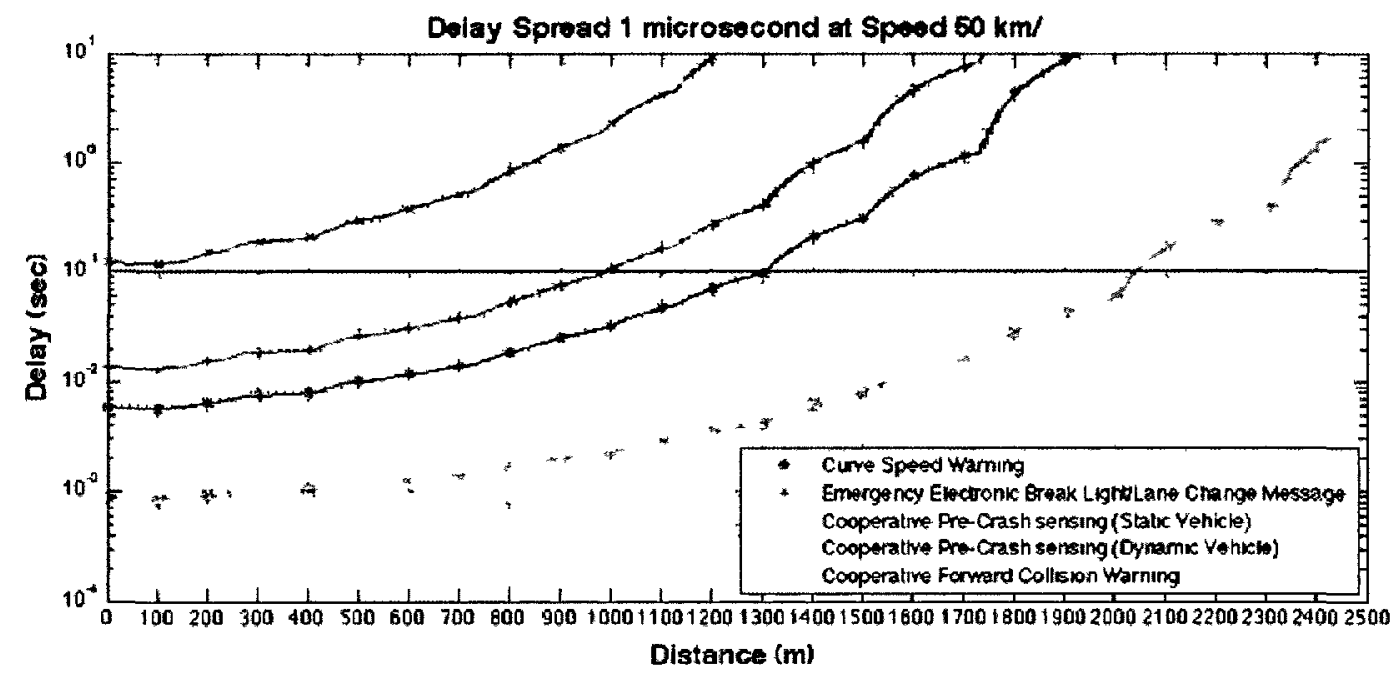

Figure A.27: Delay time vs Distance for Urban environment with $1 \mu$ sec at 50 $\mathrm{km} / \mathrm{h}$ 


\section{A.3.2 Test 2 (NLOS)}

Table A.5: Values used to generate results for Test 2 for Urban (NLOS) Environments

\begin{tabular}{|c|c|}
\hline System Parameters & Values \\
\hline$\gamma$ & 2.8 \\
\hline$\sigma$ & 4.4 \\
\hline
\end{tabular}

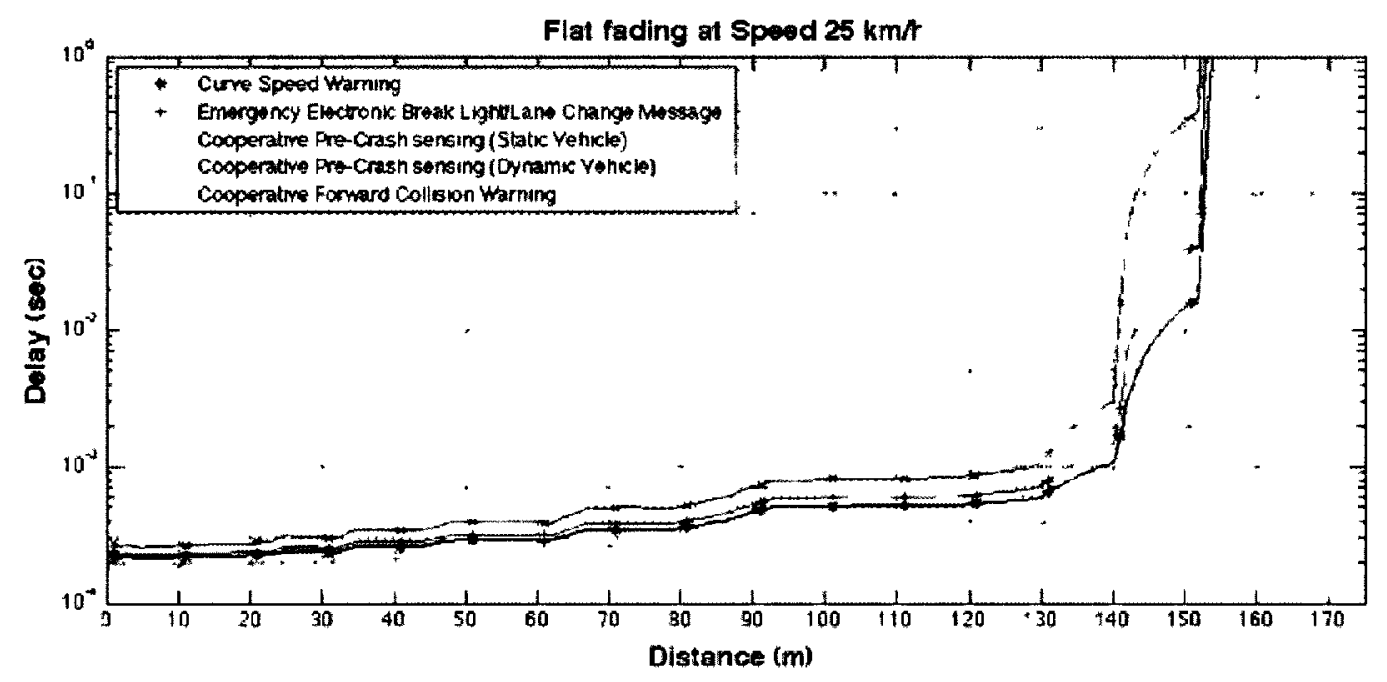

Figure A.28: Delay time vs. Distance for Urban environment with flat fading at 25 $\mathrm{km} / \mathrm{h}$ 
Flat fading at Spard $50 \mathrm{~km} /$

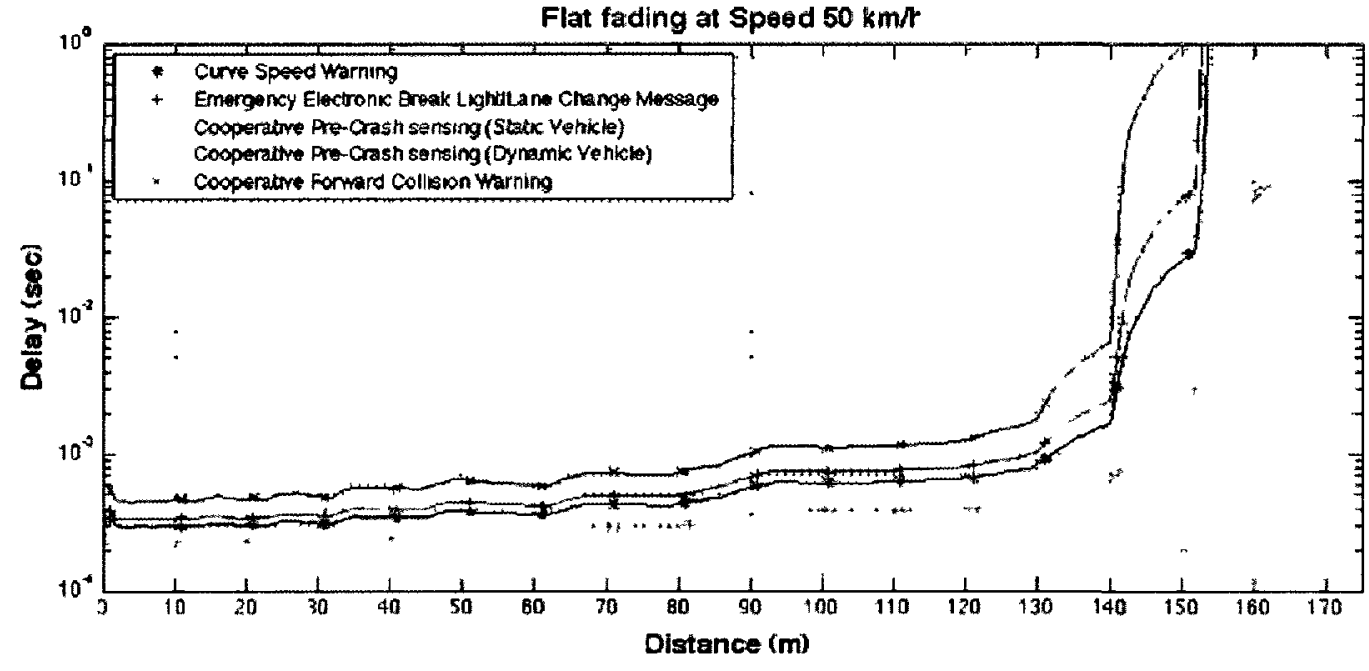

Figure A.29: Delay time vs Distance for Urban environment with flat fading at 50 $\mathrm{km} / \mathrm{h}$

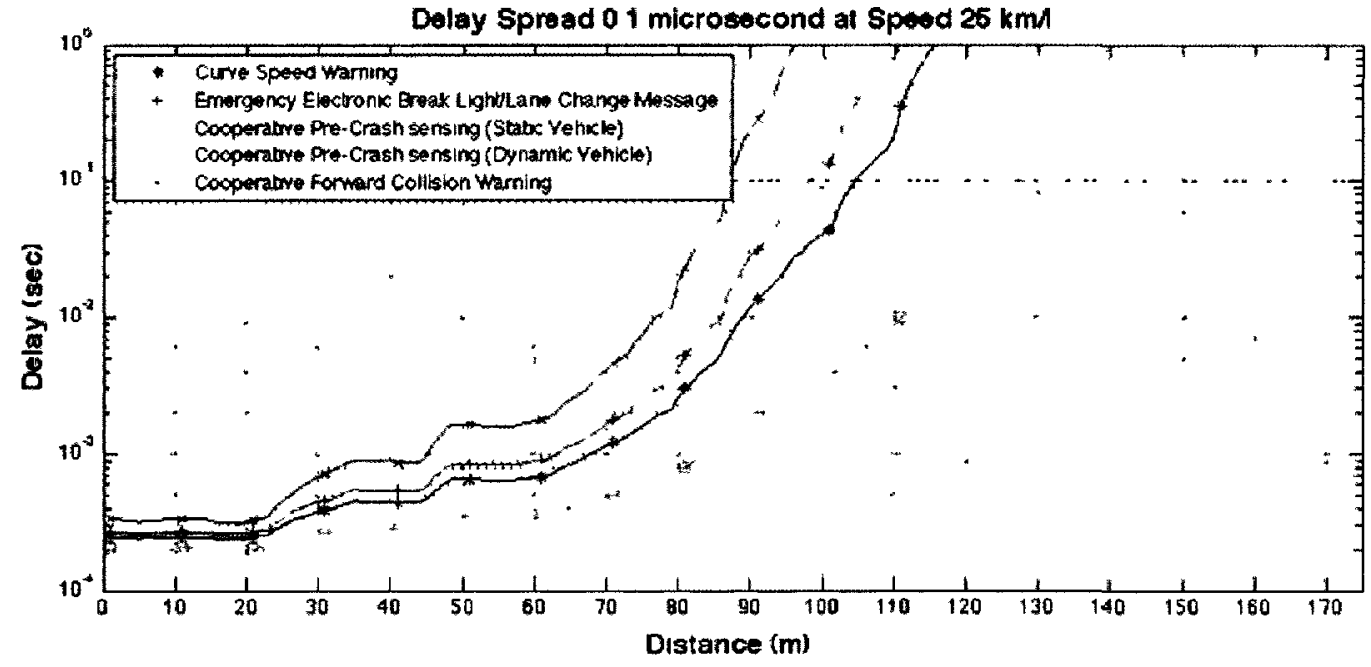

Figure A.30: Delay time vs Distance for Urban environment with $0.1 \mu$ sec at 25 $\mathrm{km} / \mathrm{h}$ 


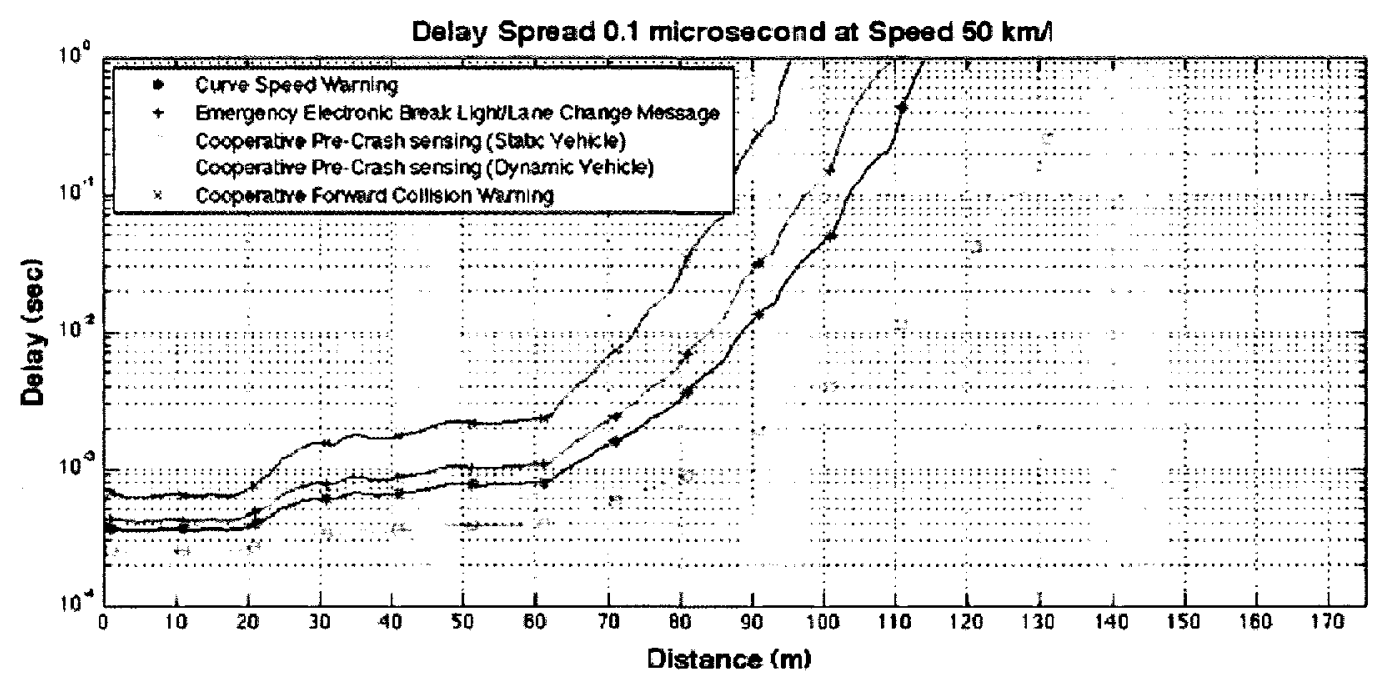

Figure A.31: Delay time vs. Distance for Urban environment with $0.1 \mu$ sec at 50 $\mathrm{km} / \mathrm{h}$

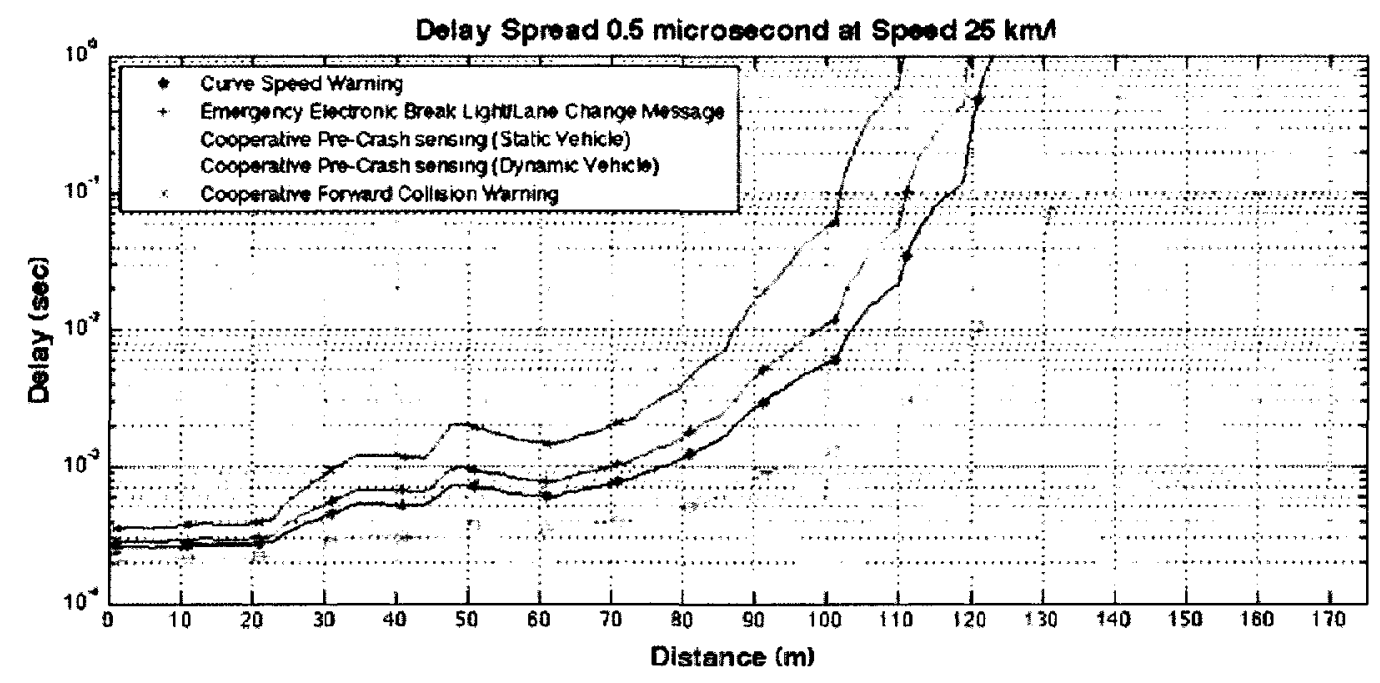

Figure A.32: Delay time vs. Distance for Urban environment with $0.5 \mu$ sec at 25 $\mathrm{km} / \mathrm{h}$ 


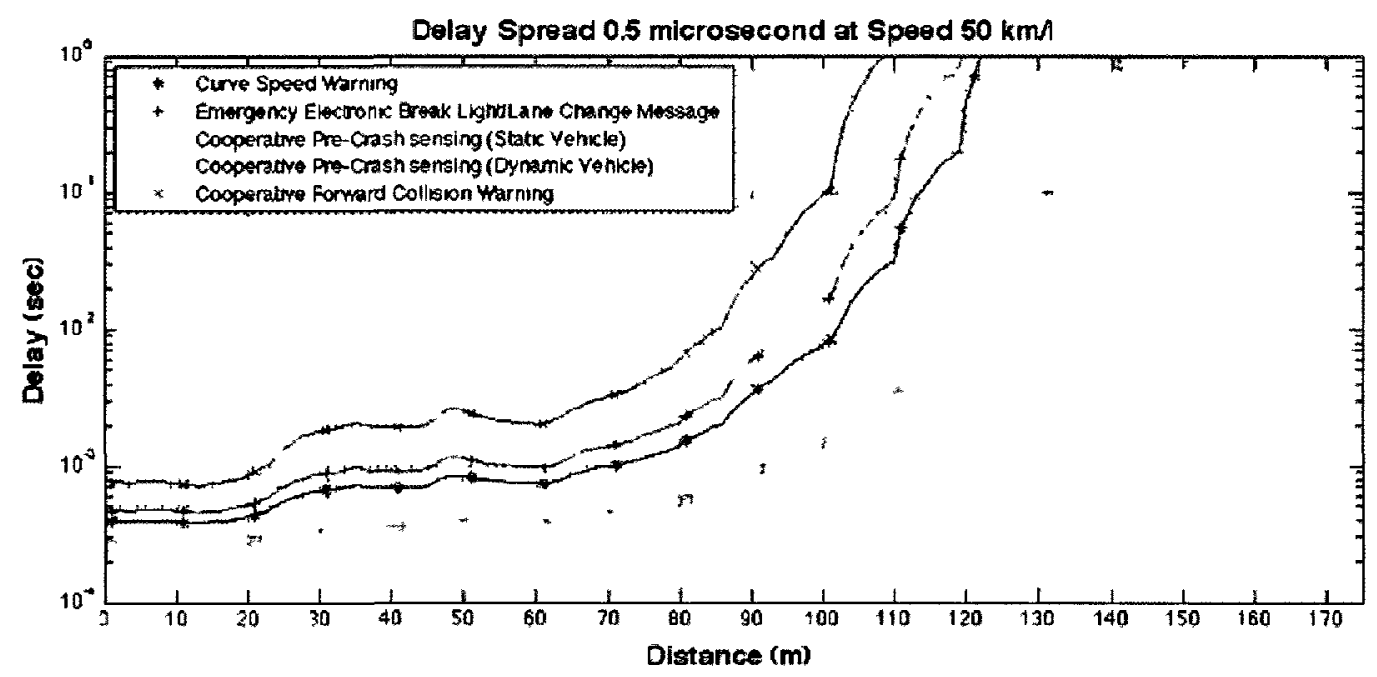

Figure A.33: Delay time vs Distance for Urban environment with $05 \mu$ sec at 50 $\mathrm{km} / \mathrm{h}$

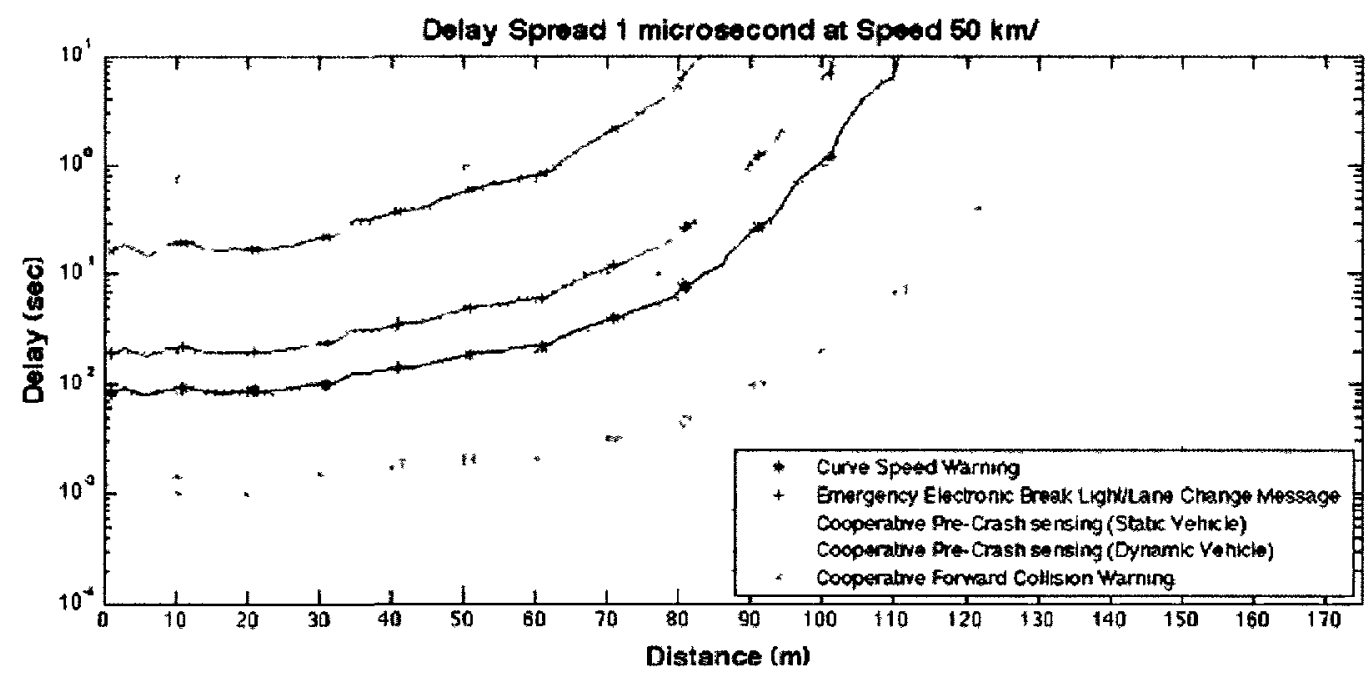

Figure A.34: Delay time vs Distance for Urban environment with $1 \mu$ sec at 50 $\mathrm{km} / \mathrm{h}$ 


\section{A.4 Rural Environments}

\section{A.4.1 Test 1 (LOS)}

Table A.6: Values used to generate results for Test 1 for Rural (LOS) Environments

\begin{tabular}{|c|c|}
\hline System Parameters & Values \\
\hline$\gamma$ & 179 \\
\hline$\sigma$ & 27 \\
\hline
\end{tabular}

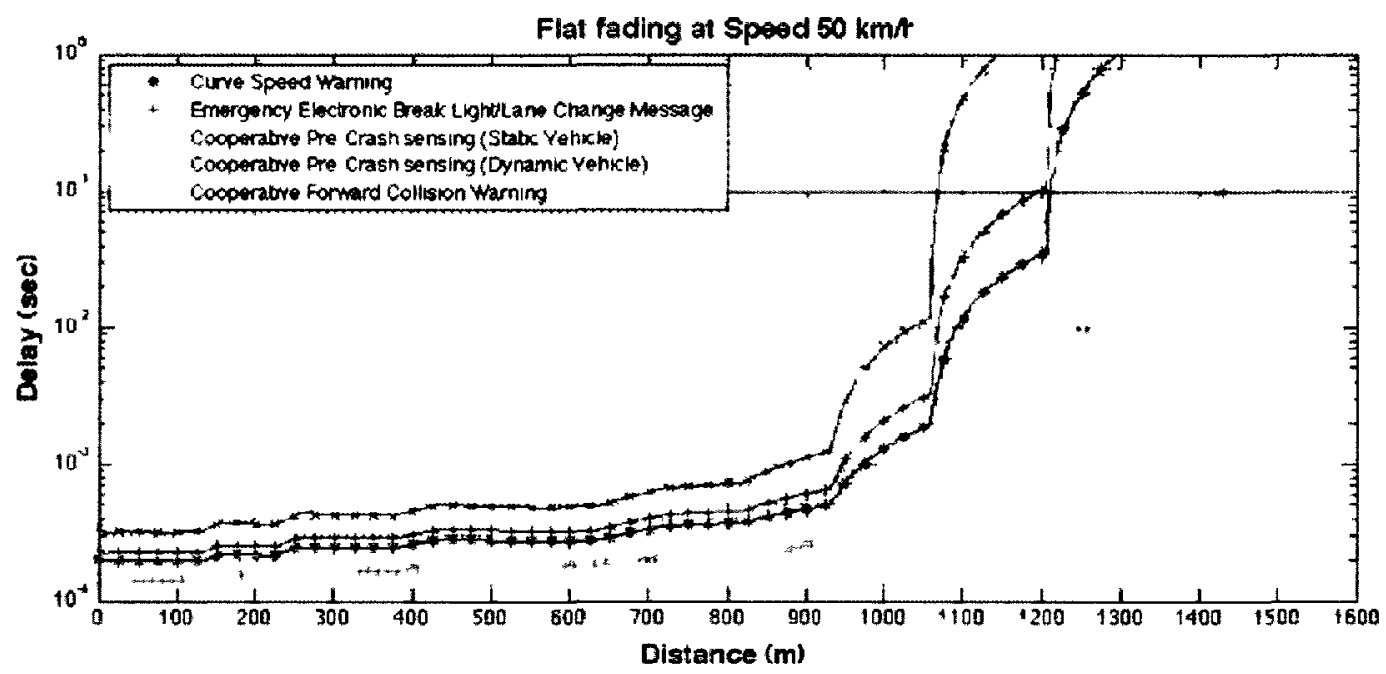

Figure A.35: Delay tıme vs Distance for Rural environment with flat fadıng at 50 $\mathrm{km} / \mathrm{h}$ 


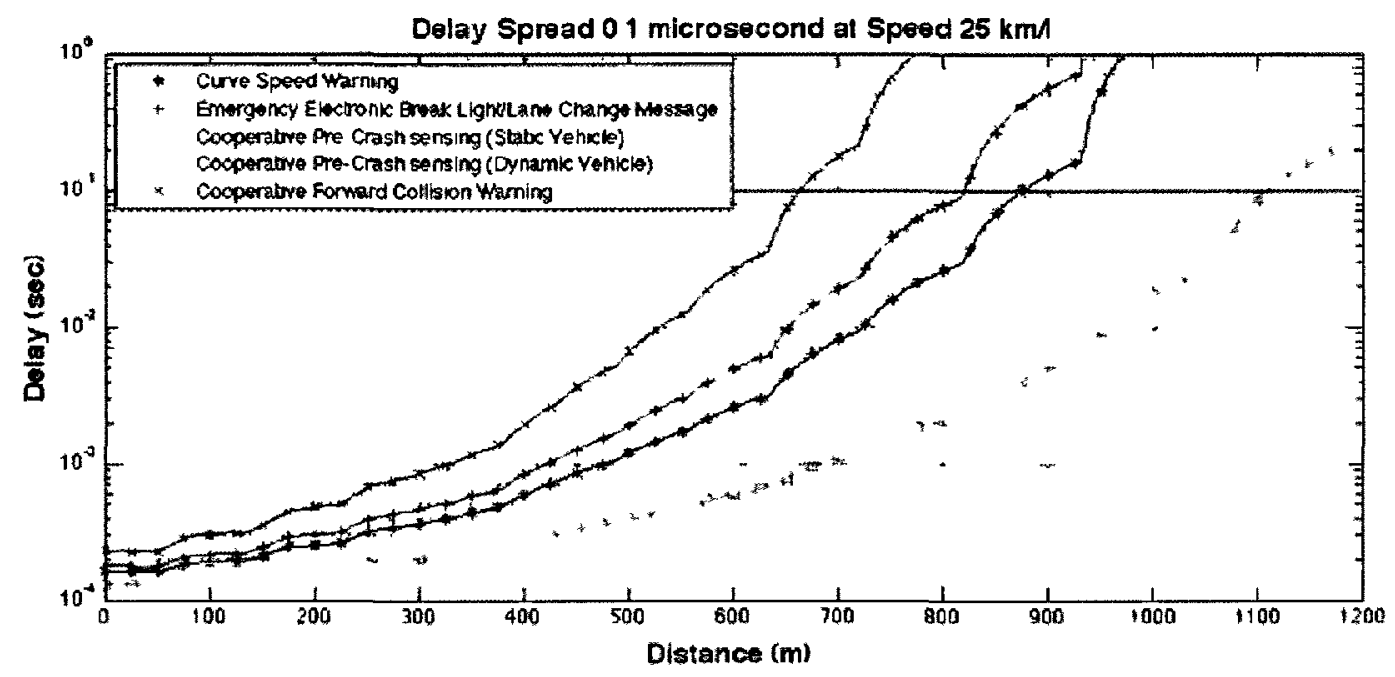

Figure A.36: Delay time vs Distance for Rural environment with $01 \mu$ sec at 25 $\mathrm{km} / \mathrm{h}$

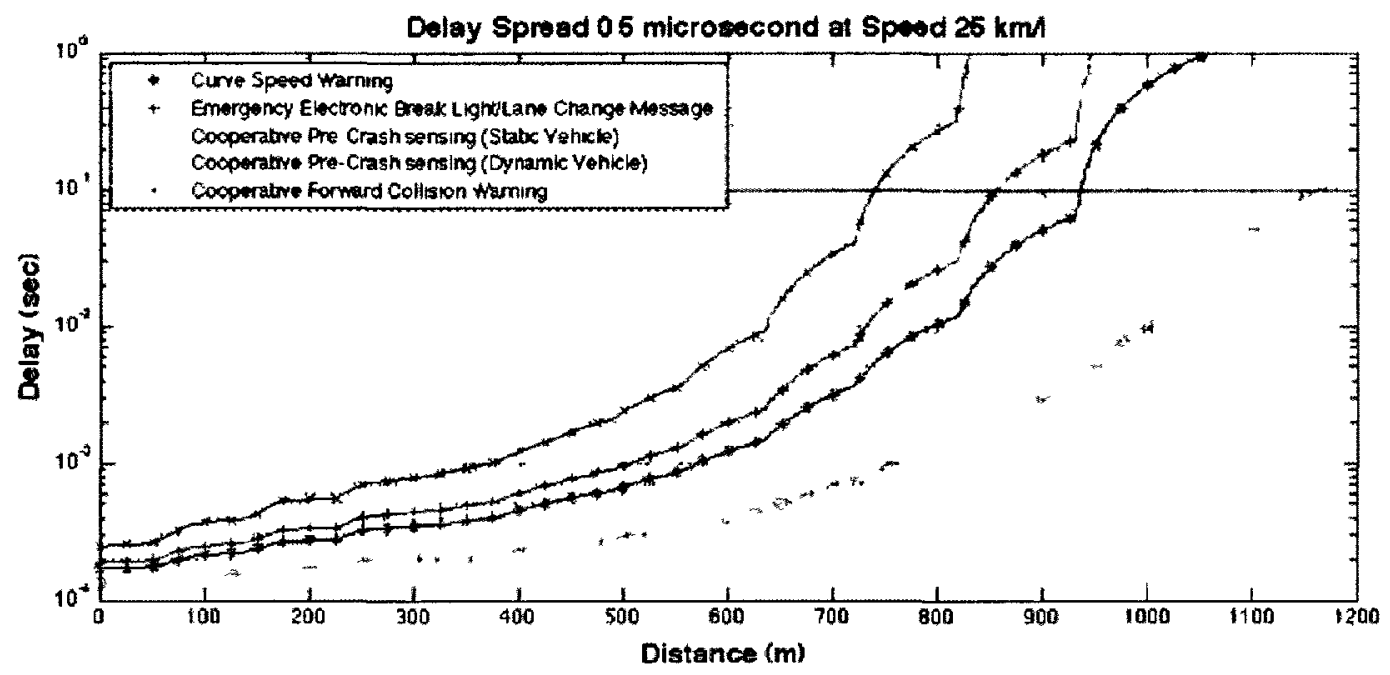

Figure A.37: Delay time vs Distance for Rural environment with $05 \mu$ sec at 25 $\mathrm{km} / \mathrm{h}$ 


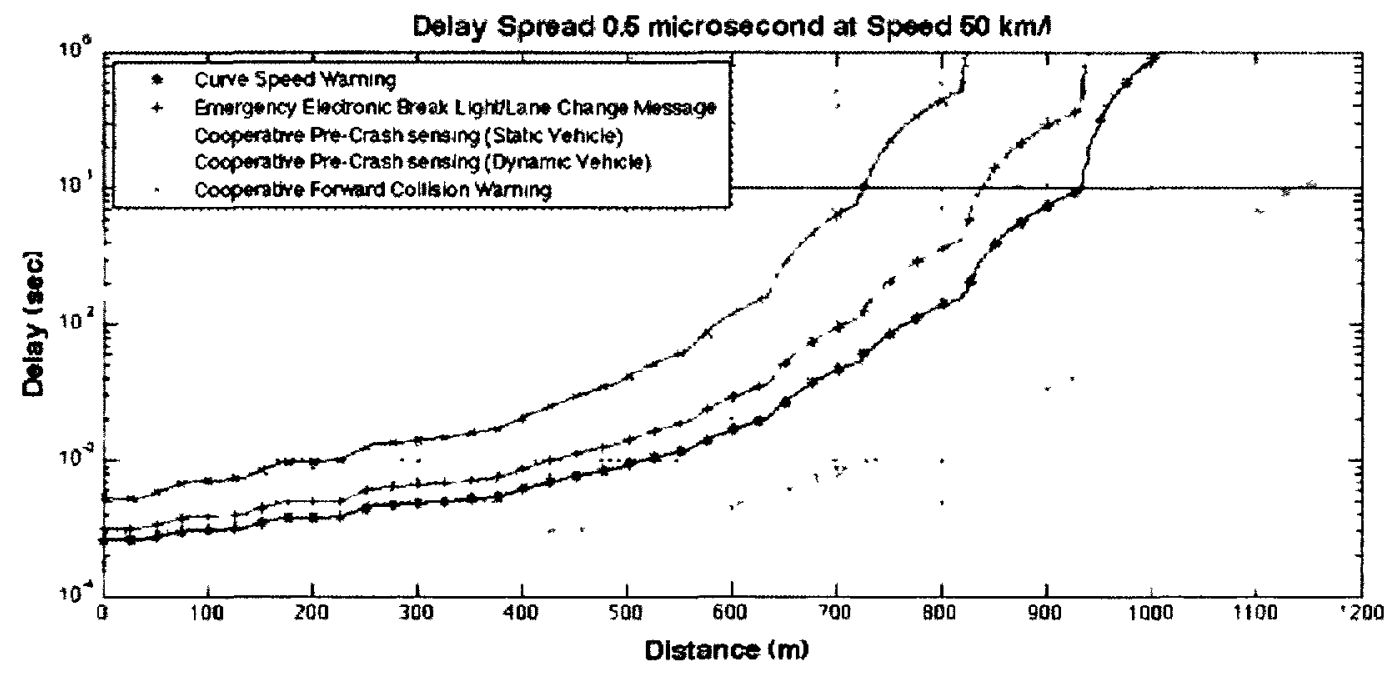

Figure A.38: Delay time vs. Distance for Rural environment with $0.5 \mu$ sec at 50 $\mathrm{km} / \mathrm{h}$ 


\section{A.4.2 Test 2 (NLOS)}

Table A.7: Values used to generate results for Test 2 for Rural (NLOS) Environments

\begin{tabular}{|c|c|}
\hline System Parameters & Values \\
\hline$\gamma$ & 2.3 \\
\hline$\sigma$ & 2.7 \\
\hline
\end{tabular}

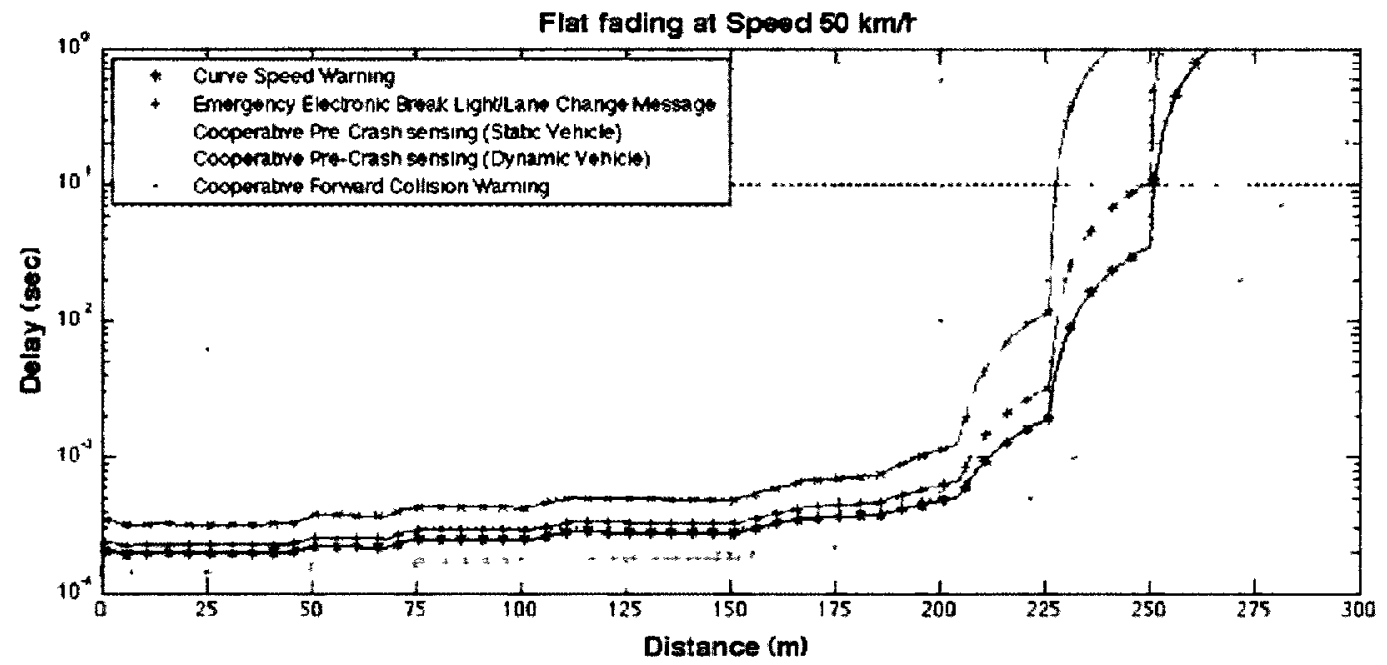

Figure A.39: Delay time vs. Distance for Rural environment with flat fading at 50 $\mathrm{km} / \mathrm{h}$ 


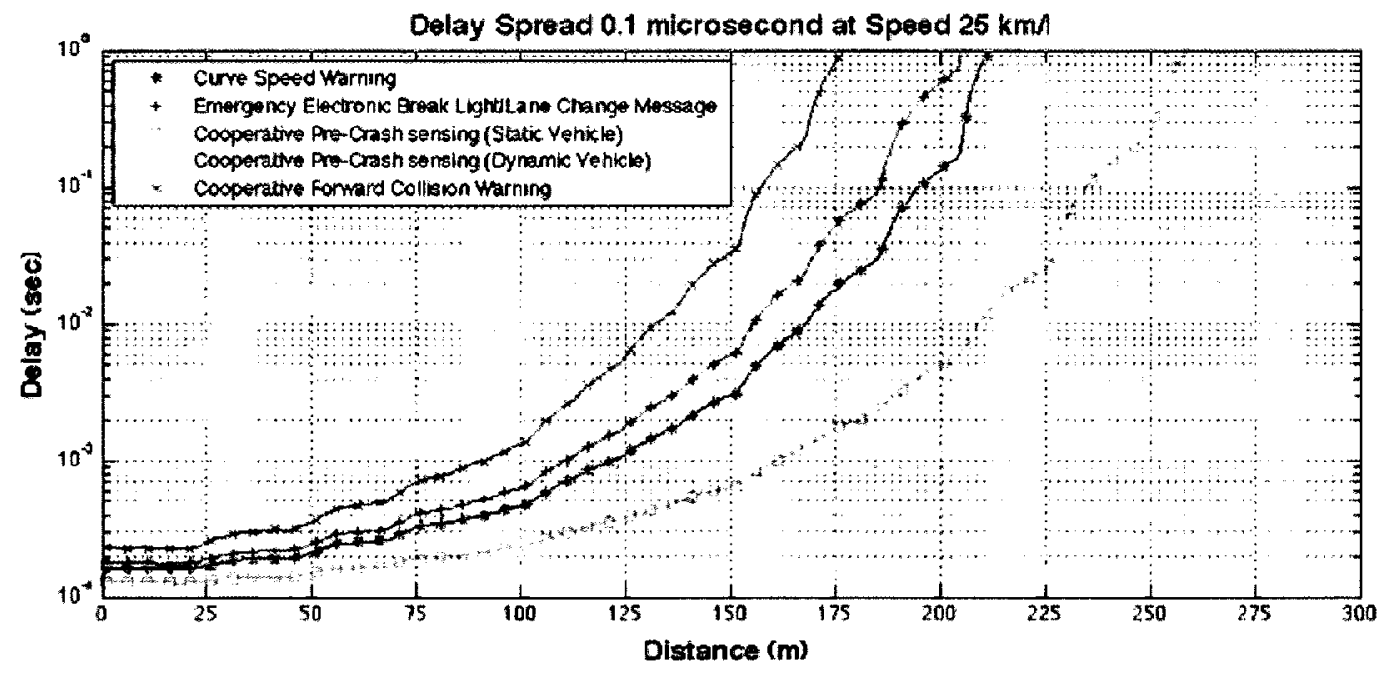

Figure A.40: Delay time vs. Distance for Rural environment with $0.1 \mu \mathrm{sec}$ at 25 $\mathrm{km} / \mathrm{h}$

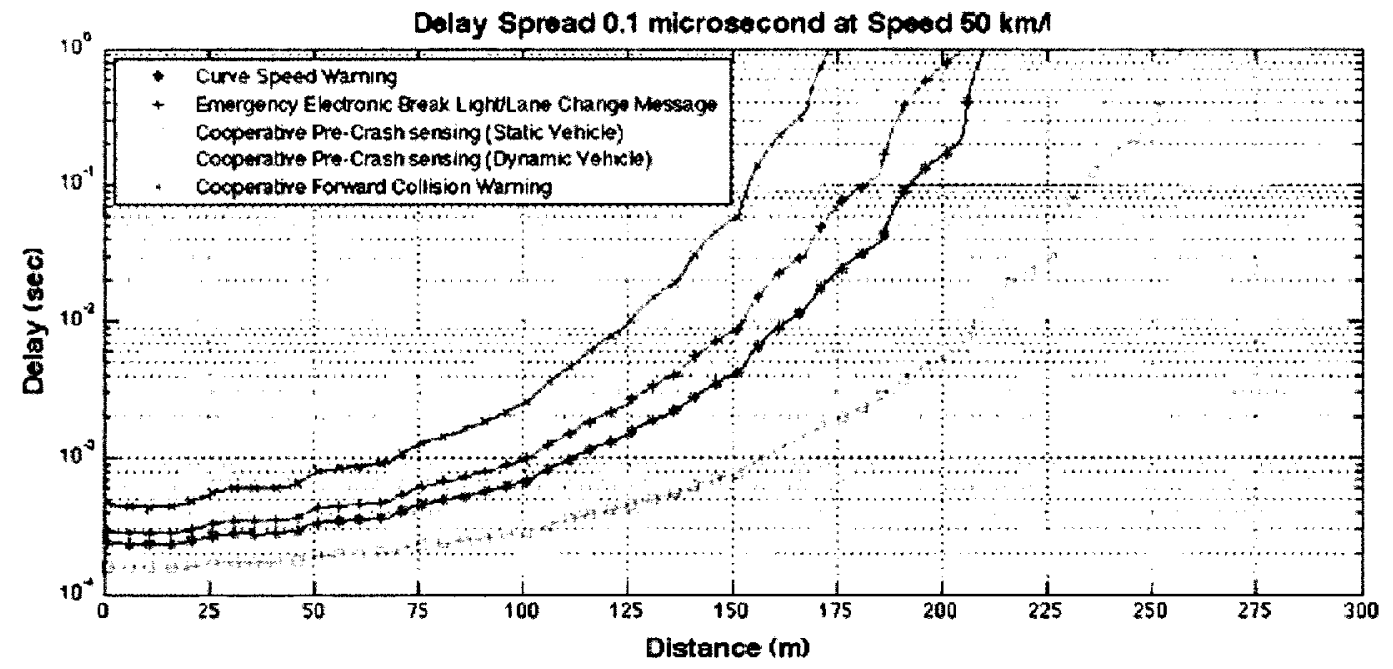

Figure A.41: Delay time vs. Distance for Rural environment with $0.1 \mu$ sec at 50 $\mathrm{km} / \mathrm{h}$ 


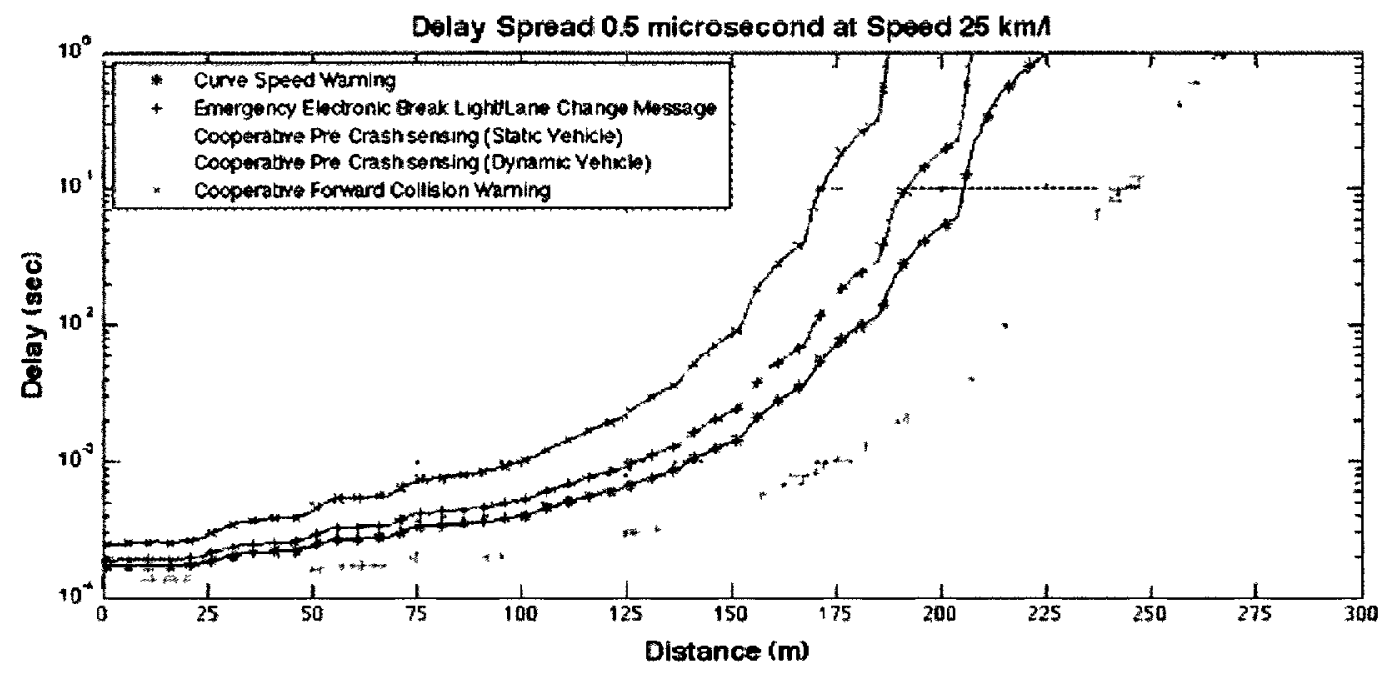

Figure A.42: Delay time vs Distance for Rural environment with $05 \mu$ sec at 25 $\mathrm{km} / \mathrm{h}$

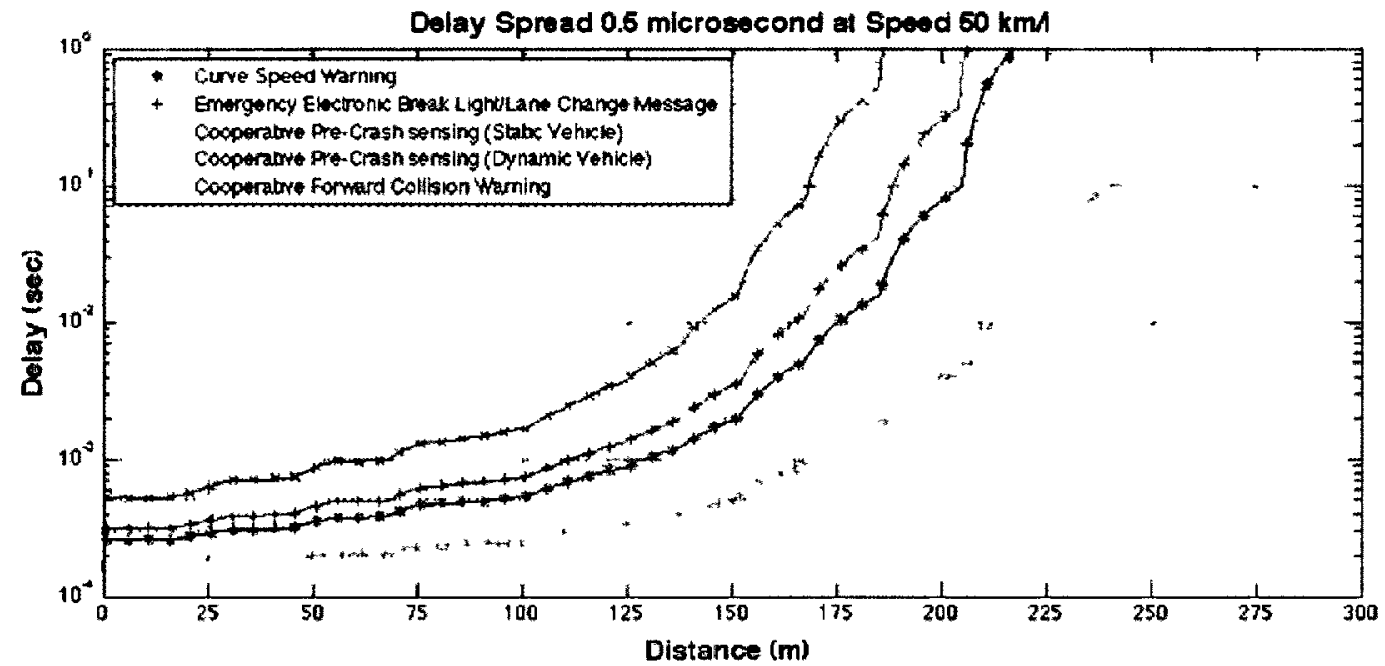

Figure A.43: Delay time vs Distance for Rural environment with $05 \mu$ sec at 50 $\mathrm{km} / \mathrm{h}$ 


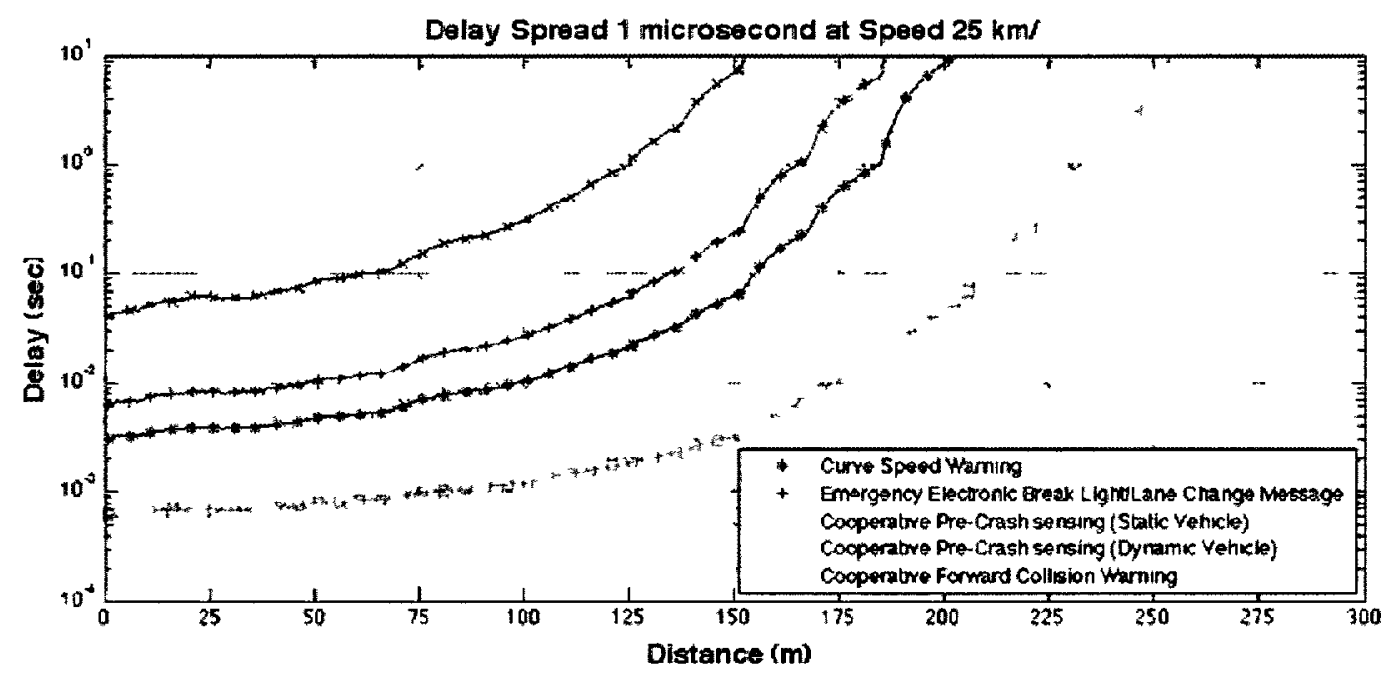

Figure A.44: Delay time vs Distance for Rural environment with $1 \mu \mathrm{sec}$ at 25 $\mathrm{km} / \mathrm{h}$

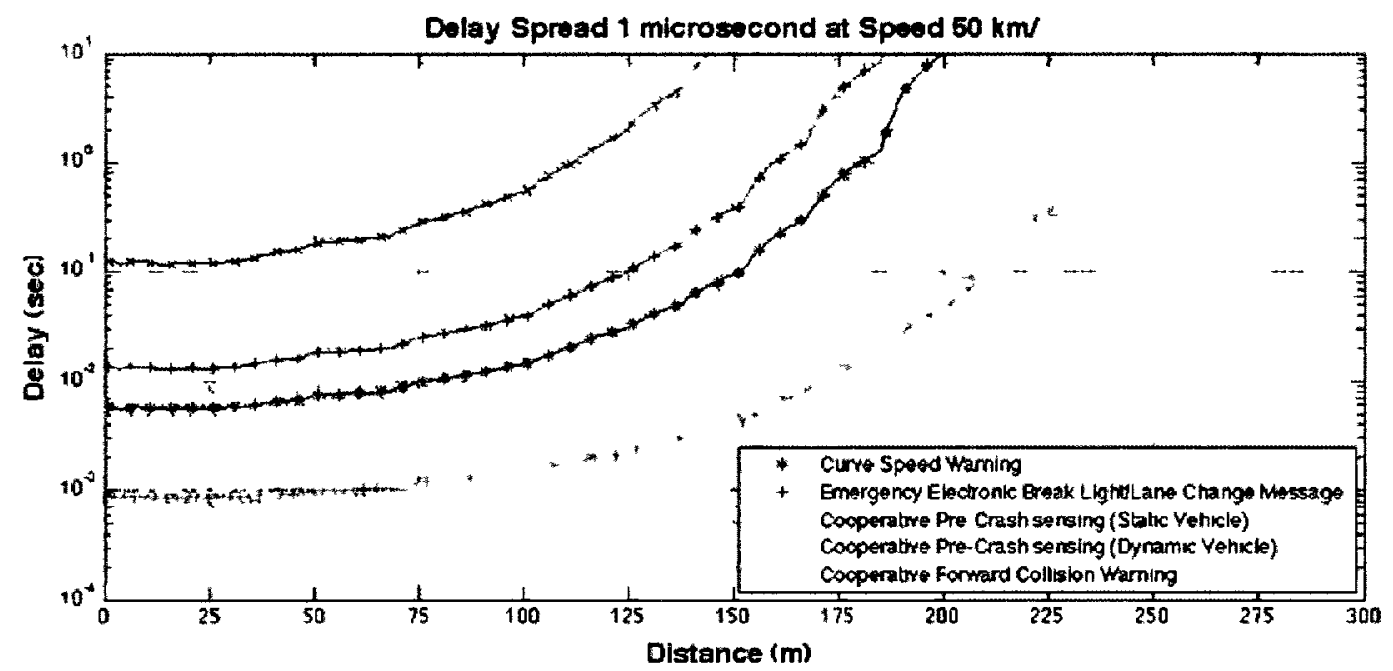

Figure A.45: Delay time vs Distance for Rural environment with $1 \mu$ sec at 50 $\mathrm{km} / \mathrm{h}$ 


\section{List of References}

[1] B. McKeever, "Working paper:estimating the potential safety benefits of intelligent transportation systems, mitretek systems." [Online]. Available: http://ntl.bts.gov/lib/jpodocs/repts_te/8883.pdf

[2] A. Molisch, F. Tufvesson, J. Karedal, and C. Mecklenbrauker, "A survey on vehicle-to-vehicle propagation channels," Wireless Communications, IEEE, vol. 16, no. 6, pp. $12-22$, Dec. 2009.

[3] A. Paier, J. Karedal, N. Czink, H. Hofstetter, C. Dumard, T. Zemen, F. Tufvesson, C. Mecklenbrauker, and A. Molisch, "First results from car-to-car and carto-infrastructure radio channel measurements at $5.2 \mathrm{GHz}$," in Personal, Indoor and Mobile Radio Communications, 2007. PIMRC 2007. IEEE 18th International Symposium on, Sept. 2007, pp. $1-5$.

[4] T. Monahan, "'war rooms" of the street: Surveillance practices in transportation control centers. the communication review," 2007.

[5] "Examples of intelligent transportation systems (its) applications," Sep. 2010. [Online]. Available: http://www.itsoverview.its.dot.gov/

[6] L. Breheret, "Real-time information on road traffic based on floating car data," SODIT, France, Tech. Rep. [Online]. Available: http://www.urba2000.com/ club-ecomobilite-DUD/IMG/pdf/THNS_Shanghai08_Breheret_Sinergit.pdf

[7] (2010, May) Research and innovative technology administration (intelligent transportation systems). [Online]. Available: http://www.itsoverview.its.dot. gov/

[8] M. D. Bunn and G. T. Savage, "Integrated traffic management and emergency response: Success factors," Sep. 2003. 
[9] S. A. Cooner and K. N. Balke, "Use of photogrammetry for investigation of traffic incident scenes," Texas Department of Transportation, Tech. Rep. 4907-2, Oct. 2000 .

[10] J. Njord, D. J. Peters, M. Freitas, B. Warner, K. C. Allred, D. R. Bertini, R. Bryant, R. Callan, M. Knopp, L. Knowlton, C. Lopez, and T. Warne, "Safety applications of intelligent transportation systems in europe and japan," Washington, DC: U.S. Department of Transportation, Federal Highway Administration, Tech. Rep., Feb. 2007. [Online]. Available: http://www.international.fhwa.dot.gov/ipsafety/ipsafety.pdf

[11] C. R. A. Inc, "Consumer acceptance of automotive crash avoidance devices," USDOT, Tech. Rep., Jan. 1998.

[12] "Information about drowsy driving," Oct. 2010. [Online]. Available: http: //www.nhtsa.gov/people/injury/drowsy_driving1/Drowsy.html

[13] "Intelligent transportation systems enhance safety," Tech. Rep.

[14] H. Abdulhamid, K. E. Tepe, and E. Abdel-Raheem, "Performance of DSRC systems using conventional channel estimation at high velocities," $A E U$ International Journal of Electronics and Communications, vol. 61, no. 8, pp. 556 - 561, 2007. [Online]. Available: http://www.sciencedirect.com/science/ article/B7GWW-4MH8HVP-1/2/8cde18201e7da0fc0bce3271ae572393

[15] L. Cheng, B. Henty, D. Stancil, F. Bai, and P. Mudalige, "Mobile vehicle-tovehicle narrow-band channel measurement and characterization of the $5.9 \mathrm{ghz}$ dedicated short range communication (dsrc) frequency band," Selected Areas in Communications, IEEE Journal on, vol. 25, no. 8, pp. 1501 -1516, Oct. 2007.

[16] DSRC implementation guide a guide to users of SAE J2735 message sets over DSRC. [Online]. Available: http://www.sae.org/standardsdev/dsrc/ DSRCImplementationGuide.pdf

[17] D. Jiang and L. Delgrossi, "IEEE 802.11p: Towards an international standard for wireless access in vehicular environments," in Vehicular Technology Conference, 2008. VTC Spring 2008. IEEE, May 2008, pp. 2036 -2040.

[18] Y. Xiao and J. Rosdahl, "Throughput and delay limits of IEEE 802.11," Communications Letters, IEEE, vol. 6, no. 8, pp. 355 - 357, Aug. 2002. 
[19] B. C. J. Landt, "Shrouds of time the history of rfid," AIM Publication, 2001. [Online]. Available: http://www.rfidconsultation.eu/docs/ficheiros/shrouds_of_ time.pdf

[20] IEEE 802.11: Wireless LAN Medium Access Control (MAC) and Physical Layer (PHY) Specifications, ser. (2007 revision). [IEEE-SA], 2007.

[21] "Vehicle safety communications project: Task 3 final report - identify intelligent vehicle safety applications enabled by DSRC," Crash Avoidance Metrics Partnership, National Highway Traffic Safety Administration, Tech. Rep., Jul. 2005. [Online]. Available: http://www-nrd.nhtsa.dot.gov/pdf/nrd-12/ 1665CAMP3web/images/CAMP3scr.pdf

[22] N. Hojjat, A. Mehrtash, B. Boghrati, S. Safavi-Naeini, A. Shishegar, R. AliHemmati, G. Dadashzadeh, and E. Jedari, "A Matlab Simulink model for simulation of post-FFT smart antenna in 802.11a standard," in Antennas and Propagation Society International Symposium, 2005 IEEE, vol. 4A, Jul. 2005, pp. 34 -37 vol. $4 \mathrm{~A}$.

[23] J. Yin, T. ElBatt, G. Yeung, B. Ryu, S. Habermas, H. Krishnan, and T. Talty, "Performance evaluation of safety applications over DSRC vehicular ad hoc networks," in Proceedings of the 1st ACM international workshop on Vehicular ad hoc networks, ser. VANET '04. New York, NY, USA: ACM, 2004, pp. 1-9. [Online]. Available: http://doi.acm.org/10.1145/1023875.1023877

[24] C.-D. Iskander, "A matlab -based object-oriented approach to multipath fading channel simulation."

[25] M. Clark, "Matlab 2009b: Communication blockset IEEE 802.11a WLAN physical layer demo." [Online]. Available: http://www.mathworks.com/ matlabcentral/fileexchange/3540

[26] Emmelmann, Marc, B. Bochow, and C. Kellum, Vehicular Networking: Automotive Applications and Beyond, 1st ed. Wiley, Jun. 2010.

[27] L. Cheng, B. Henty, F. Bai, and D. Stancil, "Highway and rural propagation channel modeling for vehicle-to-vehicle communications at $5.9 \mathrm{GHz}$," in Antennas and Propagation Society International Symposium, 2008. AP-S 2008. IEEE, Jul. 2008, pp. $1-4$.

[28] J. Kunisch and J. Pamp, "Wideband car-to-car radio channel measurements and model at $5.9 \mathrm{GHz}$," in Vehicular Technology Conference, 2008. VTC 2008-Fall. IEEE 68th, Spet. 2008, pp. $1-5$. 
[29] X. Zhao, J. Kivinen, P. Vainikainen, and K. Skog, "Propagation characteristics for wideband outdoor mobile communications at $5.3 \mathrm{GHz}$," Selected Areas in Communications, IEEE Journal on, vol. 20, no. 3, pp. 507 -514, Apr. 2002.

[30] F. Schmidt-Eisenlohr, M. Torrent-Moreno, T. Tielert, J. Mittag, and H. Hartenstein, "Cumulative noise and $5.9 \mathrm{GHz}$ DSRC extensions for ns-2.28," Institute of Telematics, University of Karlsruhe, Germany, Tech. Rep., 2006.

[31] K. Hong, D. Xing, V. Rai, and J. Kenney, "Characterization of DSRC performance as a function of transmit power," in Proceedings of the sixth ACM international workshop on VehiculAr InterNETworking, ser. VANET '09. New York, NY, USA: ACM, 2009, pp. 63-68. [Online]. Available: http://doi.acm.org/10.1145/1614269.1614281

[32] J. Andersen, T. Rappaport, and S. Yoshida, "Propagation measurements and models for wireless communications channels," Communications Magazine, IEEE, vol. 33, no. 1, pp. $42-49$, Jan. 1995.

[33] G. Stuber, Principles of Mobile Communication, 2nd ed. Springer, Dec. 2000. 